\title{
Role of neutrophils in pulmonary DNA damage and repair
}

Citation for published version (APA):

Güngör, N. (2009). Role of neutrophils in pulmonary DNA damage and repair. [Doctoral Thesis, Maastricht University]. Maastricht University. https://doi.org/10.26481/dis.20091215ng

Document status and date:

Published: 01/01/2009

DOI:

10.26481/dis.20091215ng

Document Version:

Publisher's PDF, also known as Version of record

\section{Please check the document version of this publication:}

- A submitted manuscript is the version of the article upon submission and before peer-review. There can be important differences between the submitted version and the official published version of record.

People interested in the research are advised to contact the author for the final version of the publication, or visit the DOI to the publisher's website.

- The final author version and the galley proof are versions of the publication after peer review.

- The final published version features the final layout of the paper including the volume, issue and page numbers.

Link to publication

\footnotetext{
General rights rights.

- You may freely distribute the URL identifying the publication in the public portal. please follow below link for the End User Agreement:

www.umlib.nl/taverne-license

Take down policy

If you believe that this document breaches copyright please contact us at:

repository@maastrichtuniversity.nl

providing details and we will investigate your claim.
}

Copyright and moral rights for the publications made accessible in the public portal are retained by the authors and/or other copyright owners and it is a condition of accessing publications that users recognise and abide by the legal requirements associated with these

- Users may download and print one copy of any publication from the public portal for the purpose of private study or research.

- You may not further distribute the material or use it for any profit-making activity or commercial gain

If the publication is distributed under the terms of Article $25 \mathrm{fa}$ of the Dutch Copyright Act, indicated by the "Taverne" license above, 


\section{Role of Neutrophils in Pulmonary DNA damage and Repair}


(C) Nejla Güngör, Maastricht 2009

ISBN 978-90-9024887-5

Cover design: Cor Gerstel \& Raf Peeters

Layout: Wim Loth

Production: Drukkerij Castro, Riemst
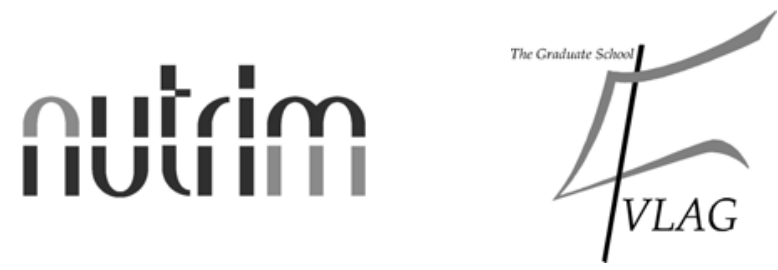

The studies presented in this thesis were performed at the Nutrition and Toxicology Research Institute Maastricht (NUTRIM), which participates in the Graduate School VLAG (Food Technology, Agrobiotechnology, Nutrition and Health Sciences), accredited by the Royal Netherlands Academy of Arts and Sciences. 


\section{Role of Neutrophils in Pulmonary DNA damage and Repair}

\section{PROEFsChRIFT}

ter verkrijging van de graad van doctor aan de Universiteit Maastricht, op gezag van de Rector Magnificus, Prof. mr. G.P.M.F. Mols volgens het besluit van het College van Decanen,

in het openbaar te verdedigen

op dinsdag 15 december 2009 om 10.00 uur

door

\section{Nejla Güngör}

geboren te Genk op 31 augustus 1981 


\section{Promotor:}

Prof. dr. F.J. van Schooten

\section{Copromotores:}

Dr. R.W.L. Godschalk

Dr. A.M. Knaapen

\section{Beoordelingscommissie:}

Prof. dr. E.F.M. Wouters (voorzitter)

Prof. dr. F.C.S. Ramaekers

Dr. R.P.F. Schins (Heinrich Heine University Düsseldorf, Germany)

The study described in this thesis was supported by the Province of Limburg.

Financial support by the Netherlands Society of Toxicology (NVT) for the publication of this thesis is gratefully acknowledged. 




\section{Contents}

$\begin{array}{lll}\text { Chapter } 1 & \text { General introduction } & 9\end{array}$

$\begin{array}{lll}\text { Chapter } 2 & \text { Neutrophils and respiratory tract DNA damage } & 17\end{array}$ and mutagenesis: a review

Chapter $3 \quad$ Genotoxic effects of neutrophils and hypochlorous acid $\quad 45$

Chapter $4 \quad$ Activated neutrophils inhibit nucleotide excision repair 63 in human pulmonary epithelial cells:

role of myeloperoxidase

Chapter $5 \quad$ Lung inflammation is associated with reduced 85 pulmonary nucleotide excision repair in vivo

$\begin{array}{lll}\text { Chapter } 6 & \text { Transcriptional profiling of the pulmonary inflammatory } & 101\end{array}$ response induced by LPS: role of neutrophils

$\begin{array}{lll}\text { Chapter } 7 & \text { Summary and general discussion } & 119\end{array}$

$\begin{array}{ll}\text { Samenvatting en algemene discussie } & 129\end{array}$

$\begin{array}{ll}\text { Dankwoord } & 137\end{array}$

$\begin{array}{ll}\text { Curriculum Vitae and Publications } & 141\end{array}$ 



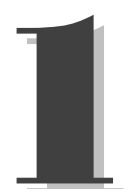

\section{General introduction}


The lung is a highly specialised organ that facilitates the uptake of oxygen and the release of carbon dioxide. Due to its unique structure, which provides enormous surface area to outside ambient air, it is continuously exposed to numerous pathogens and toxicants that are inhaled from air polluted with, for instance, cigarette smoke, automobile exhaust, diesel, etc., which makes the lung susceptible to varying degrees of injury. To combat these unrelenting physical, chemical and biological insults, the respiratory epithelium is covered with a thin layer of lining fluid containing several antioxidants and surfactants, serving as a first line of defence. Nonetheless, inhalation of such toxic air pollutants and microorganisms can result in lung injury and the generation of reactive oxygen/nitrogen species (ROS/RNS), which in turn leads to a cascade of signalling events that trigger the inflammatory response by the release of proinflammatory cytokines and chemokines [1].

Inflammation is the primary reaction of a tissue to eliminate pathogenic insults and injured tissue components in order to restore normal physiological functions or replace the irreparable tissue with scar tissue. A key component of this innate defence mechanism of the lung is the influx and accumulation of inflammatory phagocytes, namely polymorphonuclear neutrophils (PMN) and alveolar macrophages. These cells play a pivotal role in eliminating the pathogen or other biological intruders through the generation of various ROS. The most significant and important ROS generating cell system in the lung is the pool of inflammatory neutrophils. In the course of their defence activities, they produce a vast amount of oxidants, including superoxide $\left(\mathrm{O}_{2}{ }^{--}\right)$, hydrogen peroxide $\left(\mathrm{H}_{2} \mathrm{O}_{2}\right)$, hypochlorous acid $(\mathrm{HOCl})$ and nitric oxide $(\mathrm{NO})^{\circ}$. This spectrum of different oxidants can be attributed to the action of four different enzymes, respectively NADPH oxidase, superoxide dismutase, myeloperoxidase (MPO) and nitric oxide synthase, catalysing different reactions [for review, see chapter 2]. These reactive species help in killing the pathogen, and the inflammation often subsides after the insulting agent is removed or following the completion of the repair process. However, repeated tissue damage and regeneration due to persistent inhalation of toxic agents, such as by smoking cigarettes, may result in increased macrophage recruitment, delayed neutrophil clearance and increased ROS/RNS production. This may ultimately lead to chronic inflammation and lung injury. In contrast to the protective effects, such overwhelming ROS production by inflammatory cells may damage macromolecules (DNA, lipids, proteins) in proliferating lung epithelial cells. This may ultimately result in permanent genomic alterations, such as point mutations, deletions or rearrangements [2]. In this way, chronic inflammation provides a microenvironment, which is rich in inflammatory cells, ROS/RNS, recurring DNA damage and growth factors; thereby further facilitating malignant transformation in the lung [3].

The functional relationship between inflammation and cancer is not a novel concept. As early as in the $19^{\text {th }}$ century, it was observed that tumours often arose at sites of chronic irritation [4]. More recently, a large number of epidemiological studies have confirmed that chronic inflammation in selected organs predisposes for cancer. Also in pulmonary pathologies, such as chronic obstructive pulmonary disease (COPD) 
and cancer induced by exposure to cigarette smoke, inflammation is considered as a major precursor or "hallmark" for cancer development [5].

The communalities in smoking, COPD and lung cancer begin with profound alterations induced by cigarette smoke, which contains known carcinogens as well as high levels of ROS. The induction of ROS after tobacco smoke exposure leads to the impairment of epithelial and endothelial cell function as well as inflammation. The ongoing inflammatory processes in COPD may persist after smoking cessation and have been related to disease progression and lung cancer risk [6, 7]. As COPD progresses, the percentage of the airways that contains neutrophils, macrophages and $T$ cells increases [6]. This prominent presence of neutrophils associated with COPD, suggest a significant role of the ongoing neutrophilic inflammation in the carcinogenic response [8].

Neutrophils are the major source of oxidants in the inflamed lung. The constant release of ROS by these cells provides a plausible mechanism by which inflammatory processes and pulmonary carcinogenesis might be related; ROS cause genetic alterations in the lung epithelium, which may promote cancer development [9]. At this moment, it is indeed generally accepted that the carcinogenic capacity of neutrophils is at least partly attributable to the generation of DNA damaging and mutagenic ROS. Additionally, considering the exposure to inhaled carcinogens as well as the simultaneous presence of inflammatory neutrophils in the lung of smokers, neutrophils are also implicated in pulmonary genotoxicity via the MPO mediated peroxidative metabolic activation of inhaled chemical carcinogens, thereby generating highly DNA reactive and mutagenic compounds [for review, see chapter 2]. Furthermore, it should be noted that the induction of DNA damage and mutagenesis alone does not cause cancer and that neutrophil derived ROS may also be implicated in a wide variety of other processes that could contribute to tumourigenesis. Apart from inducing oxidative DNA damage, oxidising species could also be implicated in modifying DNA repair capacity of target cells [for review, see chapter 2]. Such an inhibitory effect on DNA repair could provide an additional contribution of neutrophil derived ROS to the mutagenic environment during chronic inflammation. Moreover, neutrophils may also have an impact on a variety of other (pre-)neoplastic processes besides cell proliferation, such as angiogenesis and metastasis, by generating a prooxidant environment, as well as by releasing defensins, proteases or growth factors.

\section{AIMS and OUTLINE of the thesis}

Because pulmonary inflammation plays an important role in the pathogenesis of lung cancer, a thorough understanding of lung cancer pathogenesis requires consideration of the tumour microenvironment and the inflammatory pathways cooperative in carcinogenesis.

Presently, there is convincing evidence indicating a crucial role of neutrophils in pulmonary carcinogenesis by their genotoxic capacity. This is mainly thought to occur through the release of mutagenic ROS leading to oxidative DNA damage. On the 
other hand, the metabolic activation of chemical carcinogens is known to be promoted via the neutrophil derived enzyme MPO, resulting in DNA adducts. These DNA lesions may be converted to mutations due to mispairing during DNA replication, unless they are repaired by DNA repair processes. Apart from inducing oxidative DNA damage, neutrophil derived ROS have also been implicated in modifying the DNA repair capacity of target cells. Moreover, several oxidising species are reported to act as endogenous inhibitors of nucleotide excision repair (NER), the most important DNA repair process involved in the removal of bulky DNA adducts. This provides a possible additional explanation for the association between neutrophils and lung cancer risk in subjects exposed to DNA adduct forming chemicals. Nevertheless, there are only limited data available on a potential role of the major neutrophil derived oxidant $\mathrm{HOCl}$ in the pathophysiology of inflammation related carcinogenesis. Therefore, the central aim of the present thesis was to investigate mechanisms of neutrophil induced genotoxicity and to elucidate the specific role of the neutrophil derived enzyme MPO and its product $\mathrm{HOCl}$ herein.

This thesis will highlight three distinct pathways of neutrophil induced genotoxicity in lung epithelial cells:

- $\quad$ Genotoxic effects of neutrophils and $\mathrm{HOCl}$;

- $\quad$ DNA repair inhibition by neutrophils and $\mathrm{HOCl}$;

- Neutrophil induced inflammatory pathways and gene expression changes in the lung microenvironment.

The studies described in this thesis primarily focus on epithelial cells (type II) that line the respiratory tract, since these are considered to be a specific target for smoking associated carcinogenesis. Both in vitro and in vivo models were used. Since current in vivo models are not well suited to distinguish between the different cell types integrated into the lung tissue, the in vitro models were applied to determine specific mechanisms underlying the influence of neutrophils and $\mathrm{HOCl}$ on lung epithelial target cells.

As a general overview, the scientific literature on the DNA damaging and mutagenic capacity of neutrophils is reviewed in chapter 2 , as well as a discussion of the implication of these processes in pulmonary carcinogenesis.

With respect to direct neutrophil induced genotoxicity, in chapter 3, the DNA damaging and mutagenic capacity of $\mathrm{HOCl}$ in epithelial lung cells in vitro is studied. Moreover, to extend the in vitro observations into the whole organism, $\mathrm{HOCl}$ induced DNA damaging effects were assessed in the mouse lung, using an acute lung inflammation model in combination with neutrophil depletion.

Considering the widespread exposure to inhaled DNA adduct forming carcinogens, as well as the simultaneous presence of neutrophils in the inflamed lung, in chapter 4, the reduction of NER by neutrophils and their product $\mathrm{HOCl}$ (produced by MPO) is proposed as a significant contributory factor in the development of inflammation related pulmonary mutagenesis and carcinogenesis. The effect of activated neutrophils on the NER capacity of lung target cells was studied using a coincubation 
model of neutrophils and type II epithelial cells. Based on initial in vitro findings, the effect of neutrophil inflammation on NER was investigated in the mouse lung following acute inflammation (chapter 5). The causal role of MPO and neutrophils in this in vivo effect was addressed respectively in MPO knockout mice and mice depleted of circulating neutrophils.

Another way to explore the relation between lung inflammation and cancer, and the role of neutrophils herein is a gene expression profiling of airway epithelial cells using microarray technology. Chapter 6 describes the normal airway transcriptome of mice and the neutrophil induced alterations following inflammation to define pathogenic changes in the microenvironment that could contribute to tumour development.

Finally, chapter 7 comprises a summary of the results and a general discussion. 


\section{References}

1. Emmendoerffer, A., Hecht, M., Boeker, T., Mueller, M. and Heinrich, U. (2000) Role of inflammation in chemical-induced lung cancer. Toxicol Lett, 112-113, 185-191.

2. Coussens, L.M. and Werb, Z. (2002) Inflammation and cancer. Nature, 420, 860-867.

3. Ardies, C.M. (2003) Inflammation as cause for scar cancers of the lung. Integr Cancer Ther, 2, 238-246.

4. Virchow, R. (1860) Cellular pathology. 7th edition. Translated by Chance F. Dewitt, New York, $p$ 554.

5. Skillrud, D.M., Offord, K.P. and Miller, R.D. (1986) Higher risk of lung cancer in chronic obstructive pulmonary disease. A prospective, matched, controlled study. Ann Intern Med, 105, 503-507.

6. Hogg, J.C., Chu, F., Utokaparch, S., Woods, R., Elliott, W.M., Buzatu, L., Cherniack, R.M., Rogers, R.M., Sciurba, F.C., Coxson, H.O. and Pare, P.D. (2004) The nature of small-airway obstruction in chronic obstructive pulmonary disease. N Engl J Med, 350, 2645-2653.

7. Tockman, M.S., Anthonisen, N.R., Wright, E.C. and Donithan, M.G. (1987) Airways obstruction and the risk for lung cancer. Ann Intern Med, 106, 512-518.

8. de Visser, K.E., Eichten, A. and Coussens, L.M. (2006) Paradoxical roles of the immune system during cancer development. Nat Rev Cancer, 6, 24-37.

9. Weitzman, S.A. and Gordon, L.I. (1990) Inflammation and cancer: role of phagocyte-generated oxidants in carcinogenesis. Blood, 76, 655-663. 



\title{
Neutrophils and respiratory
}

\section{tract DNA damage and}

\author{
mutagenesis:
}

a review

Mutagenesis 2006; 21:225-236.

Knaapen AM

Güngör N

Schins RP

Borm PJ

van Schooten FJ 



\begin{abstract}
Inflammation has been recognised as an important factor in cancer development. For the lung, experimental studies with rats, as well as molecular epidemiological studies in humans have provided evidence that the influx of neutrophils into the airways may be an important process linking inflammation with carcinogenesis. Currently, it is believed that the genotoxic capacity of neutrophils is a crucial etiological factor in this carcinogenic response. In the present review, we discuss two major pathways of neutrophil induced genotoxicity: i) Induction of oxidative DNA damage through release of reactive oxygen species (ROS), and ii) Myeloperoxidase related metabolic activation of chemical carcinogens. So far, direct evidence for a role of neutrophils in pulmonary genotoxicity has largely been derived from in vitro studies using cocultures of activated neutrophils and target cells. Current evidence from in vivo studies is primarily indirect and additional animal studies are needed to substantiate causality. A further challenge will be to extrapolate results from such studies to humans. Taken together, this will provide a better insight into the role of neutrophils in pulmonary carcinogenicity, and may hence lead to novel approaches for cancer prevention strategies.
\end{abstract}




\section{Introduction}

The association between chronic inflammation and the development of cancer has been recognised for a long time [1, 2]. In fact, as early as the late 1800's, Rudolf Virchow described the appearance of tumours developed at sites of chronic irritation [3]. Currently, there is a large number of clinical data confirming these early observations. Colon carcinomas are for example closely associated with chronic inflammatory bowel diseases, including colitis ulcerosis [4]. Similarly, patients with chronic infections, such as osteomylitis or decubitus ulcers, can develop very aggressive carcinomas [5] and urinary bladder cancer is frequently found in patients who suffer from urinary tract infection [6]. Also in the lung, chronic inflammatory diseases, such as sarcoidosis, fibrosis and chronic obstructive pulmonary disease (COPD), have been associated with a higher risk of cancer development [2, 7-10]. In addition, other studies demonstrated that human lung cancer risk can be modified by polymorphisms in proinflammatory genes, such as $I L-1 \beta$ and $T N F-\alpha[11,12]$. The strongest support for the involvement of chronic inflammation in carcinogenesis, however, is possibly derived from studies showing that long-term users of anti-inflammatory drugs may be at a reduced risk of cancer development [13].

Within the lung, many sources of inflammation may be effective in accelerating carcinogenesis, including inflammatory reactions caused by air pollution particles (e.g. cigarette smoke, diesel, quartz) [for review: 14, 15]. Inflammatory processes in the lung are characterised by the influx of neutrophils into the airways and it is generally accepted that these cells are crucially involved in the pathogenesis of various chronic pulmonary diseases. The pulmonary vasculature represents the largest reservoir of circulating polymorphonuclear neutrophils (PMN) in the human body. The concentration of neutrophils within the pulmonary capillary blood is 35-100x greater than within the large vessels of the systemic circulation, thereby providing a pool of rapidly recruitable neutrophils [16]. Neutrophils are a major source of oxidants in the inflamed lungs, and the constant release of reactive oxygen species (ROS) by these cells provides a plausible mechanism by which inflammatory processes and pulmonary carcinogenesis might be related: ROS cause genetic alterations in the lung epithelium, which may promote cancer development [17]. In this paper, we provide a review of the DNA damaging and mutagenic capacity of neutrophils as well as a discussion of the implications of these processes for pulmonary carcinogenesis. We will specifically focus on the lung, as the concept of neutrophil infiltration in relation to tumour development is largely derived from studies investigating the pulmonary pathogenicity of inhaled particles [review: 14, 15, 18]. This review will highlight two distinct pathways of neutrophil induced genotoxicity: i) Oxidative DNA disturbances caused by neutrophil derived ROS and ii) Myeloperoxidase (MPO) mediated metabolic activation of inhaled chemical carcinogens. It should be realised that induction of DNA damage and mutagenesis alone does not cause cancer and that neutrophils, for instance by generating a prooxidant environment, as well as by releasing defensins [19], proteases or growth factors may have an impact on a variety of other neoplastic processes, including cell proliferation, metastasis and angiogenesis. However, these topics are beyond the 
scope of this paper, and are discussed in several excellent reviews [e.g. 1, 2, 17 and others].

\section{Pulmonary neutrophils: friend or foe?}

Inflammation is a normal response of tissues to 'inactivate' invading microbial, chemical or physical agents. A key component in the inflammatory reaction is the transport and accumulation of phagocytes into the injured tissue. The role of neutrophils in host defence was first discovered in the late 1800's by Elie Metchnikoff, who observed that 'wandering' cells crowded around sharp thorns which he had pierced into transparent starfish larvae [20]. In the lung, the recruitment of neutrophils upon inhalation of inflammogenic agents largely depends on an elaborate network of cytokines [21]. In this process, resident alveolar macrophages have a pivotal role. In normal conditions, alveolar macrophages clear most of the invading microorganisms or particles. However, when macrophages are overwhelmed by the intrinsic inflammogenic activity of the pathogens, they will be activated to release a wealth of cytokines and chemokines, eliciting a rapid inflammatory reaction. In general, neutrophil recruitment is characterised by three subsequent steps: adherence, extravasation and migration [22, 23]. The adherence of PMN to the vascular endothelium is mediated by specific adhesion molecules [22]. Subsequent processes of pulmonary neutrophil recruitment (extravasation and migration) are controlled by chemokines, including IL-8 [24-26]. For a more detailed description of the processes involved in neutrophil trafficking into the airways, readers are referred to other reviews [e.g 16, 22, 27-29]. Once migrated into the lung, the PMN will be activated to release a myriad of products dedicated to kill invading pathogens. Currently, more than fifty neutrophil derived toxins have been identified, including proteolytic enzymes and bactericidal proteins [for extensive review: 27, 30]. A hallmark of neutrophil activation, however, is their respiratory burst. This is characterised by an increased consumption of oxygen that is used to generate large amounts of ROS. This process ultimately leads to the conversion of $\mathrm{H}_{2} \mathrm{O}_{2}$ into hypochlorous acid $(\mathrm{HOCl})$ by the neutrophilic enzyme $\mathrm{MPO}$. $\mathrm{HOCl}$ is a very strong oxidant which plays a crucial role in actual killing of inhaled pathogens by migrated neutrophils [31].

In contrast to their protective role in innate immunity, PMN are also implicated in the pathogenesis of a variety of acute or chronic inflammatory pulmonary diseases, including chronic obstructive pulmonary disease [32, 33], idiopathic pulmonary fibrosis [34] and the adult respiratory distress syndrome [35]. In these diseases, neutrophils are associated with several pathogenic processes. For instance, PMN derived oxidants and proteolytic compounds are implicated in a great variety of injurious effects, including lung matrix degradation, killing of pulmonary epithelial and vascular endothelial cells and inducing detachment of these cells from their matrix support [36, 37]. Furthermore, oxidants released by neutrophils might have a role in deregulation of the airway smooth muscle function, disturbing its contractile response [38]. Finally, neu- 
trophil derived ROS cause oxidative DNA damage that may provoke mutagenesis in pulmonary target cells.

\section{Neutrophils as a source of ROS}

The most significant and important ROS generating system in the lung is constituted by the pool of inflammatory neutrophils. In the course of their defence activities, they produce a vast amount of oxidants. The whole spectrum of oxidants generated by neutrophils is more or less due to the action of four different enzymes, catalysing different reactions (summarised in Table 1). NADPH-oxidase is the enzyme by which the oxidant generation is initiated. It is a membrane-bound enzyme, which is dormant in resting cells, but comes into action when the cell is activated by phagocytosis of invading microorganisms or particles. NADPH-oxidase is composed of a number of subunits, which are distributed in the cytosol and the membranes of intracellular vesicles and organelles. Upon activation, the cytosolic subunits migrate to the membranes where they bind to membrane-bound subunits, assembling the active oxidase. The intracellular organelles then fuse with the plasma membrane resulting in the release of $\mathrm{O}_{2}{ }^{*-}$ into the extracellular environment or into phagocytic vesicles [39]. This $\mathrm{O}_{2}{ }^{--}$is a substrate for the enzyme superoxide dismutase (SOD), which catalyses the formation of $\mathrm{H}_{2} \mathrm{O}_{2}$ from $\mathrm{O}_{2}{ }^{--}$[40]. $\mathrm{H}_{2} \mathrm{O}_{2}$ is relatively stable and is known for its capacity to diffuse and to cross cellular membranes. As such, this provides a phagocyte the possibility to 'act at a distance'. In neutrophils, however, most of the hydrogen peroxide (up to $70 \%$ ) is consumed by the enzyme MPO [41]. MPO is the most abundant protein in neutrophils and catalyses the conversion of $\mathrm{H}_{2} \mathrm{O}_{2}$ into $\mathrm{HOCl}$ [31]. In addition, neutrophils are also able to produce reactive nitrogen species (RNS), which is facilitated by inducible nitric oxide synthase (iNOS), catalysing the production of $\mathrm{NO}^{\circ}$ from L-arginine, oxygen and NADPH [42]. However, the ability of neutrophils to yield NO is much less compared to macrophages $[43,44]$, and studies on the activity of iNOS in isolated blood neutrophils have yielded contradictory results $[45,46]$.

Table 1: Enzymes and rections involved in oxidant generation by neutrophils

\begin{tabular}{lll}
\hline Enzymes & Reactions & Product \\
\hline NADPH oxidase & $2 \mathrm{O}_{2}+\mathrm{NADPH} \rightarrow 2 \mathrm{O}_{2}^{--}+\mathrm{NADP}^{+}+\mathrm{H}^{+}$ & $\mathrm{O}_{2}{ }^{--}$ \\
Superoxide dismutase & $2 \mathrm{O}_{2}^{--}+2 \mathrm{H}^{+} \rightarrow \mathrm{O}_{2}+\mathrm{H}_{2} \mathrm{O}_{2}$ & $\mathrm{H}_{2} \mathrm{O}_{2}$ \\
Myeloperoxidase & $\mathrm{Cl}^{-}+\mathrm{H}_{2} \mathrm{O}_{2} \rightarrow \mathrm{HOCl}+\mathrm{OH}^{-}$ & $\mathrm{HOCl}^{\circ}$ \\
Nitric oxide synthase & $\mathrm{L}-\mathrm{arg}+\mathrm{O}_{2}+\mathrm{NADPH} \rightarrow \mathrm{NO}^{\circ}+\mathrm{L}_{\text {-citrulline }+\mathrm{NADP}^{+}}$ & $\mathrm{NO}^{\circ}$ \\
\hline
\end{tabular}

The enzymes as listed in Table 1 give rise to the four oxidants initially generated by activated neutrophils, $\mathrm{O}_{2}{ }^{-}, \mathrm{H}_{2} \mathrm{O}_{2}, \mathrm{HOCl}, \mathrm{NO}^{\circ}$. Because of their reactivity, these products will constantly interact with each other, causing the formation of a myriad of oxidants (see Fig. 1), among which the hydroxyl radical is recognised as being the most DNA reactive compound by far $[47,48]$. 


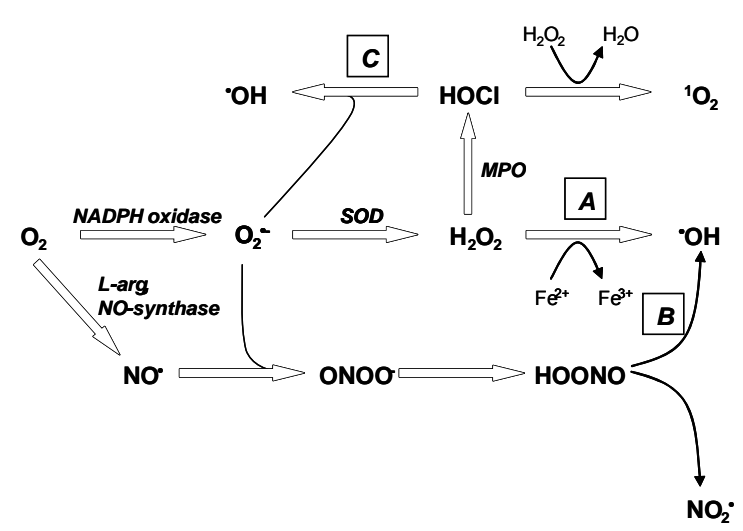

Figure 1. Schematic overview of the generation and interaction of reactive oxygen species produced by neutrophils. Three different pathways for the generation of ${ }^{\circ} \mathrm{OH}$ are indicated $(A, B, C)$.

\section{Oxidant induced genotoxicity by neutrophils}

Genotoxic processes may lead to irreversible changes in the structure of the genetic material of cells. This effect is considered as an important process in cancer development. The term 'genotoxic' has been used for the first time in 1973 by Hermann Druckrey during a conference on 'Evaluation of genetic risks of environmental chemicals' in Sweden. He stated: "In order to describe the components of chemical interaction with genetic material, the term genotoxic is proposed as a general expression to cover toxic, lethal and heritable effects to karyotic and extracaryotic genetic material in germinal and somatic cells" [49]. At this moment, it is generally accepted that the carcinogenic capacity of neutrophils is at least partly attributable to the generation of DNA damaging and mutagenic ROS. However, it should be realised that neutrophilic ROS may be implicated in a wide variety of other processes that could all contribute to tumourigenesis (Fig. 2).

In the past, a variety of genotoxic properties of phagocyte derived ROS have been investigated, including their capacity to induce DNA damage, DNA mutations, and chromosomal aberrations. Before discussing the mechanisms by which neutrophils may cause oxidative damage to target cellular DNA, some background information about the processes by which neutrophil derived ROS per se may damage DNA is provided in the next paragraph. 


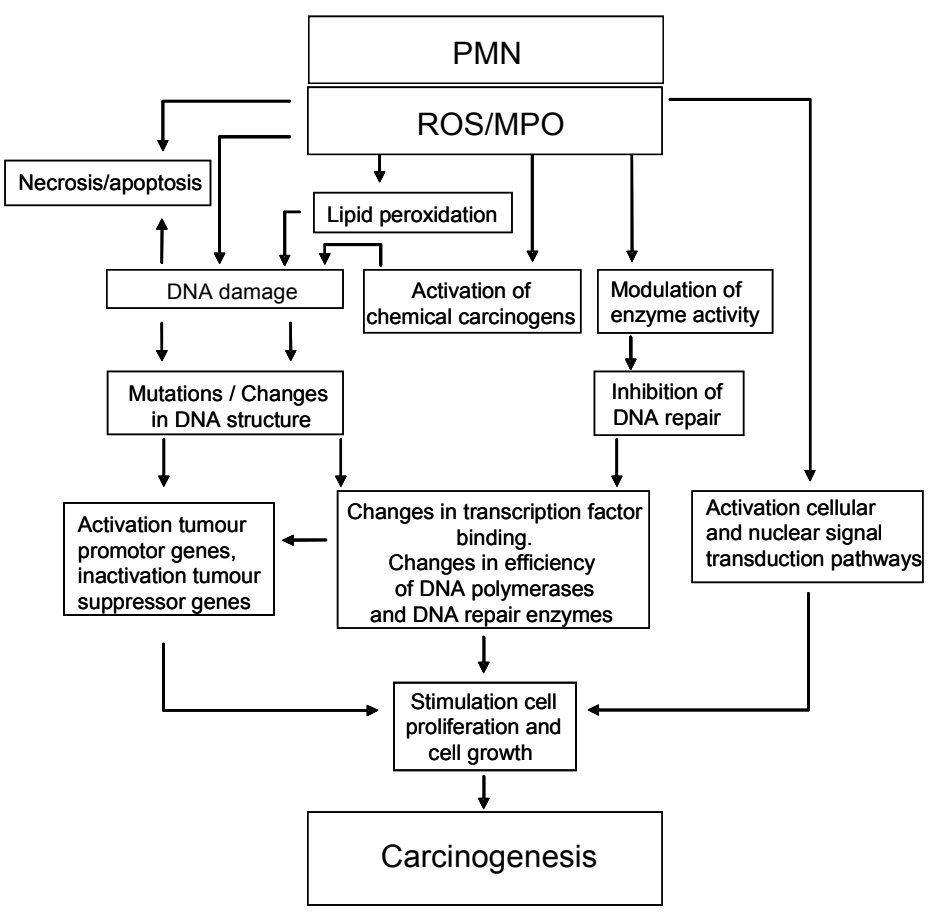

Figure 2. Overview of a variety of processes by which neutrophil derived ROS may promote tumour development. The present review specifically focuses on the processes involved in neutrophil induced DNA damage and mutagenesis.

\section{Modification of DNA by ROS}

A major development in carcinogenesis research in the past 20 years has been the discovery of DNA damage induced by ROS derived from both endogenous and exogenous sources [50]. In the mid 1980's, Ames and coworkers discovered that oxidised DNA bases were abundantly present in tissues of both humans and rodents [51]. At the same time, it became evident that ROS induced DNA damage was likely to be involved in carcinogenesis. Many of the ROS indeed have characteristics which indicate that they are possible carcinogens [52] (also see Fig. 2). Generally, the reactions contributing to ROS induced DNA damage are oxidation, nitration, depurination, methylation and deamination. The reactivity of the various ROS towards the DNA is extremely variable. For instance, superoxide and hydrogen peroxide are thought not to react with DNA at all [52]. The hydroxyl radical on the other hand, is the most DNA reactive ROS, which generates a multiplicity of products from all 4 bases [53]. The best studied DNA lesion caused by hydroxyl radical attack is 8hydroxydeoxyguanosine (8-oxo-dG), which is produced by a hydroxylation of the C-8 position of the guanine derivative of the DNA [54]. Currently, there is a consensus that the presence of 8-oxo-dG, which is in fact a premutagenic lesion, is associated with 
the carcinogenic process [55]. In addition to 8-oxo-dG, numerous other kinds of ${ }^{\circ} \mathrm{OH}$ modified DNA bases have been described, including 5-hydroxymethyluracil, 5hydroxyuracil, 5-hydroxyadenine, 8-hydroxyadenine, 2,6-diamino-4-hydroxy-5formamidopyrimidine [52]. However, in contrast to 8-oxo-dG, the biological implications and significance of these lesions for carcinogenesis are often less well understood.

Although ${ }^{\circ} \mathrm{OH}$ causes the most significant and abundant DNA base lesions in mammalians, other neutrophil derived ROS may also interact with DNA. HOCl for instance, which is one of the major oxidants produced by neutrophils, is shown to react with DNA, thereby inducing DNA-protein crosslinks, chlorination of DNA bases, as well as pyrimidine oxidation products [56-58]. One specific nucleobase damage product that is formed by treatment of naked DNA as well as cellular DNA with $\mathrm{HOCl}$ is 5-chlorouracil, which is also suggested to act as a fingerprint of DNA damage by $\mathrm{HOCl}[56,59,60]$. Due to its extreme cytotoxic activity, $\mathrm{HOCl}$ induced DNA damage in target cells is often associated with cell death. Therefore, the consequence of such DNA damage with regard to mutagenicity in competent proliferating cells is still controversial. Peroxynitrite is also suggested to damage DNA bases, likely by deamination or nitration $[61,62]$. Neutrophil derived ROS may also indirectly damage DNA through production of lipid hydroperoxides. In this process, a variety of very reactive side-products can be generated, such as epoxides or aldehydes. Among these, malondialdehyde and 4-hydroxynonenal are extensively studied and are shown to be highly DNA reactive $[63,64]$ and mutagenic [65]. In addition to oxidising DNA bases, ROS may cause DNA strand breakage due to free radical attack of the DNA sugarphosphate backbone [66]. DNA strand breaks can be categorised as either singlestrand or double-strand breaks, and may cause mutagenic and clastogenic effects.

A large amount of knowledge about the DNA reactivity of various ROS as described above is obtained from incubations of purified ROS with naked DNA. However, the relevance of such a-cellular assays with respect to the mechanism of ROS induced genotoxicity by neutrophils can be questioned, because the kinetics of ROS production by neutrophils and subsequent availability of these ROS to damage target cellular DNA are totally different. Therefore, mechanistic in vitro analysis of genotoxic effects of neutrophils should ideally involve cocultures of neutrophils and target cells, since this more closely mimics the real life situation.

\section{Neutrophil induced oxidative genotoxicity}

\section{Evidence from cocultures with target cells}

In Table 2, a historical overview of studies reporting oxidant induced genotoxic effects of activated phagocytes, mostly of PMN, is listed. The general concept of these studies is that they all use cocultures of phagocytes and specific target cells. In these experiments, the phagocytic oxidative burst is generally initiated by addition of phorbol esters, like PMA, to trigger protein kinase $\mathrm{C}$ mediated activation of NADPH-oxidase. A variety of genotoxic endpoints is then assessed in cocultured bacteria or specific 
mammalian target cells. The first observation of phagocyte induced genotoxicity and the crucial role of ROS herein was reported by Weitzman and Stossel in 1981 [67]. They found that the ability of peripheral blood leukocytes to induce mutations in bacteria was markedly attenuated when cells were used from a patient with chronic granulomatous disease (CGD). In CGD, neutrophils have a defect in the NADPH-oxidase mediated generation of $\mathrm{O}_{2}{ }^{--}$, and are thus unable to generate ROS. The first study on leukocyte mediated genotoxic (clastogenic) effects in mammalian cells was published by Weitberg et al. in 1983, describing leukocyte induced sister chromatide exchanges (SCE's) in hamster ovary cells [69]. Further studies from Weitzman and Stossel (1984), describing the induction of mutations in mammalian cells by phagocytes [71], finally led to a publication from the same group showing the development of tumours in athymic mice injected with fibroblasts which were previously exposed to activated human neutrophils [73]. This was a rather important finding, since it provided a causal link between neutrophil activity, ROS release and carcinogenesis. Mechanisms were then further elucidated by the discovery of oxidative DNA base damage induced by neutrophils, first in naked DNA [87, 88] and later also in target cellular DNA $[79,83]$. Such oxidised DNA bases, including 8-oxo-dG are premutagenic and could possibly explain the reported mutagenic effects of neutrophils. In other studies, neutrophils were also found to induce target cellular DNA strand breakage [e.g. 75-77, 86]. Further crucial observations with regard to effects in the lung were published by Driscoll and coworkers [82, 89], who demonstrated that neutrophils, obtained by bronchoalveolar lavage (BAL) from particle exposed rats, were mutagenic to alveolar epithelial cells in vitro.

The specific role of ROS in phagocyte induced genotoxicity was not only confirmed by using PMN from chronic granulomatous disease patients, but also by the use of a variety of specific antioxidants [81, 82]. This approach, and more specifically, the use of catalase, has led to a consensus that hydrogen peroxide is the major ROS that is mediating genotoxic processes induced by activated phagocytes $[75,76,82$, 90]. Indeed, by using various target cells in vitro, it was shown that reagent hydrogen peroxide was able to induce base damage and strand breakage in nuclear DNA [75, 83, 86, 91, 92]. Furthermore, it has been established that the type of DNA base modifications as detected in target cells exposed to reagent $\mathrm{H}_{2} \mathrm{O}_{2}$ is highly comparable with the damage induced by activated neutrophils. In general, these reflect hydroxyl radical specific DNA modifications, indicating that neutrophil derived $\mathrm{H}_{2} \mathrm{O}_{2}$ acts as a progenitor of the hydroxyl radical, which then ultimately attacks cellular DNA [76, 79, 88, 92]. This is further illustrated by own observations showing that activated neutrophils cause induction of hydroxyl radical mediated 8-oxo-dG in pulmonary epithelial cells [83]. In addition, other studies revealed that hydroxyl radical scavengers were effective in reducing neutrophil induced sister chromatide exchanges [72], mutations [93] and DNA strand breakage [76] in target cells. Now, based on these collaborate findings, it is hypothesised that neutrophil derived $\mathrm{H}_{2} \mathrm{O}_{2}$, which is relatively stable, diffuses through the plasma membrane towards the nucleus where it reacts with DNA bound transition metals to form hydroxyl radicals via the Fenton reaction. We observed that close contact between target cells and activated neutrophils is a prerequi- 
site for this process to occur, as supernatants from activated neutrophils were unable to induce cellular DNA damage, likely since $\mathrm{H}_{2} \mathrm{O}_{2}$ is consumed by neutrophilic MPO or catalase [85]. But even when close contact between neutrophils and target cells is allowed (e.g. in coculture systems), there will be a constant balance between the consumption of $\mathrm{H}_{2} \mathrm{O}_{2}$ by MPO, versus the capturing of diffusible $\mathrm{H}_{2} \mathrm{O}_{2}$ by the neighbouring target cells [94]. This is possibly illustrated by recent experiments in which we observed that neutrophil induced DNA strand breakage in cocultured pulmonary target cells was increased upon inhibition of MPO activity, suggesting an increased availability of diffusible and DNA breaking $\mathrm{H}_{2} \mathrm{O}_{2}$ [86].

Table 2: Chronological overview of in vitro coculture studies showing (oxidant mediated) genotoxic properties of phagocytes (neutrophils and macrophages) in a variety of target cells

\begin{tabular}{lll}
\hline Target & Genotoxic endpoint & Reference \\
\hline Salmonella & Mutations & Weitzman and Stossel, 1982 [67] \\
Photobact. Fischeri & Mutations & Baker et al., 1983 [68] \\
Chinese hamster ovary cells & Sister chromatid exchanges & Weitberg et al., 1983 [69] \\
Salmonella & Mutations & Fulton et al., 1984 [70] \\
Chinese hamster ovary cells & Mutations (Hprt) & Weitzman and Stossel, 1984 [71] \\
Chinese hamster ovary cells & Sister chromatid exchanges & Weitberg et al., 1985 [72] \\
Mouse fibroblasts & Malignant transformation & Weitzman et al., 1985 [73] \\
E. Coli & Mutations & De Togni et al., 1988 [74] \\
Human lymphocytes & Strand breaks and PARP activity & Schraufstätter et al., 1988 [75] \\
Plasmacytoma celline & DNA strand breaks & Shacter et al., 1988 [76] \\
Tumour cells & DNA strand breaks & Chong et al., 1989 [77] \\
Tumour cells & DNA strand breaks & Shacter et al. , 1990 [78] \\
Human Ad293 cells & DNA base modifications & Dizdaroglu et al., , 1993 [79] \\
Mononuclear leukocytes & DNA strand breaks & Van Staden et al., 1993 [80] \\
Human Ad293 cells & Mutations (frequency and spectrum) & Akman et al., 1996 [81] \\
Alveolar epithelial cells & Mutations (HPRT) & Driscoll et al., 1997 [82] \\
Alveolar epithelial cells & 8-oxo-dG & Knaapen et al., 1999 [83] \\
Chinese hamster ovary cell line & Mutations (Gpt) & Kim et al., 2003 [84] \\
Alveolar epithelial cells & DNA strand breaks & Knaapen et al., 2005 [85] \\
\hline
\end{tabular}

Although the studies as described above contribute to a concept of $\mathrm{H}_{2} \mathrm{O}_{2}$ induced genotoxicity by neutrophils, also $\mathrm{H}_{2} \mathrm{O}_{2}$ independent mechanisms of neutrophil induced genotoxicity should be considered. For instance, Gera and Lichtenstein (1991) demonstrated that neutrophil derived defensins were able to induce DNA strand breaks in target cells [95]. The possible role of neutrophil derived ROS beside $\mathrm{H}_{2} \mathrm{O}_{2}$, is further illustrated by the observation that the mutational spectrum induced by activated neutrophils was different from the one induced by reagent $\mathrm{H}_{2} \mathrm{O}_{2}$ alone [81]. One likely alternative candidate $\mathrm{ROS}$ would be $\mathrm{HOCl}$. As described above, $\mathrm{HOCl}$ may induce a variety of mutagenic DNA base lesions, and studies have revealed the presence of $\mathrm{HOCl}$ related DNA modifications in human and experimental animal inflammatory tissues $[59,60]$.

Apart from inducing oxidative DNA damage, neutrophil derived ROS have also been implicated in modifying DNA repair capacity of target cells. In vitro studies have for instance shown that neutrophils are able to inhibit poly(ADP-ribose) polymerase and DNA strand break repair in neighbouring cells by virtue of their $\mathrm{HOCl}$ generating capacity $[96,97]$. Others showed that nitric oxide is a potent inhibitor of human Ogg1, 
a glycosylase that is involved in the repair of 8-oxo-dG lesions [98]. Although these observations need to be confirmed in vivo, they support the concept that an inhibitory effect on DNA repair is an additional contribution of neutrophil derived ROS to the mutagenic environment of chronic inflammation.

\section{Evidence from in vivo studies}

A large body of evidence for a role of neutrophils in pulmonary ROS mediated genotoxicity has been derived from rat studies investigating toxicity of inhaled particles [for review: 14, 15, 18]. By the use of these animals, it has been demonstrated that chemical and physical differences between various poorly soluble particles (e.g. coal dust, carbon black, titanium dioxide) may not be the only factors predicting the lung tumour response, since patterns of tumour formation were not associated with any inherent genotoxic activity of such particles [99]. This suggests that there must be a common mechanism by which high doses of both toxic (e.g. quartz, diesel soot) and non-toxic particles (e.g. titanium dioxide, carbon black) induce carcinogenesis in the rat. By considering such a mechanism, it is currently hypothesised that high particle doses induce a chronic inflammatory response, mainly caused by impairment of particle clearance by alveolar macrophages. Consequently, it is proposed that tumour formation is only found at particle doses eliciting a certain minimal level of phagocyte influx with associated ROS release, at levels that overwhelm pulmonary antioxidant and DNA repair protection systems. The constant release of ROS by activated inflammatory phagocytes is indeed assumed to be a crucial event, since ROS may cause genotoxic effects in the lung epithelium as described above. These genetic alterations, together with increased and chronic target cell proliferation and tissue remodelling, are now considered to be crucial components in the particle induced carcinogenic response of the rat lung [9, 18, 99-101] (also see Fig. 2).

The inflammatory response in a particle exposed rat lung is characterised by an influx of neutrophils. For instance, in addition to an overall increase in inflammatory cells found in the bronchoalveolar lavage fluid, the percentage of neutrophils has been reported to increase from 3-4 \% in healthy non-exposed rats, up to levels above $50 \%$ after acute or subchronic exposure to particles, such as quartz, particulate matter or titanium dioxide [82, 89, 102-105]. Regarding a role of neutrophils in pulmonary genotoxicity, it has been established that in vivo mutagenicity in rat alveolar type II cells, isolated after particle exposure, was paralleled by a neutrophilic inflammation $[82,89]$. Specifically, we and others demonstrated that the association between neutrophil numbers in bronchalveolar lavage and Hprt mutation or DNA strand breakage in pulmonary epithelial cells shows a threshold, suggesting that endogenous protection mechanisms (e.g. DNA repair, antioxidant capacity) first need to be overwhelmed by neutrophil derived ROS in order to cause significant genotoxicity [101, 106]. A further confirmation of the neutrophils' role in particle induced tumour formation in the rat was obtained by the observation that BAL derived neutrophils from quartz exposed rats were mutagenic (Hprt) to alveolar type II cells in vitro, whereas no direct effect of quartz was found in the same system. Notably, these in vitro effects of neutrophils were attenuated by the use of catalase, indicating that the crucial role of $\mathrm{H}_{2} \mathrm{O}_{2}$ in neu- 
trophil induced genotoxicity, as described above for in vitro cocultures is also valid for the in vivo situation [82]. Importantly, in the studies from Driscoll and coworkers, the capacity of alveolar macrophages to induce ex vivo mutagenesis was found to be significantly lower than the capacity of neutrophils, which is in line with observations describing an increased ROS generating capacity of neutrophils compared to macrophages or monocytes [107, 108]. Further indications that neutrophils are indeed involved in early stages of particle induced carcinogenicity are found in studies showing that levels of DNA strand breakage, as well as 8-oxo-dG in lungs of acute and chronic quartz exposed rats, were associated with the intensity of neutrophil influx [106, 109111].

Table 3 provides an overview of in vivo studies, showing a relation between neutrophil influx and pulmonary genotoxicity in experimental animals. However, evidence obtained from such particle exposure studies is primarily associative, and no causal relationship between the presence of neutrophils and the induction of genotoxicity can be inferred from these studies. In fact, with respect to particle toxicology, there is still a lack of solid evidence that neutrophils are the true driving force behind particle induced pulmonary genotoxicity in the rat. Indeed, in the last few years, various contrasting results have been published. For instance, despite a massive neutrophil influx, we did not observe increased 8-oxo-dG levels in rat lungs seven days after silica exposure. In parallel, we found a significant induction of APE/Ref-1, which led us to suggest that the absence of steady-state 8-oxo-dG increases under conditions of persistent neutrophilic inflammation may result from a compensatory base excision repair [115]. In another study, differential mutagenic effects were observed in rats which were exposed to crystalline or amorphous silica, both titrated at exposure levels to result in similar neutrophil influx. Despite these similar neutrophil 'doses', increased mutations in the Hprt gene were only found in rats exposed to crystalline silica [116]. In addition, others observed that DNA strand breaks in BAL cells from carbon black exposed mice were independent of neutrophil infiltration [117].

Table 3: In vivo studies showing an association between neutrophil influx and oxidant related genotoxicity in the lung

\begin{tabular}{llll}
\hline Species & Exposure & Genotoxic endpoint & Reference \\
\hline Rat & Quartz/carbon black (i.t.) & Mutagenesis (Hprt) & Driscoll et al. , 1997/1996 [82, 89] \\
Rat & Quartz (i.t.) & DNA strand breaks & Knaapen et al., 2002 [106] \\
Rat & Quartz (i.t.) & 8-oxo-dG & Nehls et al..,1997 [110] \\
Rat & Quartz (i.t.) & 8-oxo-dG, p53 mutations & Seiler et al., 2002 [111] \\
Rat & Hyperoxia & 8-oxo-dG & Auten et al., 2002 [112] \\
Rat & Carbon black (inhalation) & 8-oxo-dG & Gallagher et al. , 2003 [113] \\
Mouse & Diesel (inhalation) & 8-oxo-dG, DNA strand breaks & Dybdahl et al. , 2004 [114] \\
& & (no increased mutagenesis) & \\
\hline
\end{tabular}

Rather simple approaches to test the causality between neutrophil influx and pulmonary genotoxicity would be either to use animals that are systemically depleted from neutrophils, for instance by administration of anti-PMN antibodies, or to use animals in which pulmonary influx of neutrophils is prevented by depletion of alveolar macrophages or by treatment with anti-chemokine antibodies [112, 118]. At present, we are 
only aware of one single study that addressed pulmonary pathogenicity (unfortunately not genotoxicity) of particles in rats that were depleted from PMN. Interestingly however, this study showed that the recruitment of PMN to the alveolar region is not necessarily linked with silica induced pulmonary toxicity [119]. In contrast, in a more recent and similar study, systemic depletion of neutrophils was shown to protect against airway pathogenicity induced after a 4 week inhalation challenge with LPS [120]. Still, there is a lack of studies that have used such approaches to elucidate the causal role of neutrophils on pulmonary genotoxicity specifically. One crucial example is a study by Auten and colleagues, which showed that blocking of neutrophil influx by treatment with anti-CINC antibodies caused a significant reduction of pulmonary oxidative DNA damage (8-oxo-dG and DNA nicking) in hyperoxia exposed newborn rats [112]. So far, this is the only study providing solid evidence for a causal role of neutrophils in eliciting pulmonary oxidative DNA damage in vivo. It is, however, questionable whether this approach, i.e. blocking neutrophil influx into the lung, can be applied in studies that focus on chronic effects of pulmonary neutrophilic inflammation. With regard to tumour formation, for instance, it must be realised that neutrophils might play a dual role in later stages of the carcinogenic process. On the one hand, PMN infiltration into tumours might stimulate tumour progression by facilitating tumour growth, metastasis and angiogenesis through the release of a variety of proteases and growth factors like vascular endothelial growth factor [1], as well as by contributing to genetic instability of the tumour cells through release of ROS [121]. In line with this, it has been shown that tumour growth can be inhibited by the elimination of circulating PMN [122]. On the other hand, PMN have also been identified as potent anti-tumour cells and studies suggest that neutrophil infiltration into some tumours is associated with a favourable prognosis [123]. Paradoxically, this inhibitory role largely depends on the same weaponry of neutrophils, e.g. release of cell damaging ROS, which is assumed to mediate their tumour promoting activity.

\section{Implications for the human situation}

The major question to be answered is whether the concept of in vitro and in vivo neutrophil induced pulmonary oxidative DNA damage and mutagenicity, as described above, can be extrapolated to humans. Current knowledge concerning the relation between neutrophils and pulmonary genotoxicity or carcinogenicity is largely obtained from high particle dose exposures using rats, which is recognised as a highly sensitive species with regard to particle induced tumour formation. In humans, however, neutrophil influx is generally much less compared to (particle exposed) rats: e.g. total cell numbers in the rat lung lavage can be increased more than 10-fold, with neutrophils exceeding $50 \%$. In contrast, heavy smokers, for instance, show a total cell recovery in bronchoalveolar lavage of about 4-5x greater than from non-smoking healthy individuals, with increases of neutrophils up to $10-30 \%$ [124, 125]. In addition, in humans that are chronically exposed to crystalline silica, the inflammatory response in the lung is mainly characterised by an influx of lymphocytes and macrophages rather than neutrophils [9], suggesting that neutrophils only play a minor part. Nevertheless, more recent data on effects of pulmonary instillation of particulate matter in 
human volunteers indicate that neutrophils might have a role in the more acute phase of particle exposure, with BAL neutrophil percentages up to $40 \%$ [126]. However, even if such a profound neutrophil influx occurs in humans, it remains unclear whether this could lead to oxidant induced genotoxicity. For instance, up to now there is still a lack of studies that tried to assess pulmonary oxidative DNA damage in lung diseases that are specifically characterised by neutrophil influx, such as chronic obstructive pulmonary disease or acute respiratory distress syndrome. An indication of the possible role of neutrophils in human pulmonary genotoxicity could be provided by previous studies from our own laboratory, where we focussed on the nose as a more easily accessible part of the respiratory tract to evaluate respiratory neutrophil induced DNA damage. To our own surprise however, we could not find a relation between neutrophil numbers present in nasal lavage and 8-oxo-dG formation in nasal epithelial cells, although the presence of neutrophils was closely associated with epithelial cell proliferation [85]. Although one should be cautious by interpreting these data, they indicate that the presence of neutrophils is not necessarily linked to oxidative DNA damage in the human respiratory tract. This would probably point to highly efficient antioxidant or DNA repair responses in humans, as opposed to the rat.

In considering the validity of the rat neutrophil model of pulmonary genotoxicity for the human situation, assessment of species specific host factors may provide useful information. In contrast to the rat, exposure of mice and hamsters to high lung particle doses has been much less associated with development of lung tumours, which is directly related to a less pronounced inflammatory response in these animals [15]. Regardless of the actual numbers of neutrophils that enter the airways, the inherent capacity of neutrophils to generate ROS, as well as the differential ability of species and/or target cells to counteract the adverse effects of ROS may be further crucial factors in defining the resulting neutrophil induced genotoxic effect. For instance, studies showed that the ROS releasing capacity of pulmonary neutrophils obtained from particle exposed hamsters was much less in comparison with cells obtained from the rat [127]. In addition, the hamster appeared to be far more effective at sustaining its antioxidant defences, suggesting a further explanation of the increased resistance of this species towards inflammation induced carcinogenicity [128].

\section{Metabolic activation of chemical carcinogens by neutrophils}

By inhalation of polluted air (e.g. diesel exhaust, cigarette smoke, etc.), the human respiratory tract is exposed to a variety of environmental chemical carcinogens. Currently, it is largely accepted that in addition to the direct genotoxic effects of ROS, neutrophil derived oxidants are also implicated in pulmonary genotoxicity via the promotion of metabolic activation of such inhaled chemicals, thereby generating highly DNA reactive and mutagenic compounds. For instance, neutrophils are able to transform aromatic compounds, such as benzene, into more carcinogenic metabolites through oxidant mediated hydroxylation and nitration reactions [129]. In addition, neutrophil derived nitrite was associated with increased formation of mutagenic $\mathrm{N}$ - 
nitrosamines in the presence of nitrosatable amine precursors [130], whereas others showed that neutrophil derived oxidants are able to activate heterocyclic amines, such as 2-amino-3,8-dimethylimidazo[4,5-f]quinoxaline (MelQx), into mutagenic electrophilic products [131]. However, probably the most relevant pathway by which neutrophils may enhance metabolic activation of chemical carcinogenesis is a myeloperoxidase mediated peroxidative metabolism. A selection of studies showing neutrophil mediated metabolic activation of chemical carcinogens is listed in Table 4.

\begin{tabular}{llll} 
Table 4: Examples of neutrophil or MPO mediated activation of environmental chemicals into genotoxic metabolites & \\
\hline Parent compound & Mutagenic/carcinogenic product or effect & Proposed mechanism & Ref. \\
\hline Amines & N-nitrosamines & Nitrosation mediated by NO release by PMN & 130 \\
N-arylhydroxamic acids & Formation of 2-nitroso-fluorene (2-NOF) & MPO mediated peroxidation & 132 \\
Aromatic amine (ABZ) & Formation of ABZ-DNA adducts & MPO mediated peroxidation & 133 \\
Aromatic amine (ABZ) & Formation of 3'-Nitro-ABZ & Nitrosation, catalysed by MPO in presence of nitrite & 134 \\
2-Aminofluorene (2-AF) & 2-AF-DNA adducts & MPO catalysed & 135 \\
& Mutagenesis (Ames test) & MPO catalysed & 136 \\
Benzene & Formation of phenol and p-nitrophenol & Peroxynitrite mediated hydroxylation and nitration \\
Heterocyclic amines (MelQx) & Formation of electrophilic mutagenic products & one electron oxidation mediated by ROS \\
Heterocyclic amines (MelQx) & Formation of N-nitroso-compounds & MPO catalysed nitrosation & 129 \\
Heterocyclic amines (IQ) & Formation of IQ-DNA adducts & MPO catalysed & 131 \\
Aromatic Amine (3-ABA) & Formation of 3-ABA-DNA adducts & MPO catalysed & 137 \\
PAH (B]a]P) & Bla]P-DNA adducts & peroxyl/peroxide dependent epoxidation \\
\hline
\end{tabular}

At present, there is accumulating evidence that $M P O$ gene polymorphisms are associated with lung cancer risk [e.g.: 146-151]. One of the most frequently occurring polymorphisms is a $-463 \mathrm{G} \rightarrow \mathrm{A}$ transition in the promoter region of MPO. Early studies showed that the presence of the A allele is associated with decreased MPO gene (mRNA) and protein expression in primary acute myeloid leukaemia cells, indicating a possible functionality of this polymorphism [152]. Consequently, a number of casecontrol studies showed that persons carrying the mutant AA genotype have an up to 40-70\% reduced risk for lung cancer [146-151], although other studies could not confirm these results $[153,154]$. Nonetheless, since pulmonary MPO is largely derived from recruited neutrophils [155], these studies further suggest an involvement of neutrophils in human pulmonary carcinogenesis.

Considering the role of MPO in the generation of $\mathrm{HOCl}$, it would be expected that the possible protective effect of the $-463 \mathrm{~A}$ allele is mediated through a reduced production of $\mathrm{HOCl}$. Although $\mathrm{HOCl}$ formation has been linked to induction of DNA damage in vitro and in vivo, as we discussed above, there is currently no evidence in support of a causal role of $\mathrm{HOCl}$ in pulmonary carcinogenesis. On the contrary, there is growing evidence that the protective effect of the A allele is predominantly observed in smokers, mainly suggesting an interaction between neutrophils, MPO and cigarette smoke constituents [148, 149]. This is further supported by data showing that the protective effect of the MPO polymorphism was found to be strongest for small cell lung cancer specifically, which is a type of lung cancer strongly associated with cigarette smoking [150]. Cigarette smoke is a potent source of chemical carcinogens, and at present, it is believed that the association between MPO and pulmonary carcinogenesis can be explained by the involvement of neutrophil derived MPO in metabolic activation of inhaled chemical carcinogens, including aromatic amines [156-158] and heterocyclic amines [132]. However, MPO activity has most frequently been linked to 
the metabolism of carcinogenic polycyclic aromatic hydrocarbons (PAH) [117, 138141].

PAH account for a large group of structurally related, widespread environmental pollutants that are formed during incomplete combustion processes. In the western world, PAH are produced by, for example, power plants and combustion engines. The most potent source for human exposure however, is smoking. Benzo[a]pyrene (B[a]P) is the best studied $\mathrm{PAH}$, and has widely been used as a prototype $\mathrm{PAH}$ to reveal the relationship between metabolic activation processes and chemical carcinogenesis [159-162]. Briefly, the activation of $B[a] P$ involves a specific sequence of enzymatic reactions, resulting in the generation of bay region diol-epoxide (BPDE), which can form a covalent adduct with the exocyclic aminogroup of guanine in DNA [159-163] These BPDE-DNA adducts are mutagenic to bacteria as well as mammalian cells [164], elicit the transformation of cells in culture and are carcinogenic in several tissues including the lung $[165,166]$.

\section{Activation of PAH by neutrophil derived MPO}

The capacity of neutrophils to metabolise PAH to their DNA binding metabolites was already described in the 1980's by in vitro and in vivo studies from Trush et al. [145] and Kensler et al. [144]. In these studies, they found that the interaction of the B[a]P metabolite B[a]P-7,8-dihydrodiol with phorbol ester activated neutrophils, but not alveolar macrophages (which lack MPO), resulted in the generation of a metabolite, which covalently binds to added calf thymus DNA. This effect could be ameliorated by the addition of the heme enzyme inhibitor sodium azide, suggesting the involvement of MPO [145]. In addition, activated PMN were shown to enhance the mutagenicity of $\mathrm{B}[\mathrm{a}] \mathrm{P}-7,8-d i h y d r o d i o l$ in the S. typhimurium strain TA100 [145]. These initial in vitro observations were also confirmed in vivo, by showing that recruitment and activation of PMN caused a $50 \%$ increase in covalent binding of $\mathrm{B}[\mathrm{a}] \mathrm{P}-7,8$-dihydrodiol metabolites to epidermal DNA in the skin of CD-1 mice [144]. The specific role of MPO was further revealed by showing that the $\mathrm{B}[\mathrm{a}] \mathrm{P}$ metabolite $( \pm)-\mathrm{B}[\mathrm{a}] \mathrm{P}-7,8-$ diol may serve as a substrate for MPO, thereby generating (+)-anti-benzo[a]pyrene diol epoxide (BPDE), which is the highly DNA reactive and most mutagenic metabolite of $B[a] P[141,142]$. Specifically, by stereochemical analysis of tetrol products, it was shown that PMA activated PMN, as well as an in vitro $\mathrm{MPO}-\mathrm{H}_{2} \mathrm{O}_{2}$ system, primarily generated antidiolepoxides with an anti/syn ratio $>5$. Such ratios indicate that MPO epoxidises $\mathrm{B}[\mathrm{a}] \mathrm{P}-7,8-d i o l$ via a peroxyl/peroxide dependent activation mechanism [141]. The consequences of these processes for pulmonary neutrophilic inflammation have been described by studies demonstrating that bronchoalveolar lavage neutrophils, obtained from mice exposed to bacteria by inhalation, were able to transform B[a]P-7,8-diol to a DNA binding metabolite ex vivo. Again, this effect was shown to be MPO dependent [142]. More recently, these observations were confirmed by studies in our laboratory, showing that activated neutrophils enhance BPDE-DNA adduct formation in cocultured alveolar epithelial target cells that were exposed to B[a]P-7,8-dihydrodiol [143].

A major link between these mechanistic studies describing the role of MPO in the activation of chemical carcinogens, and the epidemiological studies indicating an 
association between MPO and pulmonary carcinogenesis in smokers is possibly provided by a study in which we found a strong relationship between the MPO -463 $\mathrm{G} \rightarrow \mathrm{A}$ polymorphism and PAH-DNA adduct levels in skin of atopic dermatitis patients treated with PAH containing coal tar ointments [167]. With regard to the situation in the lung, support is provided by our observation that the MPO $-463 \mathrm{G} \rightarrow \mathrm{A}$ polymorphism was indeed associated with a reduced MPO enzyme activity in bronchoalveolar lavage of smoking individuals. This was accompanied by a significant reduction in PAH-DNA adduct levels in pulmonary cells [125]. Since the formation of PAH-DNA adducts is considered as a crucial process in smoking related carcinogenesis [168], these observations provide a first indication of the possible causal relation between neutrophils, MPO and pulmonary carcinogenesis in humans. Overall, these related studies further define a role of neutrophils in human pulmonary carcinogenesis in addition to their capacity to release ROS: they can enhance metabolism of environmental mutagenic carcinogens through release of MPO.

\section{Neutrophils and pulmonary genotoxicity: gaps and needs}

The association between chronic inflammation and the carcinogenic process has been observed for considerable time. However, the causal mechanisms that can explain for this association are still unclear. In the current review, we have focussed on one possible candidate mechanism, i.e. the contribution of neutrophils to genotoxicity, with special reference to respiratory tract (Fig. 3). In vivo studies with rats have revealed a concept indicating that chronic neutrophilic inflammation upon high particle dose exposures may initiate and promote tumour growth in the lung. This seems to be largely facilitated by genotoxic processes through the release of DNA damaging ROS, as well as by inducing cell proliferation. It should be clear, however, that the causal role of neutrophils in ROS mediated DNA damage and mutagenesis is still primarily described by in vitro experiments. In vivo experiments using experimental animals have mainly provided indirect evidence, and additional research is needed to further test the relationship between neutrophils and ROS induced genotoxicity in the respiratory tract. Systemic depletion of neutrophils, or blocking neutrophil influx into the lung by treatment with specific antibodies seems to be a promising approach to further reveal the effect of neutrophils in animals acutely exposed to inflammatory agents (inhaled particles, microorganisms, hyperoxia) [e.g. [112]]. Such studies should ideally be performed by evaluating genotoxicity in target cells relevant for neoplastic outcomes, instead of evaluating DNA damage in whole lung homogenates or in inflammatory cells obtained by BAL. We showed that isolation of pulmonary epithelial cells provides an opportunity to tackle neutrophil induced in vivo genotoxicity in a 'multiplemarker' approach, since the contribution of various factors, including inflammatory cell influx, antioxidant status and cytotoxicity can be evaluated within a single animal .

The major question that remains to be answered is whether in vitro and in vivo observations in experimental animals can be extrapolated to humans. So far, it is still unclear whether neutrophils really cause ROS induced genotoxicity in the inflamed 
human respiratory tract. On the other hand, recent molecular epidemiological studies, in combination with experimental in vitro and in vivo studies, have provided consistent evidence that neutrophils and human pulmonary carcinogenesis might be causally related by the capacity of neutrophils, via the release of MPO, to promote bioactivation of environmental carcinogens like PAH. Nonetheless, a lot of work needs to be done to provide a deeper insight into the role of PMN in pulmonary DNA damage and mutagenesis and whether this could trigger pulmonary carcinogenicity. Such knowledge may eventually lead to new approaches for inflammatory cancer prevention.

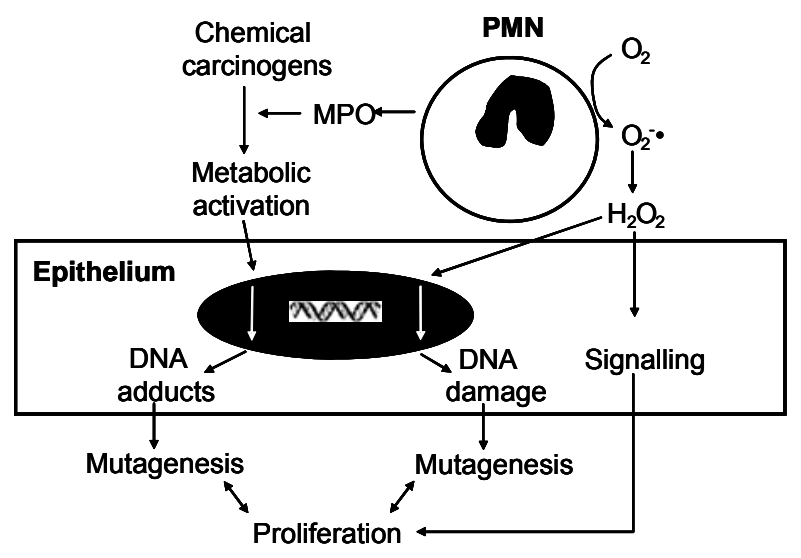

Figure 3. Simplified overview of the pathways by which neutrophils may impact on pulmonary genotoxicity. PMN cause oxidative DNA damage through generation of diffusible $\mathrm{H}_{2} \mathrm{O}_{2}$. In addition, $\mathrm{PMN}$ are able to enhance metabolic activation of inhaled chemical carcinogens, mainly by release of MPO. This may lead to increased DNA adduct formation. Both pathways of DNA damage induction, in combination with ROS induced cell signalling may ultimately lead to target cell mutagenesis and increased cell proliferation.

\section{Acknowledgements}

The authors thank Yonca Güngör for critically reviewing the manuscript. We acknowledge the financial support from the Province of Limburg, The Netherlands. A.M. Knaapen is supported by a postdoctoral fellowship from the Netherlands Organisation for Scientific Research (NWO, VENI-grant 916.46.092). 


\section{References}

1. Coussens, L.M. and Werb, Z. (2002) Inflammation and cancer. Nature, 420, 860-867.

2. Schottenfeld, D. and Beebe-Dimmer, J. (2006) Chronic inflammation: a common and important factor in the pathogenesis of neoplasia. CA Cancer J Clin, 56, 69-83.

3. Virchow, R. (1860) Cellular pathology. 7th edition ed. 1860, New York: Dewitt, R.M.

4. Collins, R.H., Jr., Feldman, M. and Fordtran, J.S. (1987) Colon cancer, dysplasia, and surveillance in patients with ulcerative colitis. A critical review. N Engl J Med, 316, 1654-1658.

5. Cruickshank, A.H., McConnell, E.M. and Miller, D.G. (1963) Malignancy in Scars, Chronic Ulcers, and Sinuses. J Clin Pathol, 16, 573-580.

6. Kantor, A.F., Hartge, P., Hoover, R.N., Narayana, A.S., Sullivan, J.W. and Fraumeni, J.F., Jr. (1984) Urinary tract infection and risk of bladder cancer. Am J Epidemiol, 119, 510-515.

7. Skillrud, D.M., Offord, K.P. and Miller, R.D. (1986) Higher risk of lung cancer in chronic obstructive pulmonary disease. A prospective, matched, controlled study. Ann Intern Med, 105, 503-507.

8. Schwartz, A.G. and Ruckdeschel, J.C. (2006) Familial lung cancer: genetic susceptibility and relationship to chronic obstructive pulmonary disease. Am J Respir Crit Care Med, 173, 16-22.

9. IARC (1997) Silica, some silicates, coal dust and para-amarid fibrils. Monograph on the evaluation of the carcinogenic risk of chemicals to humans. Vol. 68. 1997, Geneve, Switzerland: IARC Press.

10. Askling, J., Grunewald, J., Eklund, A., Hillerdal, G. and Ekbom, A. (1999) Increased risk for cancer following sarcoidosis. Am J Respir Crit Care Med, 160, 1668-1672.

11. Zienolddiny, S., Ryberg, D., Maggini, V., Skaug, V., Canzian, F. and Haugen, A. (2004) Polymorphisms of the interleukin-1 beta gene are associated with increased risk of non-small cell lung cancer. Int J Cancer, 109, 353-356.

12. Shih, C.M., Lee, Y.L., Chiou, H.L., Chen, W., Chang, G.C., Chou, M.C. and Lin, L.Y. (2006) Association of TNF-alpha polymorphism with susceptibility to and severity of non-small cell lung cancer. Lung Cancer, 52, 15-20.

13. Baron, J.A. and Sandler, R.S. (2000) Nonsteroidal anti-inflammatory drugs and cancer prevention. Annu Rev Med, 51, 511-523.

14. Knaapen, A.M., Borm, P.J., Albrecht, C. and Schins, R.P. (2004) Inhaled particles and lung cancer. Part A: Mechanisms. Int J Cancer, 109, 799-809.

15. Borm, P.J., Schins, R.P. and Albrecht, C. (2004) Inhaled particles and lung cancer, part B: paradigms and risk assessment. Int J Cancer, 110, 3-14.

16. Doerschuk, C.M. (2001) Mechanisms of leukocyte sequestration in inflamed lungs. Microcirculation, 8, 71-88.

17. Weitzman, S.A. and Gordon, L.I. (1990) Inflammation and cancer: role of phagocyte-generated oxidants in carcinogenesis. Blood, 76, 655-663.

18. Greim, H., Borm, P., Schins, R., Donaldson, K., Driscoll, K., Hartwig, A., Kuempel, E., Oberdorster, G. and Speit, G. (2001) Toxicity of fibers and particles. Report of the workshop held in Munich, Germany, 26-27 October 2000. Inhal Toxicol, 13, 737-754.

19. Aarbiou, J., Ertmann, M., van Wetering, S., van Noort, P., Rook, D., Rabe, K.F., Litvinov, S.V., van Krieken, J.H., de Boer, W.I. and Hiemstra, P.S. (2002) Human neutrophil defensins induce lung epithelial cell proliferation in vitro. $J$ Leukoc Biol, 72, 167-174.

20. Metchnikoff, E. (1983) Untersuchungen Über die intrecelluläre Verdauung bei wirbellosen Thieren. Arb. Zool. Inst. Univ. Wien, 5, 141.

21. Elias, J.A., Freundlich, B., Kern, J.A. and Rosenbloom, J. (1990) Cytokine networks in the regulation of inflammation and fibrosis in the lung. Chest, 97, 1439-1445.

22. Sibille, Y. and Marchandise, F.X. (1993) Pulmonary immune cells in health and disease: polymorphonuclear neutrophils. Eur Respir J, 6, 1529-1543.

23. Strieter, R.M. and Kunkel, S.L. (1994) Acute lung injury: the role of cytokines in the elicitation of neutrophils. J Investig Med, 42, 640-651.

24. Kunkel, S.L., Standiford, T., Kasahara, K. and Strieter, R.M. (1991) Interleukin-8 (IL-8): the major neutrophil chemotactic factor in the lung. Exp Lung Res, 17, 17-23. 
25. Miller, M.D. and Krangel, M.S. (1992) Biology and biochemistry of the chemokines: a family of chemotactic and inflammatory cytokines. Crit Rev Immunol, 12, 17-46.

26. Drost, E.M., Skwarski, K.M., Sauleda, J., Soler, N., Roca, J., Agusti, A. and MacNee, W. (2005) Oxidative stress and airway inflammation in severe exacerbations of COPD. Thorax, 60, 293-300.

27. Sibille, Y. and Reynolds, H.Y. (1990) Macrophages and polymorphonuclear neutrophils in lung defense and injury. Am Rev Respir Dis, 141, 471-501.

28. Selby, C. and MacNee, W. (1993) Factors affecting neutrophil transit during acute pulmonary inflammation: minireview. Exp Lung Res, 19, 407-428.

29. Wagner, J.G. and Roth, R.A. (2000) Neutrophil migration mechanisms, with an emphasis on the pulmonary vasculature. Pharmacol Rev, 52, 349-374.

30. Weiss, S.J. (1989) Tissue destruction by neutrophils. N Engl J Med, 320, 365-376.

31. Klebanoff, S.J. (2005) Myeloperoxidase: friend and foe. J Leukoc Biol, 77, 598-625.

32. Selby, C., Drost, E., Lannan, S., Wraith, P.K. and MacNee, W. (1991) Neutrophil retention in the lungs of patients with chronic obstructive pulmonary disease. Am Rev Respir Dis, 143, 13591364.

33. Noguera, A., Batle, S., Miralles, C., Iglesias, J., Busquets, X., MacNee, W. and Agusti, A.G. (2001) Enhanced neutrophil response in chronic obstructive pulmonary disease. Thorax, 56, 432437.

34. Hunninghake, G.W., Gadek, J.E., Lawley, T.J. and Crystal, R.G. (1981) Mechanisms of neutrophil accumulation in the lungs of patients with idiopathic pulmonary fibrosis. J Clin Invest, 68, 259269.

35. Tate, R.M. and Repine, J.E. (1983) Neutrophils and the adult respiratory distress syndrome. Am Rev Respir Dis, 128, 552-559.

36. Simon, R.H., DeHart, P.D. and Todd, R.F., 3rd (1986) Neutrophil-induced injury of rat pulmonary alveolar epithelial cells. $J$ Clin Invest, 78, 1375-1386.

37. Ward, P.A. (1991) Mechanisms of endothelial cell killing by $\mathrm{H} 2 \mathrm{O} 2$ or products of activated neutrophils. Am J Med, 91, 89S-94S.

38. Van der Vliet, A. and Bast, A. (1992) Effect of oxidative stress on receptors and signal transmission. Chem Biol Interact, 85, 95-116.

39. Babior, B.M. (2000) Phagocytes and oxidative stress. Am J Med, 109, 33-44.

40. McCord, J.M. and Fridovich, I. (1969) Superoxide dismutase. An enzymic function for erythrocuprein (hemocuprein). J Biol Chem, 244, 6049-6055.

41. Hampton, M.B., Kettle, A.J. and Winterbourn, C.C. (1998) Inside the neutrophil phagosome: oxidants, myeloperoxidase, and bacterial killing. Blood, 92, 3007-3017.

42. Weinberg, J.B., Misukonis, M.A., Shami, P.J., Mason, S.N., Sauls, D.L., Dittman, W.A., Wood, E.R., Smith, G.K., McDonald, B., Bachus, K.E. and et al. (1995) Human mononuclear phagocyte inducible nitric oxide synthase (iNOS): analysis of iNOS mRNA, iNOS protein, biopterin, and nitric oxide production by blood monocytes and peritoneal macrophages. Blood, 86, 1184-1195.

43. Gross, A., Dugas, N., Spiesser, S., Vouldoukis, I., Damais, C., Kolb, J.P., Dugas, B. and Dornand, J. (1998) Nitric oxide production in human macrophagic cells phagocytizing opsonized zymosan: direct characterization by measurement of the luminol dependent chemiluminescence. Free Radic Res, 28, 179-191.

44. Huffman, L.J., Judy, D.J. and Castranova, V. (1998) Regulation of nitric oxide production by rat alveolar macrophages in response to silica exposure. $J$ Toxicol Environ Health A, 53, 29-46.

45. Padgett, E.L. and Pruett, S.B. (1995) Rat, mouse and human neutrophils stimulated by a variety of activating agents produce much less nitrite than rodent macrophages. Immunology, 84, 135141.

46. Yan, L., Vandivier, R.W., Suffredini, A.F. and Danner, R.L. (1994) Human polymorphonuclear leukocytes lack detectable nitric oxide synthase activity. J Immunol, 153, 1825-1834.

47. Fenton, H. (1894) Oxidation of tartaric acid in the presence of iron. J. Chem. Soc., 899-910.

48. Lloyd, R.V., Hanna, P.M. and Mason, R.P. (1997) The origin of the hydroxyl radical oxygen in the Fenton reaction. Free Radic Biol Med, 22, 885-888. 
49. Weisburger, J.H. and Williams, G.M. (2000) The distinction between genotoxic and epigenetic carcinogens and implication for cancer risk. Toxicol Sci, 57, 4-5.

50. Marnett, L.J. (2000) Oxyradicals and DNA damage. Carcinogenesis, 21, 361-370.

51. Cathcart, R., Schwiers, E., Saul, R.L. and Ames, B.N. (1984) Thymine glycol and thymidine glycol in human and rat urine: a possible assay for oxidative DNA damage. Proc Natl Acad Sci U S A, 81, 5633-5637.

52. Wiseman, H. and Halliwell, B. (1996) Damage to DNA by reactive oxygen and nitrogen species: role in inflammatory disease and progression to cancer. Biochem J, 313 ( Pt 1), 17-29.

53. Pryor, W.A. (1988) Why is the hydroxyl radical the only radical that commonly adds to DNA? Hypothesis: it has a rare combination of high electrophilicity, high thermochemical reactivity, and a mode of production that can occur near DNA. Free Radic Biol Med, 4, 219-223.

54. Kasai, H. and Nishimura, S. (1984) Hydroxylation of deoxyguanosine at the C-8 position by ascorbic acid and other reducing agents. Nucleic Acids Res, 12, 2137-2145.

55. Floyd, R.A. (1990) The role of 8-hydroxyguanine in carcinogenesis. Carcinogenesis, 11, 14471450.

56. Whiteman, M., Jenner, A. and Halliwell, B. (1997) Hypochlorous acid-induced base modifications in isolated calf thymus DNA. Chem Res Toxicol, 10, 1240-1246.

57. Whiteman, M., Spencer, J.P., Jenner, A. and Halliwell, B. (1999) Hypochlorous acid-induced DNA base modification: potentiation by nitrite: biomarkers of DNA damage by reactive oxygen species. Biochem Biophys Res Commun, 257, 572-576.

58. Kulcharyk, P.A. and Heinecke, J.W. (2001) Hypochlorous acid produced by the myeloperoxidase system of human phagocytes induces covalent cross-links between DNA and protein. Biochemistry, 40, 3648-3656.

59. Jiang, Q., Blount, B.C. and Ames, B.N. (2003) 5-Chlorouracil, a marker of DNA damage from hypochlorous acid during inflammation. A gas chromatography-mass spectrometry assay. $J$ Biol Chem, 278, 32834-32840.

60. Henderson, J.P., Byun, J., Takeshita, J. and Heinecke, J.W. (2003) Phagocytes produce 5chlorouracil and 5-bromouracil, two mutagenic products of myeloperoxidase, in human inflammatory tissue. J Biol Chem, 278, 23522-23528.

61. Burney, S., Caulfield, J.L., Niles, J.C., Wishnok, J.S. and Tannenbaum, S.R. (1999) The chemistry of DNA damage from nitric oxide and peroxynitrite. Mutat Res, 424, 37-49.

62. Tuo, J., Liu, L., Poulsen, H.E., Weimann, A., Svendsen, O. and Loft, S. (2000) Importance of guanine nitration and hydroxylation in DNA in vitro and in vivo. Free Radic Biol Med, 29, 147-155.

63. Park, J.W. and Floyd, R.A. (1992) Lipid peroxidation products mediate the formation of 8hydroxydeoxyguanosine in DNA. Free Radic Biol Med, 12, 245-250.

64. Bartsch, H. and Nair, J. (2005) Accumulation of lipid peroxidation-derived DNA lesions: potential lead markers for chemoprevention of inflammation-driven malignancies. Mutat Res, 591, 34-44.

65. Basu, A.K. and Marnett, L.J. (1983) Unequivocal demonstration that malondialdehyde is a mutagen. Carcinogenesis, 4, 331-333.

66. Eastman, A. and Barry, M.A. (1992) The origins of DNA breaks: a consequence of DNA damage, DNA repair, or apoptosis? Cancer Invest, 10, 229-240.

67. Weitzman, S.A. and Stossel, T.P. (1981) Mutation caused by human phagocytes. Science, 212 , 546-547.

68. Barak, M., Ulitzur, S. and Merzbach, D. (1983) Phagocytosis-induced mutagenesis in bacteria. Mutat Res, 121, 7-16.

69. Weitberg, A.B., Weitzman, S.A., Destrempes, M., Latt, S.A. and Stossel, T.P. (1983) Stimulated human phagocytes produce cytogenetic changes in cultured mammalian cells. $N$ Engl $\mathrm{J} \mathrm{Med,}$ 308, 26-30.

70. Fulton, A.M., Loveless, S.E. and Heppner, G.H. (1984) Mutagenic activity of tumor-associated macrophages in Salmonella typhimurium strains TA98 and TA 100. Cancer Res, 44, 4308-4311.

71. Weitzman, S.A. and Stossel, T.P. (1984) Phagocyte-induced mutation in Chinese hamster ovary cells. Cancer Lett, 22, 337-341. 
72. Weitberg, A.B., Weitzman, S.A., Clark, E.P. and Stossel, T.P. (1985) Effects of antioxidants on oxidant-induced sister chromatid exchange formation. J Clin Invest, 75, 1835-1841.

73. Weitzman, S.A., Weitberg, A.B., Clark, E.P. and Stossel, T.P. (1985) Phagocytes as carcinogens: malignant transformation produced by human neutrophils. Science, 227, 1231-1233.

74. De Togni, P., Fox, H.B., Morrissey, S., Tansey, L.R., Levy, S.B. and Babior, B.M. (1988) Plasmids in bacteria exposed to activated neutrophils mediate mutagenesis when transferred to new hosts. Blood, 71, 463-466.

75. Schraufstatter, I., Hyslop, P.A., Jackson, J.H. and Cochrane, C.G. (1988) Oxidant-induced DNA damage of target cells. J Clin Invest, 82, 1040-1050.

76. Shacter, E., Beecham, E.J., Covey, J.M., Kohn, K.W. and Potter, M. (1988) Activated neutrophils induce prolonged DNA damage in neighboring cells. Carcinogenesis, 9, 2297-2304.

77. Chong, Y.C., Heppner, G.H., Paul, L.A. and Fulton, A.M. (1989) Macrophage-mediated induction of DNA strand breaks in target tumor cells. Cancer Res, 49, 6652-6657.

78. Shacter, E., Lopez, R.L., Beecham, E.J. and Janz, S. (1990) DNA damage induced by phorbol ester-stimulated neutrophils is augmented by extracellular cofactors. Role of histidine and metals. J Biol Chem, 265, 6693-6699.

79. Dizdaroglu, M., Olinski, R., Doroshow, J.H. and Akman, S.A. (1993) Modification of DNA bases in chromatin of intact target human cells by activated human polymorphonuclear leukocytes. Cancer Res, 53, 1269-1272.

80. van Staden, A.M., van Rensburg, C.E. and Anderson, R. (1993) Vitamin E protects mononuclear leucocyte DNA against damage mediated by phagocyte-derived oxidants. Mutat Res, 288, 257262.

81. Akman, S.A., Sander, F. and Garbutt, K. (1996) In vivo mutagenesis of the reporter plasmid pSP189 induced by exposure of host Ad293 cells to activated polymorphonuclear leukocytes. Carcinogenesis, 17, 2137-2141.

82. Driscoll, K.E., Deyo, L.C., Carter, J.M., Howard, B.W., Hassenbein, D.G. and Bertram, T.A. (1997) Effects of particle exposure and particle-elicited inflammatory cells on mutation in rat alveolar epithelial cells. Carcinogenesis, 18, 423-430.

83. Knaapen, A.M., Seiler, F., Schilderman, P.A., Nehls, P., Bruch, J., Schins, R.P. and Borm, P.J. (1999) Neutrophils cause oxidative DNA damage in alveolar epithelial cells. Free Radic Biol Med, 27, 234-240.

84. Kim, H.W., Murakami, A., Williams, M.V. and Ohigashi, H. (2003) Mutagenicity of reactive oxygen and nitrogen species as detected by co-culture of activated inflammatory leukocytes and AS52 cells. Carcinogenesis, 24, 235-241.

85. Knaapen, A.M., Schins, R.P., Polat, D., Becker, A. and Borm, P.J. (2002) Mechanisms of neutrophil-induced DNA damage in respiratory tract epithelial cells. Mol Cell Biochem, 234-235, 143151.

86. Knaapen, A.M., Schins, R.P., Borm, P.J. and van Schooten, F.J. (2005) Nitrite enhances neutrophil-induced DNA strand breakage in pulmonary epithelial cells by inhibition of myeloperoxidase. Carcinogenesis, 26, 1642-1648.

87. Frenkel, K. and Chrzan, K. (1987) Hydrogen peroxide formation and DNA base modification by tumor promoter-activated polymorphonuclear leukocytes. Carcinogenesis, 8, 455-460.

88. Jackson, J.H., Gajewski, E., Schraufstatter, I.U., Hyslop, P.A., Fuciarelli, A.F., Cochrane, C.G. and Dizdaroglu, M. (1989) Damage to the bases in DNA induced by stimulated human neutrophils. J Clin Invest, 84, 1644-1649.

89. Driscoll, K.E., Carter, J.M., Howard, B.W., Hassenbein, D.G., Pepelko, W., Baggs, R.B. and Oberdorster, G. (1996) Pulmonary inflammatory, chemokine, and mutagenic responses in rats after subchronic inhalation of carbon black. Toxicol Appl Pharmacol, 136, 372-380.

90. Lewis, J.G. and Adams, D.O. (1987) Inflammation, oxidative DNA damage, and carcinogenesis. Environ Health Perspect, 76, 19-27.

91. McDonald, R.J., Pan, L.C., St George, J.A., Hyde, D.M. and Ducore, J.M. (1993) Hydrogen peroxide induces DNA single strand breaks in respiratory epithelial cells. Inflammation, 17, 715-722. 
92. Spencer, J.P., Jenner, A., Chimel, K., Aruoma, O.I., Cross, C.E., Wu, R. and Halliwell, B. (1995) DNA strand breakage and base modification induced by hydrogen peroxide treatment of human respiratory tract epithelial cells. FEBS Lett, 374, 233-236.

93. Weitzman, S.A. and Stossel, T.P. (1982) Effects of oxygen radical scavengers and antioxidants on phagocyte-induced mutagenesis. J Immunol, 128, 2770-2772.

94. Test, S.T. and Weiss, S.J. (1984) Quantitative and temporal characterization of the extracellular $\mathrm{H} 2 \mathrm{O} 2$ pool generated by human neutrophils. J Biol Chem, 259, 399-405.

95. Gera, J.F. and Lichtenstein, A. (1991) Human neutrophil peptide defensins induce single strand DNA breaks in target cells. Cell Immunol, 138, 108-120.

96. Pero, R.W., Sheng, Y., Olsson, A., Bryngelsson, C. and Lund-Pero, M. (1996) Hypochlorous acid/N-chloramines are naturally produced DNA repair inhibitors. Carcinogenesis, 17, 13-18.

97. Van Rensburg, C.E., Van Staden, A.M. and Anderson, R. (1991) Inactivation of poly (ADP-ribose) polymerase by hypochlorous acid. Free Radic Biol Med, 11, 285-291.

98. Jaiswal, M., LaRusso, N.F., Nishioka, N., Nakabeppu, Y. and Gores, G.J. (2001) Human Ogg1, a protein involved in the repair of 8-oxoguanine, is inhibited by nitric oxide. Cancer Res, 61, 63886393.

99. Driscoll, K.E. (1996) Role of inflammation in the development of rat lung tumors in response to chronic particle exposure. Inhal Toxicol, 8 (suppl), 139-153.

100. Dungworth, D.L., Mohr, U., Heinrich, H., Ernst, H., Kittel, B. (1994) Toxic and carcinogenic effects od solid particles in the respiratory tract. Pathologic effects of inhaled particles in rat lungs: associations between inflammatory and neoplastic processes ed. U. Mohr. 1994, Washington: ISLI press. 75-98.

101. Borm, P.J. and Driscoll, K. (1996) Particles, inflammation and respiratory tract carcinogenesis. Toxicol Lett, 88, 109-113.

102. Duffin, R., Gilmour, P.S., Schins, R.P., Clouter, A., Guy, K., Brown, D.M., MacNee, W., Borm, P.J., Donaldson, K. and Stone, V. (2001) Aluminium lactate treatment of DQ12 quartz inhibits its ability to cause inflammation, chemokine expression, and nuclear factor-kappaB activation. Toxicol Appl Pharmacol, 176, 10-17.

103. Hohr, D., Steinfartz, Y., Schins, R.P., Knaapen, A.M., Martra, G., Fubini, B. and Borm, P.J. (2002) The surface area rather than the surface coating determines the acute inflammatory response after instillation of fine and ultrafine TiO2 in the rat. Int J Hyg Environ Health, 205, 239-244.

104. Schins, R.P., Lightbody, J.H., Borm, P.J., Shi, T., Donaldson, K. and Stone, V. (2004) Inflammatory effects of coarse and fine particulate matter in relation to chemical and biological constituents. Toxicol Appl Pharmacol, 195, 1-11.

105. Albrecht, C., Schins, R.P., Hohr, D., Becker, A., Shi, T., Knaapen, A.M. and Borm, P.J. (2004) Inflammatory time course after quartz instillation: role of tumor necrosis factor-alpha and particle surface. Am J Respir Cell Mol Biol, 31, 292-301.

106. Knaapen, A.M., Albrecht, C., Becker, A., Hohr, D., Winzer, A., Haenen, G.R., Borm, P.J. and Schins, R.P. (2002) DNA damage in lung epithelial cells isolated from rats exposed to quartz: role of surface reactivity and neutrophilic inflammation. Carcinogenesis, 23, 1111-1120.

107. Kamp, D.W., Dunn, M.M., Sbalchiero, J.S., Knap, A.M. and Weitzman, S.A. (1994) Contrasting effects of alveolar macrophages and neutrophils on asbestos-induced pulmonary epithelial cell injury. Am J Physiol, 266, L84-91.

108. Haugen, T.S., Skjonsberg, O.H., Kahler, H. and Lyberg, T. (1999) Production of oxidants in alveolar macrophages and blood leukocytes. Eur Respir J, 14, 1100-1105.

109. Yamano, Y., Kagawa, J., Hanaoka, T., Takahashi, T., Kasai, H., Tsugane, S. and Watanabe, S. (1995) Oxidative DNA damage induced by silica in vivo. Environ Res, 69, 102-107.

110. Nehls, P., Seiler, F., Rehn, B., Greferath, R. and Bruch, J. (1997) Formation and persistence of 8oxoguanine in rat lung cells as an important determinant for tumor formation following particle exposure. Environ Health Perspect, 105 Suppl 5, 1291-1296.

111. Seiler, F., Rehn, B., Rehn, S., Hermann, M. and Bruch, J. (2001) Quartz exposure of the rat lung leads to a linear dose response in inflammation but not in oxidative DNA damage and mutagenicity. Am J Respir Cell Mol Biol, 24, 492-498. 
112. Auten, R.L., Whorton, M.H. and Nicholas Mason, S. (2002) Blocking neutrophil influx reduces DNA damage in hyperoxia-exposed newborn rat lung. Am J Respir Cell Mol Biol, 26, 391-397.

113. Gallagher, J., Sams, R., 2nd, Inmon, J., Gelein, R., Elder, A., Oberdorster, G. and Prahalad, A.K. (2003) Formation of 8-oxo-7,8-dihydro-2'-deoxyguanosine in rat lung DNA following subchronic inhalation of carbon black. Toxicol Appl Pharmacol, 190, 224-231.

114. Dybdahl, M., Risom, L., Bornholdt, J., Autrup, H., Loft, S. and Wallin, H. (2004) Inflammatory and genotoxic effects of diesel particles in vitro and in vivo. Mutat Res, 562, 119-131.

115. Albrecht, C., Knaapen, A.M., Becker, A., Hohr, D., Haberzettl, P., van Schooten, F.J., Borm, P.J. and Schins, R.P. (2005) The crucial role of particle surface reactivity in respirable quartz-induced reactive oxygen/nitrogen species formation and APE/Ref-1 induction in rat lung. Respir Res, 6 , 129.

116. Johnston, C.J., Driscoll, K.E., Finkelstein, J.N., Baggs, R., O’Reilly, M.A., Carter, J., Gelein, R. and Oberdorster, G. (2000) Pulmonary chemokine and mutagenic responses in rats after subchronic inhalation of amorphous and crystalline silica. Toxicol Sci, 56, 405-413.

117. Saber, A.T., Bornholdt, J., Dybdahl, M., Sharma, A.K., Loft, S., Vogel, U. and Wallin, H. (2005) Tumor necrosis factor is not required for particle-induced genotoxicity and pulmonary inflammation. Arch Toxicol, 79, 177-182.

118. Elder, A.C., Gelein, R., Oberdorster, G., Finkelstein, J., Notter, R. and Wang, Z. (2004) Efficient depletion of alveolar macrophages using intratracheally inhaled aerosols of liposomeencapsulated clodronate. Exp Lung Res, 30, 105-120.

119. Gavett, S.H., Carakostas, M.C., Belcher, L.A. and Warheit, D.B. (1992) Effect of circulating neutrophil depletion on lung injury induced by inhaled silica particles. J Leukoc Biol, 51, 455-461.

120. Savov, J.D., Gavett, S.H., Brass, D.M., Costa, D.L. and Schwartz, D.A. (2002) Neutrophils play a critical role in development of LPS-induced airway disease. Am J Physiol Lung Cell Mol Physiol, 283, L952-962.

121. Soo, C.C., Haqqani, A.S., Hidiroglou, N., Swanson, J.E., Parker, R.S. and Birnboim, H.C. (2004) Dose-dependent effects of dietary alpha- and gamma-tocopherols on genetic instability in mouse Mutatect tumors. J Natl Cancer Inst, 96, 796-800.

122. Pekarek, L.A., Starr, B.A., Toledano, A.Y. and Schreiber, H. (1995) Inhibition of tumor growth by elimination of granulocytes. J Exp Med, 181, 435-440.

123. Di Carlo, E., Forni, G., Lollini, P., Colombo, M.P., Modesti, A. and Musiani, P. (2001) The intriguing role of polymorphonuclear neutrophils in antitumor reactions. Blood, 97, 339-345.

124. Reynolds, H.Y. (1987) Bronchoalveolar lavage. Am Rev Respir Dis, 135, 250-263.

125. Van Schooten, F.J., Boots, A.W., Knaapen, A.M., Godschalk, R.W., Maas, L.M., Borm, P.J., Drent, M. and Jacobs, J.A. (2004) Myeloperoxidase (MPO) -463G->A reduces MPO activity and DNA adduct levels in bronchoalveolar lavages of smokers. Cancer Epidemiol Biomarkers Prev, 13, 828-833.

126. Ghio, A.J. and Devlin, R.B. (2001) Inflammatory lung injury after bronchial instillation of air pollution particles. Am J Respir Crit Care Med, 164, 704-708.

127. Carter, J.M. and Driscoll, K.E. (2001) The role of inflammation, oxidative stress, and proliferation in silica-induced lung disease: a species comparison. J Environ Pathol Toxicol Oncol, 20 Suppl 1, 33-43.

128. Driscoll, K.E., Carter, J.M. and Borm, P.J. (2002) Antioxidant defense mechanisms and the toxicity of fibrous and nonfibrous particles. Inhal Toxicol, 14, 101-118.

129. Tuo, J., Wolff, S.P., Loft, S. and Poulsen, H.E. (1998) Formation of nitrated and hydroxylated aromatic compounds from benzene and peroxynitrite, a possible mechanism of benzene genotoxicity. Free Radic Res, 28, 369-375.

130. Vermeer, I.T., Henderson, L.Y., Moonen, E.J., Engels, L.G., Dallinga, J.W., van Maanen, J.M. and Kleinjans, J.C. (2004) Neutrophil-mediated formation of carcinogenic $\mathrm{N}$-nitroso compounds in an in vitro model for intestinal inflammation. Toxicol Lett, 154, 175-182.

131. Banning, D.P., O'Farrell, F. and Gooderham, N.J. (1993) Activation of the food derived carcinogen 2-amino-3,8-dimethylimidazo[4,5-f]quinoxaline by rat pleural cavity inflammatory cells. Carcinogenesis, 14, 2457-2462. 
132. Malejka-Giganti, D. and Ritter, C.L. (1994) Peroxidative metabolism of carcinogenic Narylhydroxamic acids: implications for tumorigenesis. Environ Health Perspect, 102 Suppl 6, 7581.

133. Lakshmi, V.M., Hsu, F.F., Davis, B.B. and Zenser, T.V. (2000) N-Acetylbenzidine-DNA adduct formation by phorbol 12-myristate-stimulated human polymorphonuclear neutrophils. Chem Res Toxicol, 13, 785-792.

134. Lakshmi, V.M., Hsu, F.F., Davis, B.B. and Zenser, T.V. (2001) Reactive nitrogen oxygen species metabolize N-acetylbenzidine. Chem Res Toxicol, 14, 312-318.

135. Shen, J.H., Wegenke, M. and Wolff, T. (1990) Capability of human blood cells to form the DNA adduct, C8-(N2-aminofluorenyl)-deoxyguanosine-3'-5'-diphosphate from 2-aminofluorene. Carcinogenesis, 11, 1441-1444.

136. Isola, V.J., Hartman, T.C., Trumble, S.J., Ruzek, M.C. and Gentile, J.M. (1993) Metabolism of 2aminofluorene by human polymorphonuclear leukocytes: more evidence for the association between inflammation and cancer. Environ Health Perspect, 101 Suppl 3, 27-31.

137. Lakshmi, V.M., Hsu, F.F. and Zenser, T.V. (2005) Nitric oxide-mediated nitrosation of 2-amino3,8-dimethylimidazo[4,5-f]quinoxaline potentiated by hemin and myeloperoxidase. Chem Res Toxicol, 18, 1038-1047.

138. Williams, J.A., Stone, E.M., Millar, B.C., Gusterson, B.A., Grover, P.L. and Phillips, D.H. (1998) Determination of the enzymes responsible for activation of the heterocyclic amine 2-amino-3methylimidazo[4,5-f]quinoline in the human breast. Pharmacogenetics, 8, 519-528.

139. Williams, J.A., Stone, E.M., Millar, B.C., Hewer, A. and Phillips, D.H. (2000) Pathways of heterocyclic amine activation in the breast: DNA adducts of 2-amino-3-methylimidazo[4,5-f]quinoline (IQ) formed by peroxidases and in human mammary epithelial cells and fibroblasts. Mutagenesis, 15, 149-154.

140. Arlt, V.M., Henderson, C.J., Wolf, C.R., Schmeiser, H.H., Phillips, D.H. and Stiborova, M. (2006) Bioactivation of 3-aminobenzanthrone, a human metabolite of the environmental pollutant 3nitrobenzanthrone: evidence for DNA adduct formation mediated by cytochrome P450 enzymes and peroxidases. Cancer Lett, 234, 220-231.

141. Mallet, W.G., Mosebrook, D.R. and Trush, M.A. (1991) Activation of (+-)-trans-7,8-dihydroxy-7,8dihydrobenzo[a]pyrene to diolepoxides by human polymorphonuclear leukocytes or myeloperoxidase. Carcinogenesis, 12, 521-524.

142. Petruska, J.M., Mosebrook, D.R., Jakab, G.J. and Trush, M.A. (1992) Myeloperoxidase-enhanced formation of (+-)-trans-7,8-dihydroxy-7,8-dihydrobenzo[a]pyrene-DNA adducts in lung tissue in vitro: a role of pulmonary inflammation in the bioactivation of a procarcinogen. Carcinogenesis, 13, 1075-1081.

143. Borm, P.J., Knaapen, A.M., Schins, R.P., Godschalk, R.W. and Schooten, F.J. (1997) Neutrophils amplify the formation of DNA adducts by benzo[a]pyrene in lung target cells. Environ Health Perspect, 105 Suppl 5, 1089-1093.

144. Kensler, T.W., Egner, P.A., Moore, K.G., Taffe, B.G., Twerdok, L.E. and Trush, M.A. (1987) Role of inflammatory cells in the metabolic activation of polycyclic aromatic hydrocarbons in mouse skin. Toxicol Appl Pharmacol, 90, 337-346.

145. Trush, M.A., Seed, J.L. and Kensler, T.W. (1985) Oxidant-dependent metabolic activation of polycyclic aromatic hydrocarbons by phorbol ester-stimulated human polymorphonuclear leukocytes: possible link between inflammation and cancer. Proc Natl Acad Sci U S A, 82, 5194-5198.

146. London, S.J., Lehman, T.A. and Taylor, J.A. (1997) Myeloperoxidase genetic polymorphism and lung cancer risk. Cancer Res, 57, 5001-5003.

147. Le Marchand, L., Seifried, A., Lum, A. and Wilkens, L.R. (2000) Association of the myeloperoxidase -463G-->a polymorphism with lung cancer risk. Cancer Epidemiol Biomarkers Prev, 9, 181184.

148. Schabath, M.B., Spitz, M.R., Zhang, X., Delclos, G.L. and Wu, X. (2000) Genetic variants of myeloperoxidase and lung cancer risk. Carcinogenesis, 21, 1163-1166. 
149. Schabath, M.B., Spitz, M.R., Hong, W.K., Delclos, G.L., Reynolds, W.F., Gunn, G.B., Whitehead, L.W. and $\mathrm{Wu}, \mathrm{X}$. (2002) A myeloperoxidase polymorphism associated with reduced risk of lung cancer. Lung Cancer, 37, 35-40.

150. Dally, H., Gassner, K., Jager, B., Schmezer, P., Spiegelhalder, B., Edler, L., Drings, P., Dienemann, H., Schulz, V., Kayser, K., Bartsch, H. and Risch, A. (2002) Myeloperoxidase (MPO) genotype and lung cancer histologic types: the MPO $-463 \mathrm{~A}$ allele is associated with reduced risk for small cell lung cancer in smokers. Int $J$ Cancer, 102, 530-535.

151. Lu, W., Xing, D., Qi, J., Tan, W., Miao, X. and Lin, D. (2002) Genetic polymorphism in myeloperoxidase but not GSTM1 is associated with risk of lung squamous cell carcinoma in a Chinese population. Int J Cancer, 102, 275-279.

152. Reynolds, W.F., Chang, E., Douer, D., Ball, E.D. and Kanda, V. (1997) An allelic association implicates myeloperoxidase in the etiology of acute promyelocytic leukemia. Blood, 90, 27302737.

153. Xu, L.L., Liu, G., Miller, D.P., Zhou, W., Lynch, T.J., Wain, J.C., Su, L. and Christiani, D.C. (2002) Counterpoint: the myeloperoxidase -463G-->a polymorphism does not decrease lung cancer susceptibility in Caucasians. Cancer Epidemiol Biomarkers Prev, 11, 1555-1559.

154. Misra, R.R., Tangrea, J.A., Virtamo, J., Ratnasinghe, D., Andersen, M.R., Barrett, M., Taylor, P.R. and Albanes, D. (2001) Variation in the promoter region of the myeloperoxidase gene is not directly related to lung cancer risk among male smokers in Finland. Cancer Lett, 164, 161-167.

155. Schmekel, B., Karlsson, S.E., Linden, M., Sundstrom, C., Tegner, H. and Venge, P. (1990) Myeloperoxidase in human lung lavage. I. A marker of local neutrophil activity. Inflammation, 14, 447454.

156. Culp, S.J., Roberts, D.W., Talaska, G., Lang, N.P., Fu, P.P., Lay, J.O., Jr., Teitel, C.H., Snawder, J.E., Von Tungeln, L.S. and Kadlubar, F.F. (1997) Immunochemical, 32P-postlabeling, and GC/MS detection of 4-aminobiphenyl-DNA adducts in human peripheral lung in relation to metabolic activation pathways involving pulmonary $\mathrm{N}$-oxidation, conjugation, and peroxidation. Mutat Res, 378, 97-112.

157. Kadlubar, F.F., Butler, M.A., Kaderlik, K.R., Chou, H.C. and Lang, N.P. (1992) Polymorphisms for aromatic amine metabolism in humans: relevance for human carcinogenesis. Environ Health Perspect, 98, 69-74.

158. Josephy, P.D. (1996) The role of peroxidase-catalyzed activation of aromatic amines in breast cancer. Mutagenesis, 11, 3-7.

159. Gelboin, H.V. (1980) Benzo[alpha]pyrene metabolism, activation and carcinogenesis: role and regulation of mixed-function oxidases and related enzymes. Physiol Rev, 60, 1107-1166.

160. Phillips, D.H. (1983) Fifty years of benzo(a)pyrene. Nature, 303, 468-472.

161. Xue, W. and Warshawsky, D. (2005) Metabolic activation of polycyclic and heterocyclic aromatic hydrocarbons and DNA damage: a review. Toxicol Appl Pharmacol, 206, 73-93.

162. Luch, A. (2005) Nature and nurture - lessons from chemical carcinogenesis. Nat Rev Cancer, $\mathbf{5}$, 113-125.

163. Weinstein, I.B., Jeffrey, A.M., Jennette, K.W., Blobstein, S.H., Harvey, R.G., Harris, C., Autrup, H., Kasai, H. and Nakanishi, K. (1976) Benzo(a)pyrene diol epoxides as intermediates in nucleic acid binding in vitro and in vivo. Science, 193, 592-595.

164. Wood, A.W., Wislocki, P.G., Chang, R.L., Levin, W., Lu, A.Y., Yagi, J., Hernandez, O., Herina, D.M. and Conney, A.H. (1976) Mutagenicity and cytotoxicity of benzo(a)pyrene benzo-ring epoxides. Cancer Res, 36, 3358-3366.

165. Levin, W., Wood, A.W., Yagi, H., Jerina, D.M. and Conney, A.H. (1976) (+/-)-trans-7,8-dihydroxy7,8-dihydrobenzo (a)pyrene: a potent skin carcinogen when applied topically to mice. Proc Natl Acad Sci U S A, 73, 3867-3871.

166. Tchou-Wong, K.M., Jiang, Y., Yee, H., LaRosa, J., Lee, T.C., Pellicer, A., Jagirdar, J., Gordon, T., Goldberg, J.D. and Rom, W.N. (2002) Lung-specific expression of dominant-negative mutant p53 in transgenic mice increases spontaneous and benzo(a)pyrene-induced lung cancer. Am J Respir Cell Mol Biol, 27, 186-193. 
167. Rojas, M., Godschalk, R., Alexandrov, K., Cascorbi, I., Kriek, E., Ostertag, J., Van Schooten, F.J. and Bartsch, H. (2001) Myeloperoxidase--463A variant reduces benzo[a]pyrene diol epoxide DNA adducts in skin of coal tar treated patients. Carcinogenesis, 22, 1015-1018.

168. Denissenko, M.F., Pao, A., Tang, M. and Pfeifer, G.P. (1996) Preferential formation of benzo[a]pyrene adducts at lung cancer mutational hotspots in P53. Science, 274, 430-432. 



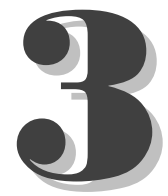

\title{
Genotoxic effects of
}

\author{
neutrophils and \\ hypochlorous acid
}

Mutagenesis, in press.

Güngör N Knaapen AM Peluso M Haenen GR Chiu RK Godschalk RWL van Schooten FJ 


\begin{abstract}
Chronic inflammation has been recognised as a contributing factor in the pathogenesis of lung cancer. In this process, reactive oxygen species (ROS) released by neutrophils may play an important role. The aim of the present study was to investigate the capacity of the major neutrophilic oxidant hypochlorous acid $(\mathrm{HOCl})$, which is formed by myeloperoxidase (MPO), to induce DNA damage and mutagenicity in lung cells. $\mathrm{HOCl}$ was mutagenic in lung epithelial A549 cells in vitro, showing at physiological concentrations a significant induction of mutations in the HPRT gene. We studied three major types of DNA lesions that could be relevant for this $\mathrm{HOCl}$ induced mutagenicity. Single strand DNA breakage and 8-hydroxydeoxyguanosine were not found to be increased following $\mathrm{HOCl}$ treatment. On the other hand, $\mathrm{HOCl}$ caused a significant increase in the formation of 3-(2-Deoxy- $\beta$-D-erythro-pentofuranosyl)pyrimido[1,2a]purin-10(3H)-one ( $\left.\mathrm{M}_{1} \mathrm{dG}\right)$, which can be formed by either malondialdehyde (MDA) or base propenals. We observed an increased MDA formation upon exposure of A549 cells to $\mathrm{HOCl}$, but a role of base propenals cannot be excluded. In line with this, we observed 4- fold increased $M_{1} d G$ adduct levels in mice that were intratracheally instilled with lipopolysaccharide to induce a pulmonary inflammation with neutrophil influx. Depletion of circulating neutrophils significantly reduced pulmonary MPO activity as well as $M_{1} d G$ adducts levels, thereby providing a causal link between neutrophils/ $\mathrm{HOCl}$ and pulmonary genotoxicity in vivo. Taken together, these data indicate that myeloperoxidase catalysed formation of hypochlorous acid during lung inflammation should be considered as a significant source of neutrophil induced genotoxicity.
\end{abstract}




\section{Introduction}

A significant fraction of the global cancer burden is attributable to chronic inflammation [1]. For instance, pulmonary inflammation linked to smoking is widely recognised as a risk factor for lung cancer development. For the respiratory tract however, the mechanism of carcinogenesis associated with chronic inflammation has not yet been fully elucidated. Alveolar and bronchial epithelial cells are exposed to a variety of reactive oxygen species (ROS) from both exogenous (e.g. cigarette smoke) and endogenous sources, such as the phagocytic respiratory burst. With regard to tumour formation, it has been postulated that ROS, produced by the prolonged activation of inflammatory polymorphonuclear neutrophils (PMN), play a role in lung tumour formation [2]. But also in later stages of the carcinogenic process, during tumour progression, neutrophil infiltration and associated release of ROS in tumours provide a growth advantage [3]. Upon activation, neutrophils induce various oxidant generating enzymes, such as NADPH oxidase, superoxide dismutase and myeloperoxidase (MPO). As a result, high concentrations of a variety of reactive oxygen species (ROS) are generated, including superoxide $\left(\mathrm{O}_{2}^{-}\right)$, hydrogen peroxide $\left(\mathrm{H}_{2} \mathrm{O}_{2}\right)$ and the MPO catalysed production of hypochlorous acid $(\mathrm{HOCl})$, which are produced to attack invading infectious agents [4]. However, excess amounts of ROS generated in inflamed tissues can also damage DNA in target cells, leading to increased mutation load and potentially carcinogenesis [5-8].

In rats, chronic exposure to particles, inducing a massive recruitment of neutrophils, is associated with tumour formation, and neutrophil induced genetic alterations and mutagenic effects in lung epithelial cells are thought to be key factors in this process $[9,10]$. In vitro coincubation of rat lung epithelial cells with bronchoalveolar lavage (BAL) cells, isolated from particle treated rats, increased mutation frequency in the hypoxanthine guanine phosphoribosyl transferase (Hprt) gene [11]. Previously reported studies, using similar in vitro coincubation models of target cells with activated neutrophils, demonstrated that neutrophils are able to induce sister chromatid exchanges [5], strand breaks [12] and mutations in neighbouring target cells [reviewed in 8], suggesting a role of neutrophil derived ROS. In a previous study, we demonstrated that activated neutrophils cause induction of 8-hydroxydeoxyguanosine (8-oxo-dG) in alveolar cells in vitro, suggesting involvement of hydroxyl radicals ( $\mathrm{OH}$ ) [13]. Altogether, these studies suggested that $\mathrm{H}_{2} \mathrm{O}_{2}$ generated by neutrophils is one of the essential mediators of the genotoxic effects, as it serves as latent form of hydroxyl radicals. Hydrogen peroxide is very stable and can cross cellular membranes, and is at the same time able to penetrate the nucleus where $\mathrm{OH}$ can be generated in the vicinity of the DNA molecule via the Fenton reaction with localised transition metals [14]. However, under physiological conditions, up to $70 \%$ of $\mathrm{H}_{2} \mathrm{O}_{2}$ is consumed by the neutrophil derived enzyme MPO to generate the strong oxidant $\mathrm{HOCl}$ [15]. Interestingly, MPO has been implicated in the pathogenesis of inflammation related carcinogenesis, with reference to the $-463 \mathrm{G} \rightarrow \mathrm{A}$ polymorphism in the promoter region of the MPO gene, which is associated with a reduced risk of cancer in the lung $[16,17]$. 
Nevertheless, there are only limited data available on a potential role of $\mathrm{HOCl}$ in the pathophysiology of inflammation related lung cancer development.

The aim of the present study was to assess the DNA damaging and mutagenic effects of neutrophil derived $\mathrm{HOCl}$. First, we assessed three different types of $\mathrm{HOCl}$ induced DNA damage (DNA single strand breakage (ssDNA), 8-oxo-dG and 3-(2Deoxy- $\beta$-D-erythro-pentofuranosyl)pyrimido[1,2- $\alpha$ ]purin-10(3H)-one $\left(\mathrm{M}_{1} \mathrm{dG}\right)$, as well as HPRT mutations in human alveolar epithelial lung cells (A549). Secondly, based on initial in vitro findings revealing $\mathrm{M}_{1} \mathrm{dG}$ adducts as the most significant $\mathrm{HOCl}$ induced DNA damaging effect in vitro, we assessed this promutagenic DNA adduct formation in the mouse lung following acute LPS instillation. The causal role of neutrophils in this in vivo genotoxic effect was addressed by depleting the animals of circulating neutrophils.

\section{Materials and Methods}

\section{Cell treatment with $\mathrm{HOCl}$}

Human epithelial lung adenoma carcinoma cell line (A549) (American Tissue Culture Collection) were cultured in DMEM (Sigma, Zwijndrecht, the Netherlands) supplemented with $10 \%$ heat inactivated foetal calf serum (FCS, Gibco Invitrogen, Breda, the Netherlands) and $1 \%$ penicillin/streptomycin (Sigma) under humidified atmosphere containing $5 \% \mathrm{CO}_{2}$ at $37^{\circ} \mathrm{C}$. Cell passages between 25 and 40 were used for experiments described in this study.

The concentration of $\mathrm{HOCl}$ stock solution (Sigma) was measured spectrophotometrically, immediately before use, at $293 \mathrm{~nm}$, using the extinction coefficient of hypochlorite $\varepsilon_{293}=349.2 \mathrm{M}^{-1} \mathrm{~cm}^{-1}$ at $\mathrm{pH} 10-12$. For comet assay and DNA isolation, nearly confluent monolayers of A549 cells grown in $75 \mathrm{~cm}^{2}$ culture flasks were used. Medium was discarded and cells were exposed to increasing concentrations of $\mathrm{HOCl}(0-$ $100 \mu \mathrm{M})$ suspended in HBSS. After $15 \mathrm{~min}$, cells were harvested by trypsinisation. Acute cytotoxicity of $\mathrm{HOCl}$ in A549 cells was tested using trypan blue dye exclusion. For the lipid peroxidation assay, A549 cells were cultivated in $100 \mathrm{~mm}$ dishes and treated at near confluency as described above. After the $15 \mathrm{~min}$ incubation period, medium was removed and the dishes were kept on ice. Cell monolayers were washed with ice-cold PBS and scraped from the dishes with $500 \mu \mathrm{l}$ of fresh PBS per dish. Cells were sonicated briefly $(15 \mathrm{sec})$ and the lysate was stored at $-20^{\circ} \mathrm{C}$ and used for malondialdehyde (MDA) measurement by thiobarbituric acid reactive substances (TBARS) formation.

Hydrogen peroxide $(250 \mu \mathrm{M})$ was used as a positive control for ssDNA, 8-oxo-dG and $\mathrm{M}_{1} \mathrm{dG}$. Positive control for MDA measurement was $\mathrm{Fe}^{2+}(10 \mu \mathrm{M})$. Benzo[a]pyrenediol-epoxide (BPDE, $1 \mu \mathrm{M}$ ) was used as positive control for HPRT mutation analysis. 


\section{Single cell gel electrophoresis}

DNA single strand breakage in A549 cells was determined by alkaline comet assay [18], implemented according to recent guidelines [19]. After the incubation, cells were washed once, harvested and resuspended in HBSS at a cell concentration of $2 \times 10^{6}$ cells $/ \mathrm{ml}$. The cell suspension was mixed with low melting point agarose (Sigma), reaching a final concentration of $0.65 \%$ LMP agarose and positioned on $1.5 \%$ agarose coated slides. Further procedures were as described earlier [20]. Comets were stained with ethidium bromide $(10 \mu \mathrm{g} / \mathrm{ml})$ for fluorescence microscopy: per blindly scored slide, a total of 50 cells were scored using the software program Comet Assay III (Perceptive Instruments Ltd, Haverhill, UK). DNA strand breakage data were expressed as Tail Moment (TM), which is defined as the product of DNA content in the tail and the mean distance of migration in the tail.

\section{DNA isolation}

DNA was isolated using standard phenol extraction [21]. The DNA extraction procedure was optimised to minimise artificial induction of 8-oxo-dG by using radical-free phenol, minimising exposure to oxygen and by adding $1 \mathrm{mM}$ deferoxamine mesylate and $20 \mathrm{mM}$ TEMPO (2,2,6,6-tetramethylpiperidine- $N$-oxyl), according to the European Standards Committee on Oxidative DNA Damage (ESCODD) [22]. DNA concentrations were quantified by NanoDrop (Isogen-Lifescience, De Meern, the Netherlands) and samples were frozen at $-20^{\circ} \mathrm{C}$ until further analysis.

\section{Quantification of 8-oxo-dG}

High pressure liquid chromatography with electrochemical detection (HPLC-ECD) of 8-oxo-dG was based on a method as described earlier [23]. Briefly, after extraction, DNA was digested into deoxyribonucleosides by treatment with nuclease P1 (1 U/ $\mathrm{ll})$ and alkaline phophatase $(0.014 \mathrm{U} / \mu \mathrm{l})$. The digest was then analysed by HPLC-ECD, using Supelcosil ${ }^{\mathrm{TM}}$ LC-18S column $(250 \times 4.6 \mathrm{~mm}$ ) (Supelco Park, Bellefonte, PA, USA) and DECADE electrochemical detector (Antec, Leiden, the Netherlands). The mobile phase consisted of $10 \%$ aqueous methanol containing $94 \mathrm{mM} \mathrm{KH}_{2} \mathrm{PO}_{4}, 13 \mathrm{mM}$ $\mathrm{K}_{2} \mathrm{HPO}_{4}, 26 \mathrm{mM} \mathrm{KCl}$ and $0.5 \mathrm{mM}$ EDTA. Elution was performed at a flow rate of 1 $\mathrm{ml} / \mathrm{min}$. 8-oxo-dG was detected at a potential of $400 \mathrm{mV}$ and $\mathrm{dG}$ was simultaneously monitored by UV absorption at $260 \mathrm{~nm}$. Results were expressed as the ratio of the determined 8-oxo-dG to dG.

\section{Quantification of $M_{1} d G$}

The ${ }^{32} \mathrm{P}$-postlabelling technique was used to analyse the levels of 3-(2-Deoxy- $\beta$-Derythro-pentofuranosyl)pyrimido[1,2- $\alpha$ ]purin-10(3H)-one $\left(\mathrm{M}_{1} \mathrm{dG}\right)$ adducts, as previously reported [24]. Briefly, a digestion method based on the DNA hydrolysis by micrococcal nuclease (Sigma) and a mixture of two spleen phosphodiesterases (Sigma) was applied. Hydrolysed samples, evaporated to dryness, were treated with nuclease P1 (Sigma). The modified nuclease P1 resistant nucleotides, evaporated to dryness, 
were incubated with carrier-free $\left[\mathrm{Y}^{32} \mathrm{P}\right]-\mathrm{ATP}$ (Amersham, Buckinghamshire, UK) and T4-polynucleotide kinase (Epicentre Technologies, Madison, WI, USA) to generate

${ }^{32} \mathrm{P}$-labelled adducts. $\mathrm{M}_{1} \mathrm{dG}$ adduct analysis was carried out by PEI-cellulose TLC chromatography according to published conditions [25]. Detection and quantification of $\mathrm{M}_{1} \mathrm{dG}$ adducts and total nucleotides were obtained by phosphor imaging technology (Typhoon 9210, Amersham) and ImageQuant software (Molecular Dynamics, Sunnyvale, CA, USA). After background subtraction, the levels of DNA adducts were expressed as relative adduct labelling (RAL = adducted nucleotides/total nucleotides). Standard MDA modified [26] and unmodified DNA were routinely processed in the analysis as controls.

\section{Lipid peroxidation assay}

The thiobarbituric acid reactive substances (TBARS) were measured by means of HPLC according to Lepage et al. [27]. Briefly, $100 \mu$ of cell lysate or MDA standard were mixed with $900 \mu \mathrm{l}$ reagent composed of 10 parts of reagent $A(0.012 \mathrm{M} 2$ thiobarbituric acid (TBA), $0.32 \mathrm{M} \mathrm{H}_{3} \mathrm{PO}_{4}$ and $0.01 \%$ EDTA) and one part of reagent $\mathrm{B}$ (butylated hydroxytoluene in ethanol, $1.5 \mathrm{mg} / \mathrm{ml}$ ). Standards were prepared using 0$10 \mu \mathrm{M}$ MDA solutions in PBS, which were derivatised in the same analytical measurements as the samples. The tubes were covered with marbles and heated for $1 \mathrm{~h}$ at $99^{\circ} \mathrm{C}$. After cooling, the product was extracted in $500 \mu$ butanol by vigorous shaking and the tubes were centrifuged for $5 \mathrm{~min}$ at $5000 \mathrm{~g} .30 \mu \mathrm{l}$ of the extract was injected on to a Nucleosil ${ }^{\mathrm{TM}} \mathrm{C} 18$ column (150 mm x $3.2 \mathrm{~mm}$ ) (Supelco Park, Bellefonte, PA, USA) and eluted with $65 \%$ water and $35 \%$ methanol $+0.05 \%$ trifluoroacetic acid. Fluorescence was recorded at $\lambda_{\mathrm{ex}} 553 \mathrm{~nm}$. The peak of TBA-MDA product was integrated and the concentration of MDA was corrected for protein content of the lysates. The results were expressed as a percentage of TBARS formation, taking the control sample as $100 \%$.

\section{Protein determination}

Protein concentrations were determined spectrophotometrically using the DC-protein assay Kit (BIORAD, Veenendaal, the Netherlands) as per manufacturers protocol.

\section{Clonogenic survival assay}

The sensitivity of A549 cells to $\mathrm{HOCl}$ was assayed by clonogenic survival. Briefly, cells were seeded at a density of $4 \times 10^{5}$ cells $/ 60 \mathrm{~mm}$ dish and grown for $24 \mathrm{~h}$ before exposure to $\mathrm{HOCl}(0-100 \mu \mathrm{M})$ or BPDE $(1 \mu \mathrm{M})$. Cells were treated for respectively 15 $\min$ and $30 \mathrm{~min}$ at $37^{\circ} \mathrm{C}$ with the indicated dosages, after which they were harvested and seeded in triplicate for each concentration. After $\sim 14$ days of growth, the medium was removed and colonies were fixed and stained with $2 \%$ bromophenolblue in $70 \%$ ethanol. Any groupings of cells containing 50 or more cells were counted as a colony. For each dose, survival was calculated from the relative colony forming ability of the $\mathrm{HOCl}$ exposed cells compared to control. 


\section{HPRT mutation analysis}

For the determination of HPRT mutant frequencies, A549 cells were seeded at $1 \times 10^{6}$ cells $/ 100 \mathrm{~mm}$ dish. The following day, cells were treated with the different doses of $\mathrm{HOCl}\left(15 \mathrm{~min}\right.$ at $\left.37^{\circ} \mathrm{C}\right)$ or $\operatorname{BPDE}\left(30 \mathrm{~min}\right.$ at $\left.37^{\circ} \mathrm{C}\right)$ and were subcultured for 1 week to allow phenotypic expression of the acquired mutations. Cells were then seeded in selective medium containing 6-thioguanine (6-TG) and incubated until colonies were formed ( $\sim 3$ weeks). 6-TG resistant colonies consisting of cells carrying HPRT mutations were fixed, stained and counted. All experiments were normalised for plating efficiency. Finally, HPRT mutant frequency was defined after correcting for clonogenic survival.

\section{LPS induced acute lung inflammation mouse model}

Male Wt C57BI6 mice ( 12 weeks old) were obtained from Charles River Breeding Laboratories (Heidelberg, Germany). Mice were housed individually in standard laboratory cages and received food and water ad libitum throughout the experiments. The studies were carried out in accordance with an approved protocol by the institutional Animal Care Committee of Maastricht University.

Mice were treated with LPS (Escherichia Coli, serotype O55:B5, Sigma) by intratracheal instillation to induce an acute pulmonary inflammation. The dose of LPS was $20 \mu \mathrm{g} /$ instillation/mouse. Intratracheal instillation was performed by a nonsurgical technique under anaesthesia as previously described [28]. Sham mice were instilled with sterile $0.9 \% \mathrm{NaCl}$.

Since a previous study [29] demonstrated that local LPS challenge in Wt C57BI6 mice results in a time dependent neutrophil accumulation peaking at day 3 , mice $(\mathrm{n}=$ 10) were sacrificed 3 days postexposure by $115 \mathrm{mg} / \mathrm{kg}$ sodium pentobarbital (Ceva Sante Animale, Maassluis, the Netherlands) and bronchoalveolar lavage (BAL) (3x with $1 \mathrm{ml}$ sterile $0.9 \% \mathrm{NaCl}$ ) was performed to remove as much as possible inflammatory cells from the airways. After centrifugation, the cell-free BAL fluid (BALF) was stored at $-80^{\circ} \mathrm{C}$ for MPO activity measurement. Lavaged lungs were snapfrozen in liquid nitrogen and pulverised using mortar and pestle. The pulverised lung tissue was stored at $-80^{\circ} \mathrm{C}$ until DNA isolation.

To unravel the direct role of neutrophils in pulmonary genotoxicity/mutagenicity, depletion of circulating neutrophils in mice $(n=5)$ was achieved by intraperitoneal injection of $0.5 \mathrm{mg}$ of the monoclonal rat anti-mouse neutrophil antibody NIMP-R14 (Hbt, Maastricht, the Netherlands), $24 \mathrm{~h}$ before i.t. LPS instillation. NIMP-R14 has been shown to selectively deplete mouse neutrophils in vivo for up to 6 days [30, 31]. In our study, a lack of MPO activity in the lung was used as a verification of this neutrophil absence. IgG (eBioscience, San Diego, CA, USA) was used as control mAb in the sham group. Again, 3 days after instillation, mice were sacrificed, and lungs were lavaged and isolated as described above. 


\section{MPO activity measurement}

Only activated neutrophils, which undergo an oxidative burst with associated release of MPO and subsequent formation of $\mathrm{HOCl}$, can induce genotoxic effects in pulmonary epithelial tissue. Therefore, extracellular MPO activity was measured in cell-free BALF as described by Klebanoff et al. [32], which is indicative for the presence of (activated) neutrophils in the lung [33].

\section{Statistical analysis}

Data are expressed as mean \pm standard error of the mean (SEM) of duplicate determinations of at least two independent incubations concerning the in vitro experiments or of at least 5 in vivo samples per group. ANOVA with post hoc testing (Dunnett's correction for multiple testing, two-sided) was applied to test differences between treatments and control. Statistical analysis was performed using SPSS v.15.0. In each case, a difference was considered statistically significant at $P<0.05$.

\section{Results and Discussion}

\section{Genotoxic effects of hypochlorous acid: use of an in vitro model}

In previous coincubation models of neutrophils and lung epithelial cells, we showed that activated neutrophils induce the formation of 8-oxo-dG and ssDNA breaks in epithelial cells, which could be mimicked by treatment of the cells with $\mathrm{H}_{2} \mathrm{O}_{2}[8,20]$. In the present study, we investigated the ability of the major oxidant derived from activated neutrophils, namely $\mathrm{HOCl}$, to induce ssDNA breaks, 8-oxo-dG and $\mathrm{M}_{1} \mathrm{dG}$ in A549 cells. When A549 cells were exposed to increasing concentrations of $\mathrm{HOCl}$, no acute cytototic effects were observed at physiological concentrations. The viability of the epithelial cells was $>90 \%$ after treatment with up to $200 \mu \mathrm{M}$ of $\mathrm{HOCl}$ during 15 min. These doses can be produced in vivo at sites of inflammation and also reflect the amount of $\mathrm{HOCl}$ produced in in vitro cocultures (1:1 ratio with activated neutrophils yields $\sim 150 \mu \mathrm{M} \mathrm{HOCl}$ ) [34].

At physiological concentrations, no significant increase in ssDNA breaks or 8-oxodG levels was detected compared to controls (Fig. 1A\&B). It should be emphasised that $\mathrm{HOCl}$ is not considered to be a highly DNA reactive agent, and mainly targets proteins and lipids, before it reaches the nucleus [35]. Early studies have shown that stimulated neutrophils can cause lipid peroxidation [36, 37]. Lipid peroxidation generates a complex variety of products among which are reactive electrophiles, such as epoxides and aldehydes [38]. Malondialdehyde is a major product of lipid peroxidation, capable of interacting with nucleic acid bases to form exocyclic DNA adducts, mainly $M_{1} d G$ [26]. $M_{1} d G$ adducts have been shown to be promutagenic in mammalian cells and to induce frameshift mutations and base pair substitutions [39]. In this way, $\mathrm{HOCl}$ may exert mutagenic effects indirectly via its attack on lipids. As a third genotoxic effect, we assessed the capacity of $\mathrm{HOCl}$ to induce $\mathrm{M}_{1} \mathrm{dG}$ adducts in A549 cells in vitro, being one of the major adducts resulting from lipid peroxidation [40]. Results 
showed a significant (up to 3-fold, $P<0.01$ ) induction of $\mathrm{M}_{1} \mathrm{dG}$ by $\mathrm{HOCl}$ at $50 \mu \mathrm{M}$ (Fig. 1C), independent from acute cytotoxicity. Clearly, such a rise in exocyclic $M_{1} d G$ adducts could be due to increased levels of MDA, but also to a decreased repair of these adducts, via the nucleotide excision repair pathway [41]. The latter is in line with recent data from our laboratory, showing that neutrophil derived $\mathrm{HOCl}$ inhibits nucleotide excision repair [42]. 
A

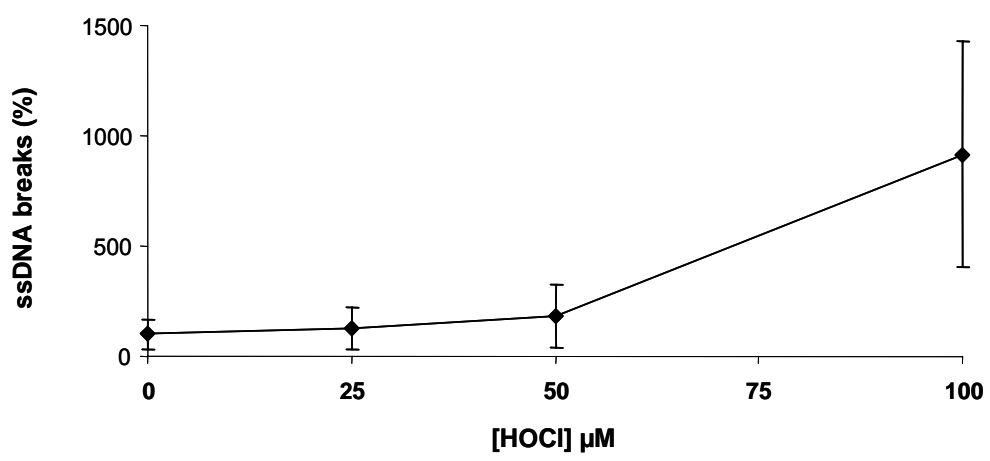

B

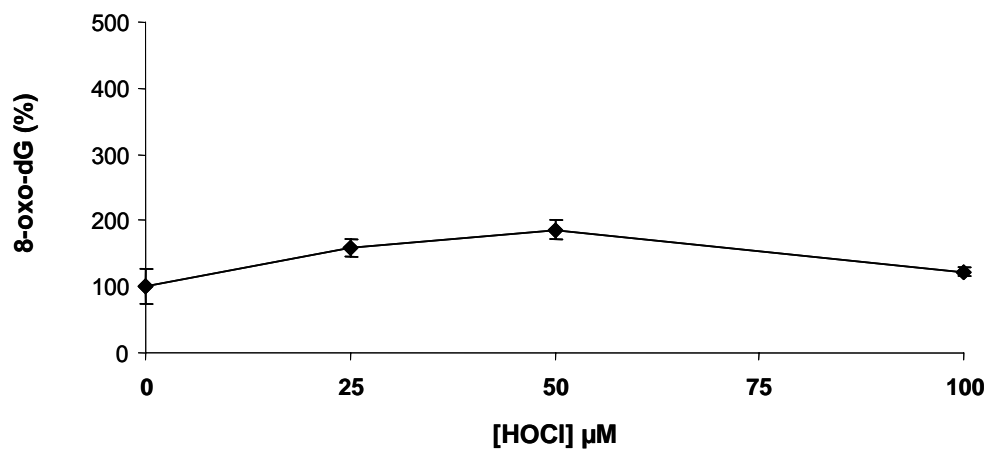

C

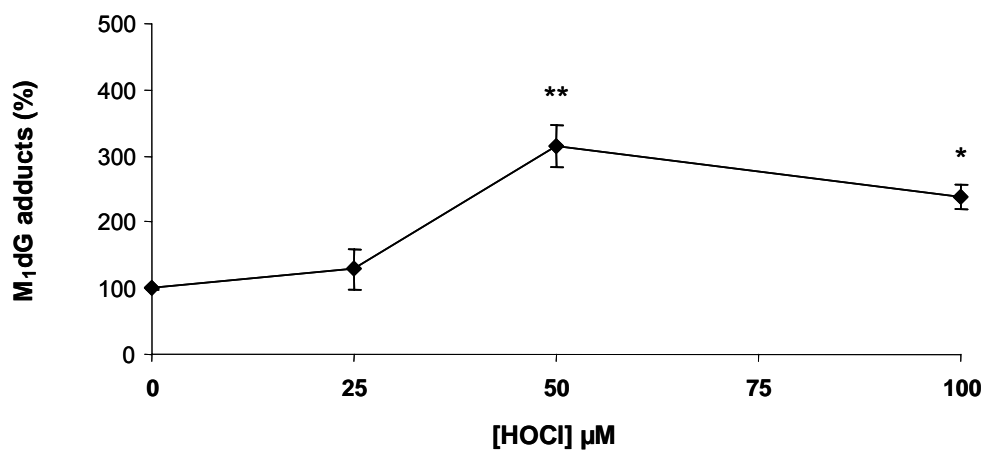

Figure 1. DNA damage in $A 549$ cells induced by $\mathrm{HOCl}$ in vitro. A549 cells were exposed to increasing concentrations of $\mathrm{HOCl}(0-100 \mu \mathrm{M})$ for $15 \mathrm{~min}$ at $37^{\circ} \mathrm{C}$. (A) ssDNA breaks in A549 cells were monitored by comet assay and are expressed as mean \pm SEM \% of control of duplicate determinations from 2 independent incubations. $250 \mu \mathrm{M} \mathrm{H}_{2} \mathrm{O}_{2}$ was assessed as positive control $(5873 \pm 3053 \%$ to control, data not shown). (B) 8-oxo-dG was measured using HPLC-ECD and is expressed as mean \pm SEM \% of control of duplicate determinations from 2 independent incubations. $250 \mu \mathrm{M} \mathrm{H} \mathrm{H}_{2} \mathrm{O}_{2}$ was used as positive control (398 $\pm 2 \%$ of control, data not shown). (C) $M_{1} d G$ adducts were detected using ${ }^{32} \mathrm{P}$ postlabeling and expressed as mean \pm SEM \% of control of triplicate determinations from 2 independent incubations. Cell treatment with $250 \mu \mathrm{M} \mathrm{H}_{2} \mathrm{O}_{2}$ gave $345 \pm 9 \%$ of $\mathrm{M}_{1} \mathrm{dG}$ adducts compared to control and was used as positive control (data not shown). ${ }^{*} P<0.05,{ }^{* *} P<0.01$ vs. control. 
To support the $\mathrm{M}_{1} \mathrm{dG}$ adduct data and to clarify if $\mathrm{HOCl}$ can induce aldehyde formation in lung epithelial cells, we measured MDA in A549 cells exposed to $\mathrm{HOCl}$ in terms of its reaction with thiobarbituric acid. Figure 2 illustrates higher MDA levels in cells treated with $\mathrm{HOCl}$ as measured by TBAR formation $(P=0.07$ at $50 \mu \mathrm{M} \mathrm{HOCl})$. This increase in MDA formation can be assigned to $\mathrm{HOCl}$ induced lipid peroxidation. It should be noted, however, that also another pathway for aldehyde formation, independent of lipid peroxidation, may be important in the observed generation of MDA and associated $\mathrm{M}_{1} \mathrm{dG}$ adducts. Hazen et al. [43] have demonstrated that $\mathrm{HOCl}$ oxidises amino acids to chloramines. The latter derivatises lose of chloride and $\mathrm{CO}_{2}$ to form imines; imines subsequently hydrolyse to aldehydes. Furthermore, $M_{1} d G$ adducts can also arise from the reaction of 2-deoxyguanosine with a DNA peroxidation product, namely base propenal, which is formed by oxidative attack of the sugar phosphate backbone. However, since we did not observe an increase of 8-oxo-dG, it is not clear whether direct oxidation of DNA by $\mathrm{HOCl}$ occurs in sufficient amounts to induce this alternative pathway leading to $\mathrm{M}_{1} \mathrm{dG}$ adduct formation.

In general, based on the genotoxic endpoints addressed in this study, these in vitro data suggest that the DNA damaging effect induced by $\mathrm{HOCl}$ is mainly secondary via an oxidative attack on lipids and/or proteins.

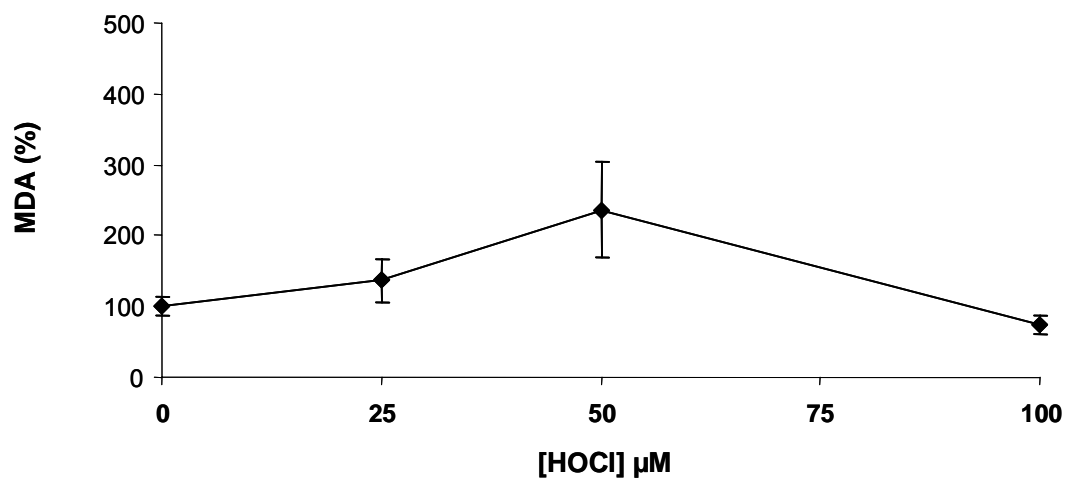

Figure 2. $\mathrm{HOCl}$ induced lipid peroxidation in A549 cells. A549 cells were treated with increasing doses of $\mathrm{HOCl}(0-100 \mu \mathrm{M})$ for $15 \mathrm{~min}$ and formed TBARs were used as a measure for lipid peroxidation. Data are corrected for protein content in the lysate and are expressed as $\%$ to control. $\mathrm{Fe}^{2+}(10 \mu \mathrm{M})$ was used as positive control and values were $281 \%$ of MDA compared to control incubation (data not shown).

\section{Mutagenic effects of hypochlorous acid}

To reveal whether $\mathrm{M}_{1} \mathrm{dG}$ adducts caused by $\mathrm{HOCl}$ are relevant to mutagenesis, the ability of $\mathrm{HOCl}$ to form mutations at the HPRT locus was investigated in A549 cells. First, long term survival after $\mathrm{HOCl}$ treatment was studied by determination of the clone forming ability. Cells counted with dye exclusion method and plated a few hours after treatment with increasing concentrations of $\mathrm{HOCl}$ showed a relative survival going from $100 \%$ to $25 \%$ at $100 \mu \mathrm{M}$ (Fig. 3A). Figure 3B illustrates the mutant fre- 
quency corrected for this cloning efficiency after the expression time, showing a dose dependent and statistically significant increase of the HPRT mutant frequency $(P=$ 0.01 at $25 \mu \mathrm{M} \mathrm{HOCl}$ ). The decrease in mutation frequency at $100 \mu \mathrm{M} \mathrm{HOCl}$ is probably due to $\mathrm{HOCl}$ induced cytotoxicity on a long term as observed by the clonogenic survival assay.

This is the first study to report on mutagenic effects of $\mathrm{HOCl}$ in mammalian cells. Both an increase in DNA lesions and the inhibition of DNA repair induced by $\mathrm{HOCl}$ may play a role in the process of HPRT gene mutation.

A

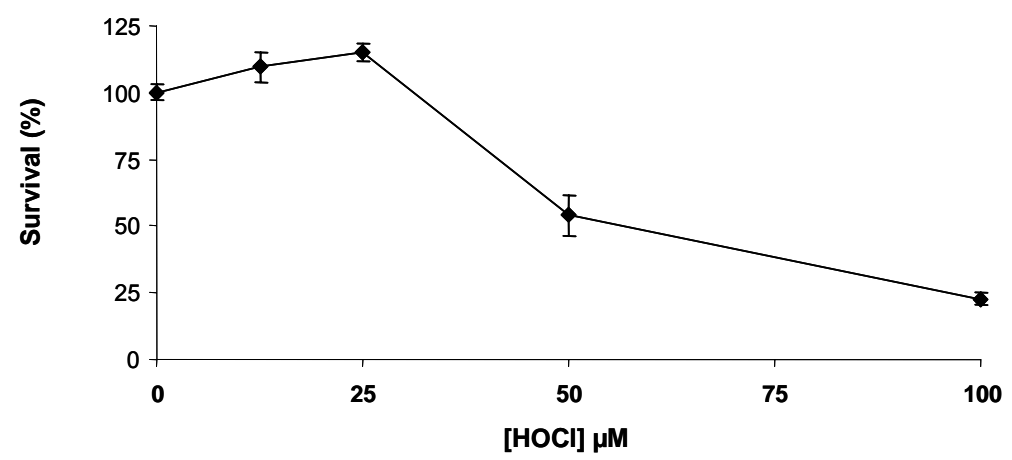

B

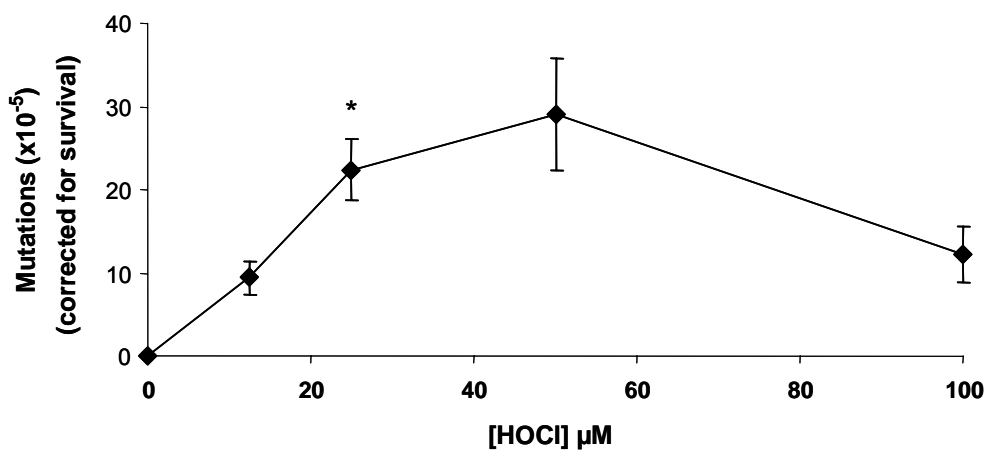

Figure 3. Mutagenicity of $\mathrm{HOCl}$. (A) Clonogenic survival assays were used to determine the sensitivity to 15 min acute treatment with $\mathrm{HOCl}$ in A549 cells. The mean values of 3 independent experiments are shown with SEM. (B) The number of HPRT mutants was determined via selection in medium containing 6-TG. Mutations were corrected for survival and $\mathrm{HOCl}$ induced mutation frequencies are expressed as mean \pm SEM of 3 independent experiments. BPDE, a well known mutagen, was assessed as positive control (data not shown). As only $25 \%$ of the A549 cells exposed to $100 \mu \mathrm{M} \mathrm{HOCl}$ survived after one week of culturing, the associated mutation frequency data point was left out statistical analysis, thus only the $\mathrm{HOCl}$ doses ranging from

$0-50 \mu \mathrm{M}$ were taken in consideration. ${ }^{*} P<0.05$ vs. control $(P=0.06$ at $50 \mu \mathrm{M} \mathrm{HOCl})$. 


\section{Neutrophil induced DNA damage in epithelial cells: an in vivo mouse model of acute lung inflammation}

Although the above in vitro findings may suggest $M_{1} d G$ adducts as being the most significant lesion underlying $\mathrm{HOCl}$ induced mutagenicity in lung epithelial cells, the relevance with respect to the mechanism of $\mathrm{HOCl}$ induced genotoxicity by neutrophils in vivo is unclear. Therefore, an LPS induced acute lung inflammation mouse model expanded with a systemic depletion of neutrophils was used to elucidate the involvement of neutrophils and associated $\mathrm{HOCl}$ production in the induction of DNA damage in respiratory tract epithelial cells in vivo.

As extracellular MPO activity is indicative for the presence of activated neutrophils and serves as a surrogate marker for $\mathrm{HOCl}$ formation in the lung [33], MPO was assessed in BALF to verify neutrophil activation. Significant MPO activity was observed in the LPS instilled mice $(81.4 \pm 20.5 \mathrm{mU} / \mathrm{ml})$, whereas no MPO activity was detected in the sham group. Absent MPO activity in the neutrophil depletion group indicates absence of $\mathrm{HOCl}$ in these animals.

To reveal whether our in vitro observation, showing $\mathrm{HOCl}$ induced $\mathrm{M}_{1} \mathrm{dG}$ adduct formation in alveolar epithelial cells, corresponds with the in vivo situation, we examined the DNA damaging effects of neutrophils in pulmonary tissue of mice after i.t. LPS instillation. Similar as the in vitro finding on direct $\mathrm{HOCl}$ induced genotoxicity, no direct oxidative DNA damage was found by 8-oxo-dG measurement in LPS instilled mice $\left(31.9 \pm 6.98\right.$-oxo-dG $/ 10^{6}$ nucleotides $)$ as compared to sham mice $(25.3 \pm 4.38$ oxo-dG $/ 10^{6}$ nucleotides). This is in line with previous studies in which we were not able to find increased 8-oxo-dG levels in lungs from rats intratracheally treated with crystalline silica at dose levels that caused massive neutrophil influx into the airways [44]. In contrast, LPS treatment caused a significant increase in the formation of $\mathrm{M}_{1} \mathrm{dG}$ adducts in the mouse lung ( 4-fold, $P<0.01$ ) (Fig. 4). Moreover, a significant correlation was found between MPO activity in BALF and $M_{1} d G$ levels in epithelial cells (Pearson correlation $=0.67, P=0.001$ ). This finding is in line with the above in vitro observations and suggests a link between neutrophil influx, MPO mediated formation of $\mathrm{HOCl}$ and formation of $\mathrm{M}_{1} \mathrm{dG}$ adducts in vivo. The causal role of neutrophils and $\mathrm{HOCl}$ in this effect is further substantiated by the observation that depletion of circulating neutrophils causes a significant reduction in $M_{1} d G$ adduct levels in the LPS treated mice. 


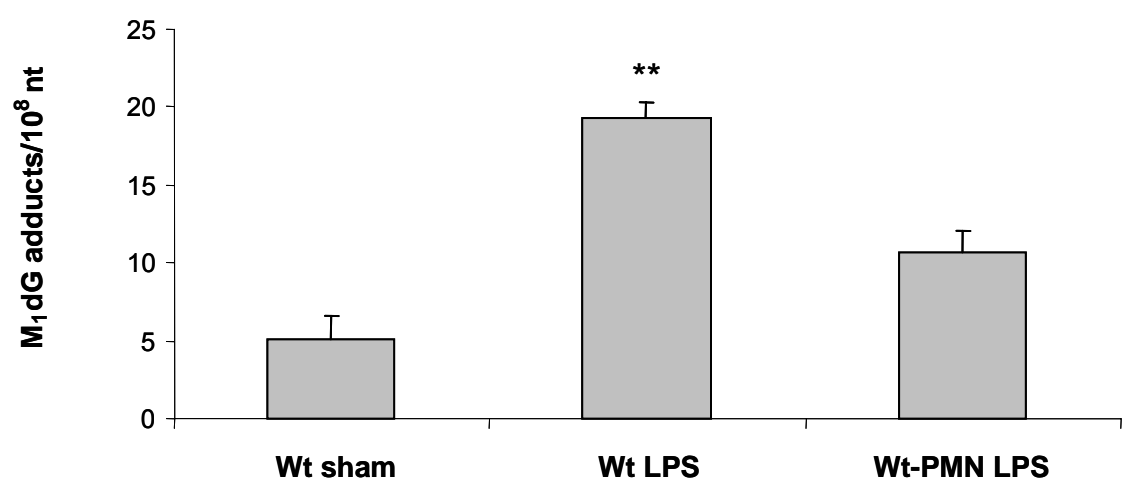

Figure 4. $M_{1} d G$ adduct levels in lung tissue after LPS exposure. Data are expressed as mean \pm SEM of $M_{1} d G$ adducts $/ 10^{8}$ nucleotides $(n=5-10)$. ${ }^{* *} P<0.01$ vs. sham animals.

\section{Conclusions}

It has been proposed that ROS generated by activated inflammatory neutrophils may be involved in mutagenic processes and, hence, play a pivotal role in carcinogenesis. Focussing on $\mathrm{HOCl}$ as the major oxidant produced by neutrophils, this study is the first to report that $\mathrm{HOCl}$ induces mutations in lung epithelial cells indicating mainly an indirect genotoxic hazard of neutrophil derived $\mathrm{HOCl}$, by its attack on lipids and/or proteins producing MDA and forming $\mathrm{M}_{1} \mathrm{dG}$ adducts. Altogether, our data indicate that MPO catalysed formation of $\mathrm{HOCl}$ should be considered as a significant source of neutrophil induced DNA damage and possibly mutagenesis. These data support recent molecular epidemiology studies, reporting a protective effect of an MPO polymorphism on lung cancer risk in smokers, and hence suggesting the involvement of the myeloperoxidase product hypochlorous acid in inflammation related lung cancer development. Moreover, with regard to neutrophil infiltration in tumours, the release of $\mathrm{HOCl}$ may also contribute to genetic instability in tumour cells, thereby further stimulating tumour progression.

\section{Acknowledgements}

The authors thank Yonca Güngör for linguistically reviewing the manuscript. This work was supported by the Province of Limburg, the Netherlands. Part of the studies was supported by the European Network of Excellence (NoE) "Environmental cancer, nutrition and individual susceptibility" (ECNIS), sixth Framework programme (FP6), FOOD-CT-2005-513943. 


\section{References}

1. Weitzman, S.A. and Gordon, L.I. (1990) Inflammation and cancer: role of phagocyte-generated oxidants in carcinogenesis. Blood, 76, 655-663.

2. Dungworth DL, M.U., Heinrich U, Ernst H, Kittel B (1994) Pathologic effects of inhaled particles in rat lungs: Associateions between inflammatory and neoplastic processes. Toxic and Carcinogenic Effects of Solid PArticles in the Respiratory Tract, ed. U. Mohr. 1994, Washington: ISLI Press. 7598.

3. Soo, C.C., Haqquani, A.S., Hidioglou, N., Swanson, J.E., Parker, R.S. and Birnboim, H.C. (2004) Dose dependent effects of dietary alpha- and gamma-tocopherols on genetic instability in mouse Mutatect tumors. J. Natl Cancer Inst., 96, 796-800.

4. Babior, B.M. (2000) Phagocytes and oxidative stress. Am J Med, 109, 33-44.

5. Weitberg, A.B., Weitzman, S.A., Destrempes, M., Latt, S.A. and Stossel, T.P. (1983) Stimulated human phagocytes produce cytogenetic changes in cultured mammalian cells. $N$ Engl $\mathrm{J} \mathrm{Med,}$ 308, 26-30.

6. Weitzman, S.A. and Stossel, T.P. (1981) Mutation caused by human phagocytes. Science, 212, 546-547.

7. Weitzman, S.A., Weitberg, A.B., Clark, E.P. and Stossel, T.P. (1985) Phagocytes as carcinogens: malignant transformation produced by human neutrophils. Science, 227, 1231-1233.

8. Knaapen, A.M., Gungor, N., Schins, R.P., Borm, P.J. and Van Schooten, F.J. (2006) Neutrophils and respiratory tract DNA damage and mutagenesis: a review. Mutagenesis, 21, 225-236.

9. Driscoll, K.E. (1996) Role of inflammation in the development of rat lung tumors in repsonse to chronic particle exposure. Inhalation Toxicology (suppl), 8, 139-153.

10. Borm, P.J. and Driscoll, K. (1996) Particles, inflammation and respiratory tract carcinogenesis. Toxicol Lett, 88, 109-113.

11. Driscoll, K.E., Deyo, L.C., Carter, J.M., Howard, B.W., Hassenbein, D.G. and Bertram, T.A. (1997) Effects of particle exposure and particle-elicited inflammatory cells on mutation in rat alveolar epithelial cells. Carcinogenesis, 18, 423-430.

12. Shacter, E., Beecham, E.J., Covey, J.M., Kohn, K.W. and Potter, M. (1988) Activated neutrophils induce prolonged DNA damage in neighboring cells. Carcinogenesis, 9, 2297-2304.

13. Knaapen, A.M., Seiler, F., Schilderman, P.A., Nehls, P., Bruch, J., Schins, R.P. and Borm, P.J. (1999) Neutrophils cause oxidative DNA damage in alveolar epithelial cells. Free Radic Biol Med, 27, 234-240.

14. Henle, E.S. and Linn, S. (1997) Formation, prevention, and repair of DNA damage by iron/hydrogen peroxide. J Biol Chem, 272, 19095-19098.

15. Hampton, M.B., Kettle, A.J. and Winterbourn, C.C. (1998) Inside the neutrophil phagosome: oxidants, myeloperoxidase, and bacterial killing. Blood, 92, 3007-3017.

16. London, S.J., Lehman, T.A. and Taylor, J.A. (1997) Myeloperoxidase genetic polymorphism and lung cancer risk. Cancer Res, 57, 5001-5003.

17. Cascorbi, I., Henning, S., Brockmoller, J., Gephart, J., Meisel, C., Muller, J.M., Loddenkemper, R. and Roots, I. (2000) Substantially reduced risk of cancer of the aerodigestive tract in subjects with variant--463A of the myeloperoxidase gene. Cancer Res, 60, 644-649.

18. Singh, N.P., McCoy, M.T., Tice, R.R. and Schneider, E.L. (1988) A simple technique for quantitation of low levels of DNA damage in individual cells. Exp Cell Res, 175, 184-191.

19. Tice, R.R., Agurell, E., Anderson, D., Burlinson, B., Hartmann, A., Kobayashi, H., Miyamae, Y., Rojas, E., Ryu, J.C. and Sasaki, Y.F. (2000) Single cell gel/comet assay: guidelines for in vitro and in vivo genetic toxicology testing. Environ Mol Mutagen, 35, 206-221.

20. Knaapen, A.M., Schins, R.P., Borm, P.J. and van Schooten, F.J. (2005) Nitrite enhances neutrophil-induced DNA strand breakage in pulmonary epithelial cells by inhibition of myeloperoxidase. Carcinogenesis, 26, 1642-1648.

21. Godschalk, R.W., Maas, L.M., Van Zandwijk, N., van 't Veer, L.J., Breedijk, A., Borm, P.J., Verhaert, J., Kleinjans, J.C. and van Schooten, F.J. (1998) Differences in aromatic-DNA adduct le- 
vels between alveolar macrophages and subpopulations of white blood cells from smokers. Carcinogenesis, 19, 819-825.

22. ESCODD (2000) Comparison of different methods of measuring 8-oxoguanine as a marker of oxidative DNA damage. . Free Radic Res, 32, 333-341.

23. de Kok, T.M., ten Vaarwerk, F., Zwingman, I., van Maanen, J.M. and Kleinjans, J.C. (1994) Peroxidation of linoleic, arachidonic and oleic acid in relation to the induction of oxidative DNA damage and cytogenetic effects. Carcinogenesis, 15, 1399-1404.

24. Munnia, A., Saletta, F., Allione, A., Piro, S., Confortini, M., Matullo, G. and Peluso, M. (2007) 32PPost-labelling method improvements for aromatic compound-related molecular epidemiology studies. Mutagenesis, 22, 381-385.

25. Munnia, A., Bonassi, S., Verna, A., Quaglia, R., Pelucco, D., Ceppi, M., Neri, M., Buratti, M., Taioli, E., Garte, S. and Peluso, M. (2006) Bronchial malondialdehyde DNA adducts, tobacco smoking, and lung cancer. Free Radic Biol Med, 41, 1499-1505.

26. Seto, H., Seto, T., Takesue, T. and Ikemura, T. (1986) Reaction of malonaldehyde with nucleic acid. III. Studies of the fluorescent substances released by enzymatic digestion of nucleic acids modified with malonaldehyde. Chem Pharm Bull (Tokyo), 34, 5079-5085.

27. Lepage, G., Munoz, G., Champagne, J. and Roy, C.C. (1991) Preparative steps necessary for the accurate measurement of malondialdehyde by high-performance liquid chromatography. Anal Biochem, 197, 277-283.

28. Vernooy, J.H., Dentener, M.A., van Suylen, R.J., Buurman, W.A. and Wouters, E.F. (2001) Intratracheal instillation of lipopolysaccharide in mice induces apoptosis in bronchial epithelial cells: no role for tumor necrosis factor-alpha and infiltrating neutrophils. Am J Respir Cell Mol Biol, 24, 569-576.

29. Haegens, A., Heeringa, P., van Suylen, R.J., Steele, C., Aratani, Y., O'Donoghue, R.J.J., Mutsaers, S.E., Mossman, B.T., Wouters, E.F. and Vernooy, J.H. (2009) Myeloperoxidase deficiency attenuates LPS induced acute lung inflammation and subsequent cytokine and chemokine production. Journal of Immunology,

30. Tacchini-Cottier, F., Zweifel, C., Belkaid, Y., Mukankundiye, C., Vasei, M., Launois, P., Milon, G. and Louis, J.A. (2000) An immunomodulatory function for neutrophils during the induction of a CD4+ Th2 response in BALB/c mice infected with Leishmania major. J Immunol, 165, 2628-2636.

31. Lopez, A.F., Strath, M. and Sanderson, C.J. (1984) Differentiation antigens on mouse eosinophils and neutrophils identified by monoclonal antibodies. Br J Haematol, 57, 489-494.

32. Klebanoff, S.J., Waltersdorph, A.M. and Rosen, H. (1984) Antimicrobial activity of myeloperoxidase. Methods Enzymol, 105, 399-403.

33. Knaapen, A.M., Albrecht, C., Becker, A., Hohr, D., Winzer, A., Haenen, G.R., Borm, P.J. and Schins, R.P. (2002) DNA damage in lung epithelial cells isolated from rats exposed to quartz: role of surface reactivity and neutrophilic inflammation. Carcinogenesis, 23, 1111-1120.

34. Foote, C.S., Goyne, T.E. and Lehrer, R.I. (1983) Assessment of chlorination by human neutrophils. Nature, 301, 715-716.

35. Weiss, S.J. (1989) Tissue destruction by neutrophils. N Engl J Med, 320, 365-376.

36. Stossel, T.P., Mason, R.J. and Smith, A.L. (1974) Lipid peroxidation by human blood phagocytes. J Clin Invest, 54, 638-645.

37. Carlin, G. and Djursater, R. (1988) Peroxidation of phospholipids promoted by myeloperoxidase. Free Radic Res Commun, 4, 251-257.

38. Esterbauer, H. (1985) Lipid peroxidation products: formation, chemical properties and biological activities. Free Radical in Liver Injury, ed. C.K. Pli G, Dianzani MU, Slater TF. 1985, Oxford: IRL Press. 29-47.

39. Benamira, M., Johnson, K., Chaudhary, A., Bruner, K., Tibbetts, C. and Marnett, L.J. (1995) Induction of mutations by replication of malondialdehyde-modified M13 DNA in Escherichia coli: determination of the extent of DNA modification, genetic requirements for mutagenesis, and types of mutations induced. Carcinogenesis, 16, 93-99.

40. Janero, D.R. (1990) Malondialdehyde and thiobarbituric acid-reactivity as diagnostic indices of lipid peroxidation and peroxidative tissue injury. Free Radic Biol Med, 9, 515-540. 
41. Fink, S.P., Reddy, G.R. and Marnett, L.J. (1997) Mutagenicity in Escherichia coli of the major DNA adduct derived from the endogenous mutagen malondialdehyde. Proc Natl Acad Sci U S A, 94, 8652-8657.

42. Gungor, N., Godschalk, R.W., Pachen, D.M., Van Schooten, F.J. and Knaapen, A.M. (2007) Activated neutrophils inhibit nucleotide excision repair in human pulmonary epithelial cells: role of myeloperoxidase. Faseb J, 21, 2359-2367.

43. Hazen, S.L., Hsu, F.F., d'Avignon, A. and Heinecke, J.W. (1998) Human neutrophils employ myeloperoxidase to convert alpha-amino acids to a battery of reactive aldehydes: a pathway for aldehyde generation at sites of inflammation. Biochemistry, 37, 6864-6873.

44. Albrecht, C., Knaapen, A.M., Becker, A., Hohr, D., Haberzettl, P., van Schooten, F.J., Borm, P.J. and Schins, R.P. (2005) The crucial role of particle surface reactivity in respirable quartz-induced reactive oxygen/nitrogen species formation and APE/Ref-1 induction in rat lung. Respir Res, 6, 129. 



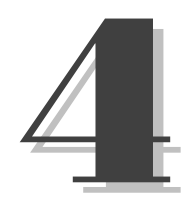

\title{
Activated neutrophils inhibit
}

\section{nucleotide excision repair}

\author{
in human pulmonary
}

$$
\text { epithelial cells: }
$$

role of myeloperoxidase

FASEB J 2007; 21(10):2359-67.

Güngör N

Godschalk RWL

Pachen DM

van Schooten FJ

Knaapen AM 


\section{Abstract}

Neutrophils are thought to affect pulmonary carcinogenesis by promoting the metabolism of inhaled chemical carcinogens, causing enhanced formation of promutagenic DNA adducts. We hypothesised that neutrophils interfere with the removal of such DNA adducts by inhibiting nucleotide excision repair (NER) in target cells. Human alveolar epithelial cells (A549) were cocultured with activated neutrophils and we observed a significant reduction of NER in the A549 cells, which was abrogated upon addition of the myeloperoxidase (MPO) inhibitor 4-ABAH. The inhibitory effect of neutrophils could be mimicked by the MPO product $\mathrm{HOCl}$, which caused an acute, dose dependent inhibition of NER in A549 cells. This was independent of cytotoxicity or ATP loss, and persisted up to $24 \mathrm{~h}$. These data were supported by showing that $\mathrm{HOCl}$ caused a delayed removal of DNA adducts in benzo[a]pyrene-diol-epoxide exposed A549 cells. The acute $\mathrm{HOCl}$ induced inhibition of NER can only be explained partly by oxidative modification of repair proteins. To explain the more persistent effects of $\mathrm{HOCl}$, we analysed the expression of $\mathrm{NER}$ genes and found that $\mathrm{HOCl}$ significantly reduced XPC expression. In conclusion, these data indicate that neutrophils are potent inhibitors of nucleotide excision repair. This may provide a further biological explanation for the association between inflammation and lung cancer development. 


\section{Introduction}

Chronic inflammation is considered to be a risk factor for the development of epithelial cell derived malignancies [1, 2]. However, the underlying processes have not yet been fully defined at the biochemical and molecular level. Within the lung, many inflammatory agents may play a part in accelerating carcinogenesis, including inhaled combustion derived particles, such as cigarette smoke, fine particulate matter (PM) and diesel exhaust particles [3]. Inhalation of such particles causes a local pulmonary inflammatory response that is characterised by the influx of polymorphonuclear neutrophils (PMN) into the airways. These inflammatory PMN are involved in the pathogenesis of various pulmonary diseases, such as chronic obstructive pulmonary disease (COPD) [4], fibrosis [5] and cancer [6].

Upon entering the lung, neutrophils are activated to release reactive oxygen species (ROS), as well as an array of proteins, such as myeloperoxidase (MPO). MPO catalyses the conversion of $\mathrm{H}_{2} \mathrm{O}_{2}$ into the bactericidal compound hypochlorous acid $(\mathrm{HOCl})$ [7]. Under physiological conditions, the concentration of $\mathrm{HOCl}$ ranges from 10 to $100 \mu \mathrm{M}$ [8], although concentrations up to $200 \mu \mathrm{M}$ have been reported in some tissues [9]. Even though $\mathrm{HOCl}$ formation has been linked to the induction of DNA damage [10], the primary cellular targets for $\mathrm{HOCl}$ appear to be proteins [11]. $\mathrm{HOCl}$ protein interactions result in side-chain modification, backbone fragmentation and crosslinking [12], which may ultimately lead to disturbed enzyme function. In vitro studies indeed have identified $\mathrm{HOCl}$ as a potent inhibitor of acetylcholinesterase [13] and glutathione S-transferase $\mathrm{P} 1-1$ [14]. In addition, $\mathrm{HOCl}$ has also been demonstrated to be an inhibitor of DNA strand break repair [15], as well as of poly (ADP-ribose) polymerase (PARP) activity, which is involved in base excision repair [16].

Epidemiological studies have indicated that neutrophils are involved in pulmonary carcinogenicity by releasing MPO in the cellular environment. For instance, there is evidence that a polymorphism in the promotor region of the MPO gene $(-463 \mathrm{G} \rightarrow \mathrm{A}$ transition) is associated with a decreased risk of developing lung cancer in smokers [17]. At present, the most widely accepted explanation for this association is the role of MPO in the bioactivation of inhaled carcinogens, such as polycyclic aromatic hydrocarbons (PAH). For example, MPO has been demonstrated to enhance the transformation of the prototype $\mathrm{PAH}$ benzo[a]pyrene $(\mathrm{B}[\mathrm{a}] \mathrm{P})$ into DNA binding metabolites [e.g. B[a]P diolepoxide (BPDE)] [18-21]. If these helix distorting DNA lesions escape from specific DNA repair (i.e. nucleotide excision repair), they may cause replication fork blocks, ultimately leading to mutagenesis and carcinogenesis [22-24].

Recent data have revealed that oxidising species, such as 4-hydroxynonenal (4$\mathrm{HNE}$ ) [25], malondialdehyde (MDA) [26] and nitric oxide [27] are endogenous inhibitors of nucleotide excision repair (NER). A comparable effect of the potent oxidising MPO product $\mathrm{HOCl}$ could, thus, provide an additional explanation for the observed association between neutrophils and lung cancer risk in subjects exposed to DNA adduct forming chemicals. In the present study, we investigated the effect of activated neutrophils on the NER capacity of pulmonary epithelial cells. We hypothesised that neutrophils, by virtue of their capacity to release $\mathrm{HOCl}$, are potent inhibitors of NER, 
thereby causing a disturbed removal of promutagenic PAH-DNA adducts. To test this hypothesis, activated neutrophils were cocultured with human epithelial lung cells. We found that neutrophils significantly reduced the NER capacity of the cocultured epithelial cells, leading to a delayed removal of bulky BPDE-DNA adducts. This effect appeared to be mediated by MPO derived $\mathrm{HOCl}$. We propose that these effects of neutrophils may provide an additional biological explanation for the observed association between inflammation and lung cancer risk [6].

\section{Materials and methods}

\section{Cell culture}

A549 cells (human epithelial lung carcinoma cells), purchased from the American Tissue Culture Collection (ATCC), were cultured in DMEM (Sigma, Zwijndrecht, the Netherlands) supplemented with $10 \%$ heat inactivated foetal calf serum (FCS, Gibco Invitrogen, Breda, the Netherlands) and $1 \%$ penicillin/streptomycin (Sigma, Zwijndrecht, the Netherlands). Cells were maintained at $37^{\circ} \mathrm{C}$ in a $5 \% \mathrm{CO}_{2}$ atmosphere. Cells were routinely grown in $75 \mathrm{~cm}^{2}$ cell-culture flasks and were passaged twice a week.

\section{Cocultures of neutrophils and epithelial lung cells}

Coincubation experiments were performed as described by Knaapen et al. [28]. Briefly, neutrophils were freshly isolated from the blood of healthy, non-smoking volunteers by gradient centrifugation $\left(800 \mathrm{x} \mathrm{g}, 20 \mathrm{~min}, 4^{\circ} \mathrm{C}\right.$ ), using lymphoprep (Axis-Shields, Oslo, Norway). Lymphocytes were removed and the remaining erythrocytes were lysed using cold $\left(4^{\circ} \mathrm{C}\right)$ lysis buffer $\left(155 \mathrm{mM} \mathrm{NH}_{4} \mathrm{Cl}, 10 \mathrm{mM} \mathrm{KHCO}_{3}, 10 \mathrm{mM}\right.$ EDTA, pH 7.4). PMN were washed and resuspended in Hanks' balanced salt solution (HBSS, Gibco Invitrogen, Breda, the Netherlands) at $10 \times 10^{6}$ cells $/ \mathrm{ml}$. This method consistently yielded PMN with a viability $>95 \%$, as assessed by trypan blue dye exclusion (Sigma, Zwijndrecht, the Netherlands). During all the stages of the isolation procedure, PMN and solutions were kept on ice to prevent premature activation.

Neutrophils were cocultured with confluent A549 cells grown in $75 \mathrm{~cm}^{2}$ culture flasks. The final volume of the incubations was always $10 \mathrm{ml}$ with a total neutrophil number of $5 \times 10^{6}$ or $10 \times 10^{6}$, yielding a final neutrophil:A549 ratio of 1:2 and 1:1 respectively. Neutrophils were subsequently activated with phorbol 12-myristate 13acetate $(100 \mathrm{ng} / \mathrm{ml})(\mathrm{PMA}$, Sigma) to elicit the respiratory burst. Cells were then coincubated during $1 \mathrm{~h}$ in $\mathrm{HBSS}\left(37^{\circ} \mathrm{C}, 5 \% \mathrm{CO}_{2}\right)$. Control incubations were without PMN and/or without PMA. Following incubation, the neutrophils were removed using two repetitive washings with $10 \mathrm{ml}$ of cold $\left(4^{\circ} \mathrm{C}\right) \mathrm{HBSS}$. The A549 cells were harvested by trypsination for analyses of toxicity and NER capacity. Cytotoxicity of PMA and/or PMN in A549 was tested using trypan blue dye exclusion. All studies were performed at $\mathrm{pH}$ 7.4. To investigate the role of MPO, $100 \mu \mathrm{M}$ of the highly specific MPO inhibitor 4-aminobenzoic hydrazide (4-ABAH, Sigma) [29] was added to coincubations of A549 
with PMA activated PMN (1:1 ratio). Coincubations were then performed as described above.

\section{Measurement of myeloperoxidase activity}

MPO activity in the supernatant of the neutrophil-A549 coincubations was assayed according to the method described by Klebanoff et al. [30]. Therefore, $100 \mu \mathrm{l}$ of supernatant was mixed with $400 \mu \mathrm{l}$ MPO assay solution, which comprised $26.9 \mathrm{ml} \mathrm{H}_{2} \mathrm{O}$, $3 \mathrm{ml}$ sodium phosphate buffer $(0.1 \mathrm{M}, \mathrm{pH} 7.0), 48 \mu \mathrm{l}$ guaiacol and $100 \mu \mathrm{H}_{2} \mathrm{O}_{2}(0.1 \mathrm{M})$ (all these chemicals were purchased from Merck, Darmstadt, Germany). The generation of tetra-guaiacol was measured spectrophotometrically (Beckman) at $470 \mathrm{~nm}$. MPO activity was calculated using the formula: $\mathrm{U} / \mathrm{ml}=\Delta \mathrm{OD} / \mathrm{min} \times 0.7518$ and was expressed as $\mathrm{mU} / \mathrm{ml}$. One unit is defined as the amount of the enzyme that consumes $1 \mu \mathrm{mol} \mathrm{H}_{2} \mathrm{O}_{2} / \mathrm{min}$.

\section{Cell treatment with $\mathrm{HOCl}$}

The concentration of the $\mathrm{HOCl}$ stock solution (Sigma) was measured spectrophotometrically, immediately before use at $293 \mathrm{~nm}$, using the extinction coefficient of hypochlorite $\varepsilon_{293}=349.2 \mathrm{M}^{-1} . \mathrm{cm}^{-1}$ at $\mathrm{pH} 10-12$. HOCl was diluted in HBSS to final, physiological concentrations ranging from 0 to $200 \mu \mathrm{M}$. Confluent A549 cells were washed twice with HBSS of $37^{\circ} \mathrm{C}$. Fresh HBSS was then added followed by the addition of $\mathrm{HOCl}$. After $15 \mathrm{~min}$ of incubation at $37^{\circ} \mathrm{C}$, cells were harvested as described above. To assess prolonged effects of $\mathrm{HOCl}$ exposure, cells were treated with $\mathrm{HOCl}$ during $15 \mathrm{~min}$, followed by washing and continued incubation in DMEM for up to $24 \mathrm{~h}$. Addition of $\mathrm{HOCl}$ did not alter the $\mathrm{pH}$ of the reaction mixture. Cytotoxicity of $\mathrm{HOCl}$ in A549 was tested using trypan blue dye exclusion.

\section{Repair assay: modified comet assay to assess phenotypically nucleo- tide excision repair}

Phenotypical assessment of NER capacity of the A549 cells was performed using a modified comet assay developed in our own laboratory [31]. This assay is based on a method described by Collins et al. [32] and is specifically designed to test the ability of cell lysates to detect and excise benzo[a]pyrene-diol-epoxide (BPDE-)DNA adducts in gel-embedded nucleoids. Briefly, nucleoids are prepared by embedding untreated A549 cells in low melting point agarose (Sigma, Zwijndrecht, the Netherlands) on microscopic slides and subsequently lysing these cells overnight in cold $\left(4^{\circ} \mathrm{C}\right)$ lysis buffer (2.5 M NaCl, 0.1 M EDTA, $10 \mathrm{mM}$ Tris, $0.25 \mathrm{M} \mathrm{NaOH}, \mathrm{pH} 10,10 \%$ dimethylsulfoxide (DMSO) and 1\% Triton $\mathrm{X}-100)$. The resulting nucleoids were then exposed to either $1 \mu \mathrm{M}$ BPDE (NCl Chemical Carcinogen Reference Standard Repository, Midwest Research Institute, Kansas City, MO, USA) or DMSO during 30 min on ice.

In parallel, cell extracts were prepared from the cocultured A549 cells or the A549 cells treated with $\mathrm{HOCl}$, based on the method developed by Redaelli et al. [33], with minor modifications [31]. In some experiments, lysates were first isolated from un- 
treated $\mathrm{A} 549$ cells and then exposed to $\mathrm{HOCl}$ in vitro, to investigate the consequences of the direct interaction of $\mathrm{HOCl}$ with the repair proteins. Protein concentrations of the cell lysates were determined by the BIO-RAD DC Protein Assay Kit (BIORAD, Veenendaal, the Netherlands), using bovine serum albumine (BSA) as external standard, and protein extracts were diluted to $1 \mathrm{mg} / \mathrm{ml}$. To assess the 'ex vivo' repair capacity, each protein extract was finally added onto DMSO exposed as well as BPDE exposed gel-embedded nucleoids and incubated during $10 \mathrm{~min}$ at $37^{\circ} \mathrm{C}$. Subsequently, the slides were processed according to the conventional comet assay as described previously [34]. Comets were visualised using a Zeiss Axioskop fluorescence microscope and quantified as tail moment. Samples were tested in two independent incubations within each single experiment. On every slide, 50 cells were analysed randomly using the Comet assay III software program (Perspective Instruments, Haverhill, UK). The increased DNA strand breakage (tail moment) in the BPDE modified nucleoids versus the DMSO treated nucleoids is indicative for the NER capacity of the cell extracts. The final repair capacity was calculated according to Langie et al. [31], and is expressed as percentage of control.

This sensitive method has the advantage that it can be performed without the use of radioisotopically labelled probes. In addition, instead of using circular plasmids or probes containing a specific DNA lesion, this assay applies whole cell derived nucleoids which are treated with BPDE, inducing BPDE-DNA adducts that are targets for the repair proteins. These nucleoids retain the normal structure of the mammalian nucleus and are, thus, a more physiological substrate for studying the efficiency of cell lysates to repair eukaryotic DNA. Our assay was validated by showing that lysates obtained from Xeroderma Pigmentosum complementation group $\mathrm{A}$ and $\mathrm{C}$ deficient fibroblasts ( $X p a$ and $X p c$ respectively) were unable to recognise and excise the BPDE-DNA adducts in the nucleoids, whereas fusion of both lysates fully restored the NER capacity [31].

\section{${ }^{32}$ P-postlabelling of BPDE-DNA adducts}

As an additional approach to reveal the effects of $\mathrm{HOCl}$ on NER capacity in target cells, we studied the influence of $\mathrm{HOCl}$ on the kinetics of BPDE adduct removal in proliferating A549 cells. Therefore, A549 cells were exposed to $0.1 \mu \mathrm{M}$ BPDE during 30 min on ice, followed by treatment with $\mathrm{HOCl}(100 \mu \mathrm{M}$, in HBSS) during 15 min. After treatment with $\mathrm{HOCl}$, the medium was replaced by DMEM $\left(37^{\circ} \mathrm{C}\right)$ to allow recovery of the cells. Cells were harvested by trypsination at different time points postexposure $(0$ to $4 \mathrm{~h})$ to assess the kinetics of DNA adduct removal using ${ }^{32} \mathrm{P}$ postlabelling. Standard high salt extraction was used to obtain genomic DNA. ${ }^{32} \mathrm{P}$ postlabelling was carried out using the nuclease P1 enrichment technique as described by Reddy and Randerath [35] with some modifications [36]. In all experiments, three BPDE-DNA standards with known adduct levels ( 1 adduct $/ 10^{6}, 1$ adduct $/ 10^{7}$ and 1 adduct $/ 10^{8}$ normal nucleotides) were analysed in parallel for quantification purposes. Quantification was performed using Phosphor-Imaging technology (Fujifilm FLA3000). Part of the digest was used to determine the final amount of DNA in the assay by HPLC-UV, and the BPDE-DNA adduct levels were corrected accordingly. 


\section{ATP measurement}

To assess the effects of $\mathrm{HOCl}$ on ATP levels in A549 cells, cells were seeded in 24well plates. At confluency, cells were washed twice with HBSS, followed by the addition of $500 \mu \mathrm{l}$ of $\mathrm{HOCl}$ containing HBSS. After $15 \mathrm{~min}$, cells were washed twice with cold HBSS to remove any residual $\mathrm{HOCl}$. Cells were lysed by adding 1x Reporter Lysis Buffer $(125 \mu \mathrm{l})$ (Promega, Leiden, the Netherlands) to the wells and incubation on ice for $10 \mathrm{~min}$. Cell lysates were centrifuged (13,000x g, $1 \mathrm{~min})$, and supernatants were placed on ice for immediate analysis. Protein concentrations were determined by the BIO-RAD DC Protein Assay Kit. ATP levels in the cells were assessed with a Molecular Probes kit (Molecular Probes Invitrogen, Leiden, the Netherlands), using luciferase and luciferin according to the instructions of the manufacturer. Bioluminescence was measured during 20 seconds by using a Lumat LB 9507 luminometer (Berthold Technologies, Belgium). Concentrations of ATP were determined by comparing the values obtained with a freshly prepared standard curve of ATP and were corrected for protein content.

\section{Measurement of protein carbonyls}

Measurement of protein carbonyls was used as an indicator of $\mathrm{HOCl}$ induced oxidation of cellular proteins. Therefore, cells were exposed to $\mathrm{HOCl}$ and proteins were extracted by the method used for the repair assay. Briefly, the cell pellets $\left(5 \times 10^{6}\right.$ cells) were resuspended in $50 \mu$ lextraction Buffer A (45 mM HEPES, $0.4 \mathrm{M} \mathrm{KCl}, 1$ $\mathrm{mM}$ EDTA, 10\% glycerol, adjusted to $\mathrm{pH} 7.8$ using $\mathrm{KOH}$ ) [31]. Since DTT is able to react quickly with $\alpha, \beta$-unsaturated carbonyl compounds, it was omitted from the original extraction buffer. Before analysis of protein carbonyl levels by ELISA, total protein concentration was determined, using the BIO-RAD DC Protein Assay kit. To load equal amounts of $20 \mu \mathrm{g}$ protein in the ELISA procedure, the protein samples were concentrated by mixing a volume containing $20 \mu \mathrm{g}$ proteins with $0.8 \mathrm{vol}$ of $28 \%$ TCA, centrifugation at 10,000x $\mathrm{g}$ and discarding the supernatant. Protein carbonyl concentrations were finally determined by a Zentech PC ELISA test (Zentech Alexis, Lausen, Switzerland), which involves a derivatisation reaction of the isolated proteins with dinitrophenylhydrazine and subsequent detection of the derivatised proteins with an anti-dinitrophenylhydrazine antibody, according to the manufacturer's instructions. Samples were calibrated against a standard curve constructed using reduced and $\mathrm{HOCl}$ oxidised albumin.

\section{Quantitative real-time PCR}

Quantitative real-time PCR was applied to assess the effects of $\mathrm{HOCl}$ on the expression of relevant NER genes. A549 cells were seeded in $28 \mathrm{~cm}^{2}$ dishes and treated with $100 \mu \mathrm{M} \mathrm{HOCl}$. After $15 \mathrm{~min}, \mathrm{HOCl}$ was removed and cells were washed with HBSS, followed by a further incubation of the cells in DMEM for 0 to $24 \mathrm{~h}$. After incubation, A549 cells were lysed in $1 \mathrm{ml} \mathrm{Trizol}{ }^{\circledR}$ (Gibco Invitrogen, Breda, the Netherlands). Total RNA was isolated and purified using the RNeasy ${ }^{\circledR}$ Mini Kit (Qiagen Westburg, Leusden, the Netherlands) in combination with a DNase treatment (Qia- 
gen), according to the manufacturer's instructions. The quantity and quality of each RNA sample were measured spectrophotometrically. First strand cDNA was generated according to the iScript ${ }^{\mathrm{TM}}$ CDNA synthesis kit protocol (BIO-RAD, Veenendaal, the Netherlands) using $1 \mu \mathrm{g}$ total RNA. The following NER genes were tested: $X P A, X P C$, $E R C C-1, X P F(=E R C C-4)$ and $X P G(=E R C C-5)$, using primers purchased from Operon (Leiden, the Netherlands) (see Table 1 for primer sequences). Real-time PCR was performed with a MyiQ Single Colour real-time PCR detection system (BioRad, Veenendaal, the Netherlands) using SYBR ${ }^{\odot}$ Green Supermix (BIO-RAD), $5 \mu$ l diluted cDNA and $0.3 \mu \mathrm{M}$ primers in a total volume of $25 \mu \mathrm{l}$. PCR was conducted in the following manner: denaturation at $95^{\circ} \mathrm{C}$ for $3 \mathrm{~min}$, followed by 40 cycles of $95^{\circ} \mathrm{C}$ for 15 seconds and $60^{\circ} \mathrm{C}$ for 45 seconds. After PCR, a melt curve $\left(60-95^{\circ} \mathrm{C}\right)$ was produced for product identification and purity. PCR efficiency of all primer sets, as assessed by the use of cDNA dilution curves, was approximately $100 \%$. Data were analysed using the MyiQ Software system (BIO-RAD) and were expressed as relative gene expression (fold increase), using the $2^{-\Delta \Delta C t}$ method and employing both $\beta$-actin and GAPDH as housekeeping genes [37].

Table 1: Primer sequences used for real-time PCR

\begin{tabular}{lll}
\hline Gene & \multicolumn{1}{l}{ Sequence $5^{`} \rightarrow 3^{\prime}$} \\
\hline$\beta$-actin & Forward primer: & CCTGGCACCCAGCACAAT \\
& Reverse primer: & GCCGATCCACACGGAGTACT \\
GAPDH & Forward primer: & GCACCACCAACTGCTTAGCA \\
& Reverse primer: & TGGCAGTGATGGCATGGA \\
ERCC-1 & Forward primer: & ACCCCTCGACGAGGATGAG \\
& Reverse primer: & CAGTGGGAAGGCTCTGTGTAGA \\
$X P A$ & Forward primer: & CCGACAGGAAAACCGAGAAA \\
& Reverse primer: & TTCCACACGCTGCTTCTTACTG \\
$X P C$ & Forward primer: & CCCAGCCCGCTTTACCA \\
& Reverse primer: & TGCATTAACTGTAAATGTTCCAATGA \\
$X P F(E R C C-4)$ & Forward primer: & CACCTCCCTCGCCGTGTA \\
& Reverse primer: & CGCAAATATAACACCACCTTGTG \\
$X P G ~(E R C C-5)$ & Forward primer: & GCATGAAATCTTGACTGATATGAAAGA \\
& Reverse primer: & TAAGCAAGCCTTTGAGTTGGTACTG \\
\hline
\end{tabular}

\section{Statistical analysis}

Data are represented as mean \pm standard error of the mean (SEM) from 3 independent experiments, unless stated otherwise. Statistical analysis was performed using SPSS version 11.5 for Windows. ANOVA with post hoc testing (Dunnett's correction for multiple, two-sided) was applied to test differences between treatments and control. Differences were considered to be statistically significant when $P<0.05$. 


\section{Results}

\section{Inhibition of NER in A549 cells coincubated with neutrophils is MPO dependent}

PMA activated neutrophils caused a significant decrease in NER capacity of lysates obtained from the cocultured A549 cells. This effect enhanced with increasing PMN numbers (Fig. 1A). In the absence of PMA, neutrophils were unable to inhibit NER in the coincubated A549 cells. The A549 cells coincubated with equal amounts of PMA activated PMN (1:1 ratio) showed a significant reduction in NER capacity up to $60 \%$ $(P<0.05)$. The supernatant of the A549-neutrophil cocultures was analysed for MPO activity. As shown in Figure 1B, MPO activity was only detected in the incubations containing PMA activated neutrophils. No MPO activity could be detected in the coculture supernatants, in the absence of PMA.

In order to evaluate the role of MPO in NER inhibition, coculture experiments were performed using the specific MPO inhibitor 4-ABAH. We applied 4-ABAH because it is known to be one of the most potent inhibitors of MPO, functioning as a suicide substrate that promotes irreversible inactivation of the enzyme and thereby fully inactivating the production of MPO derived $\mathrm{HOCl}$. Significantly, 4-ABAH does not affect neutrophil induced NADPH-oxidase and does not inhibit catalase and gluthatione peroxidase, unlike many other MPO inhibitors [29]. MPO activity was completely inhibited at a concentration of $100 \mu \mathrm{M}$ 4-ABAH (Fig. 1D). This MPO inhibition by 4ABAH resulted in a complete abrogation of the NER inhibition induced by activated PMN (Fig. 1C). In fact, Figure 1 indicates a clear inverse relation between neutrophilic MPO activity and NER capacity. Incubation of A549 cells with 4-ABAH alone did not affect NER capacity. In addition, all effects observed in the cocultures were not related to toxicity, because viability of the A549 cells was always above $95 \%$. 
A

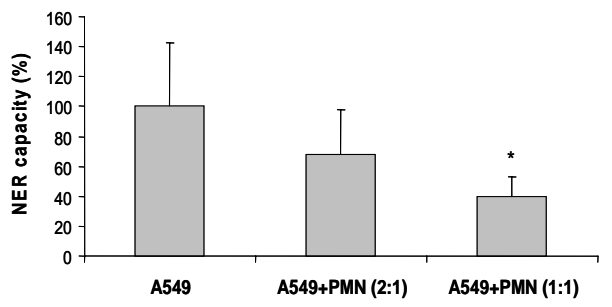

C

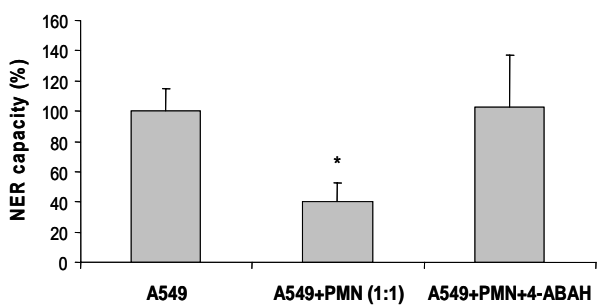

B

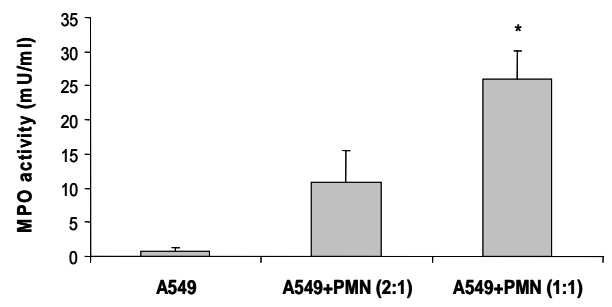

D

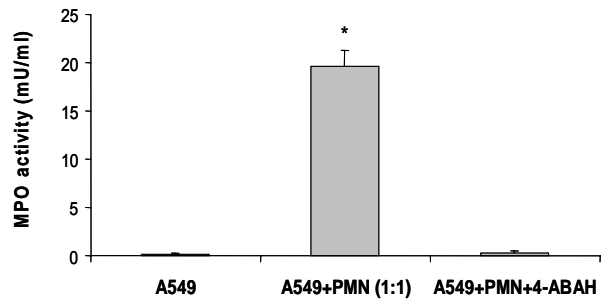

Figure 1. Effect of activated neutrophils on NER capacity in A549 cells. (A) Phenotypical NER capacity in the A549 cells coincubated for $1 \mathrm{~h}$ with PMA activated neutrophils at a 2:1 and a 1:1 ratio. ${ }^{*} P<0.05$ for 1:1 ratio vs. control ('A549'; i.e. without neutrophils, with PMA). (B) MPO activity in the supernatant of the coincubations. No MPO activity was detected in the supernatant from A549 cells only. ${ }^{*} P<0.05$, 1:1 ratio vs. control ('A549'; i.e. without neutrophils, with PMA). Data are expressed as mean \pm SEM of three independent cell cultures. (C) NER capacity in the A549 cells cocultured with neutrophils at a 1:1 ratio $\left(10 \times 10^{6}\right.$ neutrophils $\left./ \mathrm{ml}\right)$ in the presence of PMA $(100 \mathrm{ng} / \mathrm{ml})$ and $/$ or $4-A B A H(100 \mu \mathrm{M}) .{ }^{*} P<0.05$ vs. control ('A549'; i.e. without neutrophils, with PMA) and 4-ABAH condition. (D) Supernatants of the coincubations were used to assess the MPO activity (expressed as $\mathrm{mU} / \mathrm{ml}$ ). ${ }^{*} P<0.05 \mathrm{vs}$. control ('A549'; i.e. without neutrophils, with PMA) and 4-ABAH condition. Values expressed as mean \pm SEM $(n=4)$.

\section{NER inhibition by PMN is mediated by the MPO product $\mathrm{HOCl}$}

The data obtained from the coculture experiments suggest a crucial role of MPO in the NER inhibitory action of neutrophils. As MPO catalyses the formation of $\mathrm{HOCl}$, it is likely that the inhibition of NER in the cocultured epithelial cells is mediated by MPO catalysed $\mathrm{HOCl}$ formation. To investigate the role of $\mathrm{HOCl}$ as a mediator of the PMN induced NER inhibition, A549 cells were exposed to increasing concentrations of $\mathrm{HOCl}(0$ to $200 \mu \mathrm{M})$. These doses can easily be produced in vivo at sites of inflammation and also reflect the amount of $\mathrm{HOCl}$ produced in the in vitro cocultures (1:1 ratio with activated neutrophils yields $\sim 150 \mu \mathrm{M} \mathrm{HOCl}$ ).

Initially, we determined the cytotoxicity of $\mathrm{HOCl}$ in the $\mathrm{A} 549$ cells and found that the viability of the epithelial cells was more than $90 \%$ after treatment with up to 200 $\mu \mathrm{M}$ of $\mathrm{HOCl}$ during $15 \mathrm{~min}$. At higher doses, viability of the A549 cells declined to $40 \%$ at $1000 \mu \mathrm{M} \mathrm{HOCl}$ (data not shown). We observed an acute dose dependent reduction 
of NER capacity (within $15 \mathrm{~min}$ ) in the lysates obtained from A549 cells treated with nontoxic, physiological doses of $\mathrm{HOCl}(0-200 \mu \mathrm{M})$, with an inhibition up to $60-80 \%$ in cells treated with 100 to $200 \mu \mathrm{M} \mathrm{HOCl}(P<0.05)$ (Fig. 2A). The IC 50 value for $\mathrm{HOCl}$ was $52.9 \mu \mathrm{M}$, calculated using the least square fit method by fitting data points from Figure $2 A$ to the inhibition formula using the equation $I_{x}=100 e^{-k^{*}[x]}$. To investigate the persistency of this inhibiting effect, cells were incubated for 0 to $24 \mathrm{~h}$ in DMEM after an initial acute treatment $(15 \mathrm{~min})$ with $100 \mu \mathrm{M} \mathrm{HOCl}$. The data are shown in Figure $2 \mathrm{~B}$, indicating that the NER inhibitory effect of acute exposures to $\mathrm{HOCl}$ persists for up to $24 \mathrm{~h}(P<0.05)$. This effect was also observed in the absence of cytotoxicity.

A

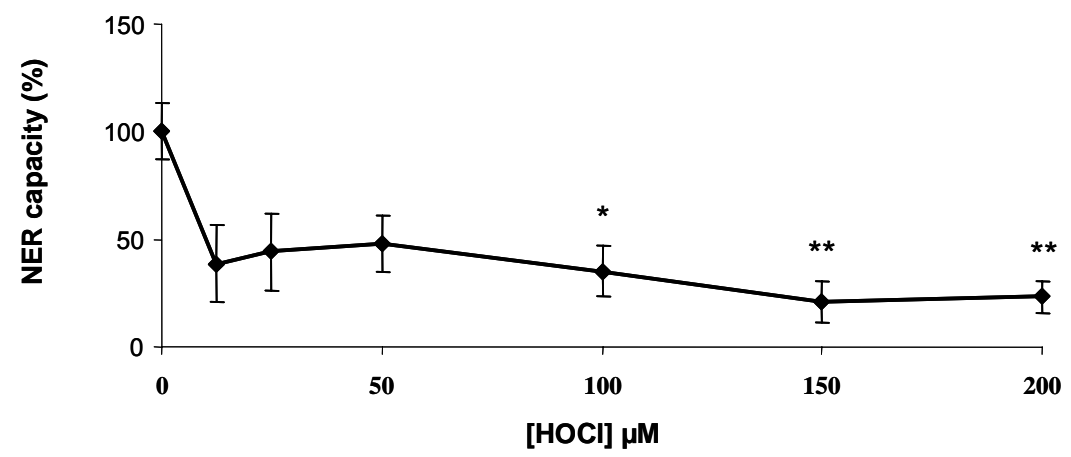

B

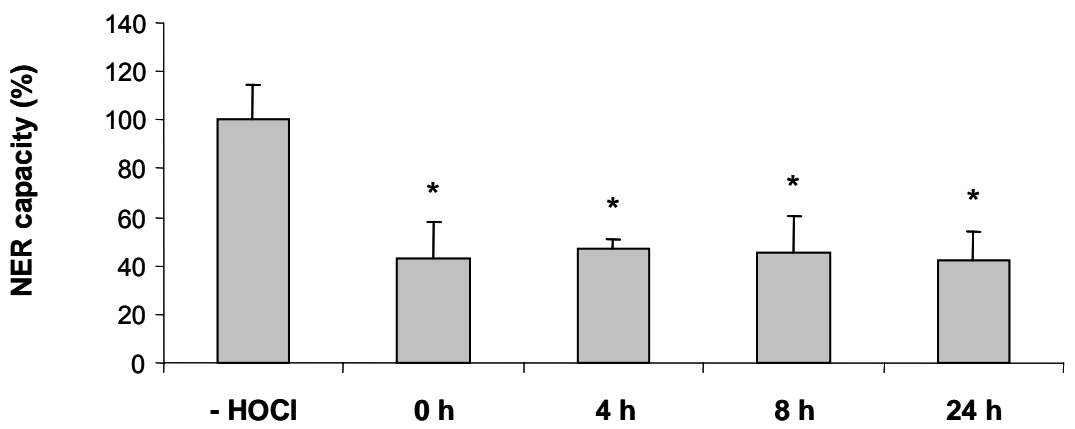

Figure 2. (A) Acute effects of $\mathrm{HOCl}$ on NER. A549 cells were treated with increasing concentrations of $\mathrm{HOCl}$ during $15 \mathrm{~min}$ at $37^{\circ} \mathrm{C}$. Data are expressed as means \pm SEM of 6 separate experiments. ${ }^{*} P<$ $0.05,{ }^{* *} P<0.01$ compared to control condition without $\mathrm{HOCl}$ treatment. (B) Persistent $\mathrm{HOCl}$ mediated inhibition of NER. A549 cells were treated with $\mathrm{HOCl}$ during $15 \mathrm{~min}$, washed and reincubated in complete medium for 0 to $24 \mathrm{~h}$. NER capacity of A549 cells was determined at the indicated time points and is expressed as percentage of control cells (mean \pm SEM, $n=4$ ). ${ }^{*} P<0.05$. 


\section{$\mathrm{HOCl}$ delays the removal of BPDE-DNA adducts in proliferating $A 549$ cells}

The results shown in Figures $2 \mathrm{~A}$ and 2B reflect the NER capacity (i.e. recognition and excision of bulky DNA adducts) of lysates isolated from epithelial cells, following exposure to $\mathrm{HOCl}$. To evaluate the implication of this effect on the kinetics of bulky DNA adduct removal in proliferating epithelial cells, cultured A549 cells were exposed to $0.1 \mu \mathrm{M}$ BPDE during $30 \mathrm{~min}$ followed by $\mathrm{HOCl}$ exposure (100 $\mu \mathrm{M}$ during $15 \mathrm{~min})$. Cells were harvested at 0 to $4 \mathrm{~h}$ postexposure, and BPDE-DNA adduct levels were analysed by ${ }^{32} \mathrm{P}$-postlabelling. $\mathrm{HOCl}$ treatment significantly delays the removal of BPDE adducts from the DNA of BPDE-treated A549 cells, further validating the NER inhibitory effect of $\mathrm{HOCl}$ (see Fig. 3).

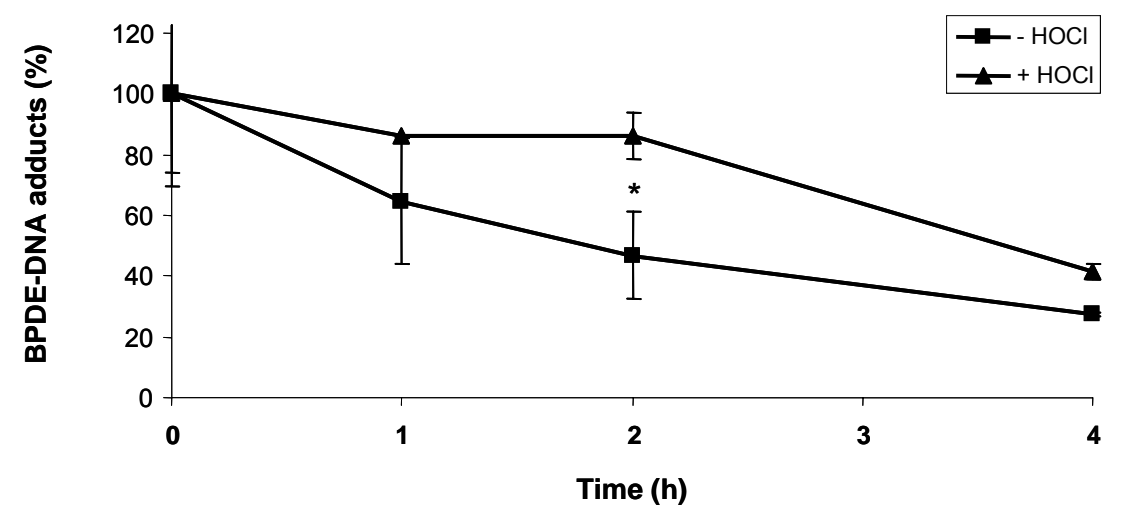

Figure 3. BPDE-DNA adduct removal in cells treated with $\mathrm{HOCl}$. A549 cells were exposed to $0.1 \mu \mathrm{M}$ BPDE followed by treatment with $100 \mu \mathrm{M} \mathrm{HOCl}$. The removal of BPDE-DNA adducts in $\mathrm{HOCl}$ treated and untreated cells was measured using ${ }^{32} \mathrm{P}$-postlabelling. The data are expressed as percentage of control incubations $\left(\mathrm{n}=3\right.$, mean \pm SEM). ${ }^{*} P<0.05$ (Mann-Whitney $U$ test)

\section{$\mathrm{HOCl}$ exposure does not affect intracellular ATP levels in A549 cells}

Exposure to $\mathrm{HOCl}$ is known to deplete acutely cellular ATP levels in a variety of target cells [38]. ATP is a crucial cofactor for the NER process. Therefore, we tested the possibility that the effects of $\mathrm{HOCl}$ on NER inhibition could be explained by a loss of epithelial cell ATP. However, after a 15 min treatment with concentrations of $\mathrm{HOCl}$ for up to $200 \mu \mathrm{M}$, no loss of ATP was observed in the A549 cells (Fig. 4). 


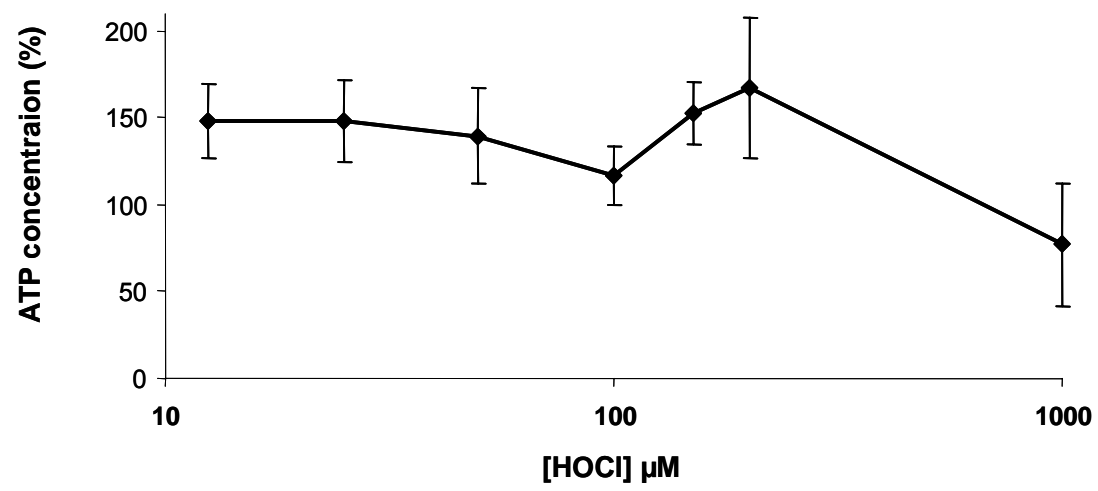

Figure 4. Effect of $\mathrm{HOCl}$ on intracellular ATP levels. $\mathrm{HOCl}(0-200 \mu \mathrm{M})$ was added to A549 cells in HBSS for a duration of $15 \mathrm{~min}$. Cells were washed in HBSS, and cellular ATP was measured by using bioluminescence. Results are expressed as percentage of control cells without $\mathrm{HOCl}$ treatment (mean \pm SEM of 5 separate experiments).

\section{Role of direct NER protein oxidation by $\mathrm{HOCl}$}

$\mathrm{OCl}$ is a potent oxidising molecule that specifically attacks proteins [11]. Direct oxidative modification of NER proteins could, therefore, explain the acute inhibitory effects of $\mathrm{HOCl}$. To study this possibility, cell extracts were isolated from unexposed A549 cells as described above and then treated in vitro with increasing concentrations of $\mathrm{HOCl}$ during $15 \mathrm{~min}$. These modified extracts were subsequently evaluated for their NER capacity (Fig. 5A). We again observed a dose dependent NER inhibition in the $\mathrm{HOCl}$ exposed extracts, but this inhibitory effect was less pronounced compared to the extracts obtained from $\mathrm{HOCl}$ treated A549 cells (cf. Fig. 2A). To further reveal direct $\mathrm{HOCl}$-protein interactions as a possible explanation for the observed effects, we analysed the formation of protein carbonyls in the A549 cells, as this is a sensitive indicator of $\mathrm{HOCl}$ induced protein oxidation in target cells [39], which is associated with disturbed enzyme function [40]. However, $\mathrm{HOCl}$ treatment did not significantly increase the protein carbonyl content in A549 cells exposed to NER inhibiting doses of $\mathrm{HOCl}$ (Fig. 5B). 
A

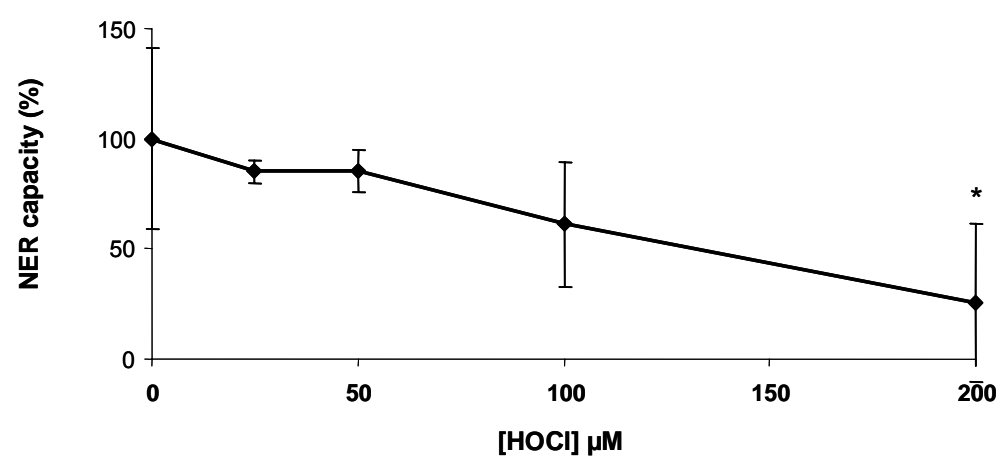

B

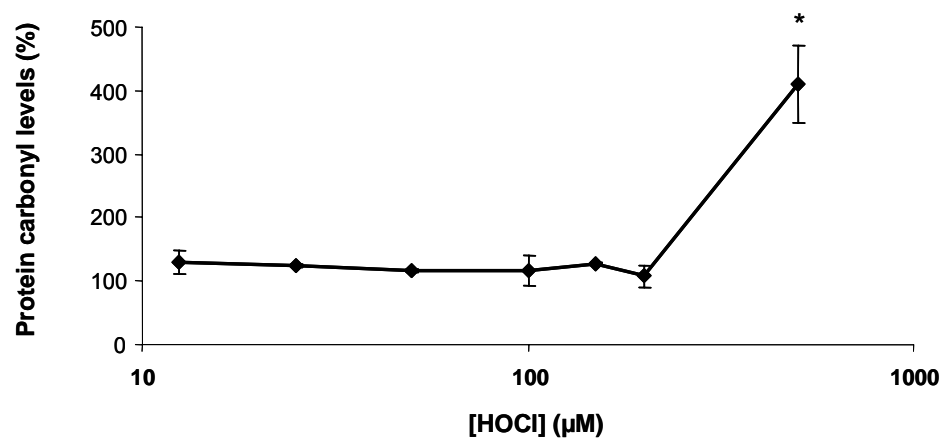

Figure 5. (A) Direct effect of $\mathrm{HOCl}$ on NER capacity of A549 lysates. Cell extracts, isolated from unexposed A549 cells, were treated with increasing concentrations of $\mathrm{HOCl}$ during $15 \mathrm{~min}$ at room temperature. Values are expressed as mean \pm SEM. ${ }^{*} P<0.05$. (B) Protein carbonyl formation in A549 cells, treated with $\mathrm{HOCl}(0-500 \mu \mathrm{M})$ during $15 \mathrm{~min}$. The data are expressed as percentage of control incubations $\left(n=4\right.$, mean \pm SEM). ${ }^{*} P<0.05$.

\section{Effect of $\mathrm{HOCl}$ on expression of NER genes}

Figure $2 \mathrm{~B}$ indicates that the NER inhibition persisted for up to $24 \mathrm{~h}$, suggesting a disturbance in gene expression and/or de-novo synthesis of repair enzymes involved in the recognition and removal of BPDE-DNA lesions. To test this possibility, direct effects of $\mathrm{HOCl}$ on the expression of NER genes were studied. The phenotypical repair assay described above reflects the capacity of lysates to perform the recognition and incision phase of the NER process. Therefore, we here focussed on genes that are crucially involved in these specific phases of NER, namely XPA and XPC for damage recognition; $E R C C-1$ and $X P F$ as 5'endonucleases and $X P G$ as 3'endonuclease. A549 cells were treated during 15 min with $100 \mu \mathrm{M} \mathrm{HOCl}$ followed by a recovery period for up to $24 \mathrm{~h}$ in complete medium. As shown in Table 2, $\mathrm{HOCl}$ was found to cause a time dependent inhibition of XPC mRNA expression, with a maximal 
effect at $8 \mathrm{~h}$ postexposure ( $50 \%)$. No further significant effects of $\mathrm{HOCl}$ were found for the expression of ERCC-1, XPA, XPF and XPG.

Table 2: Relative NER gene expression in A549 cells treated during 15 min with $100 \mu \mathrm{M} \mathrm{HOCl}$ followed by incubation in normal medium for 0 to $24 \mathrm{~h}$

\begin{tabular}{lcccc}
\hline \multicolumn{1}{c}{ Time } & $\mathbf{0 ~ h}$ & $\mathbf{4 h}$ & $\mathbf{8} \mathbf{h}$ & $\mathbf{2 4} \mathbf{h}$ \\
\hline XPC & $0.98 \pm 0.13$ & $0.73 \pm 0.13$ & $0.47 \pm 0.07 *$ & $0.68 \pm 0.08$ \\
XPA & $1.17 \pm 0.18$ & $1.69 \pm 0.18$ & $1.19 \pm 0.41$ & $1.86 \pm 0.28$ \\
ERCC-1 & $1.10 \pm 0.03$ & $1.01 \pm 0.03$ & $0.99 \pm 0.05$ & $0.92 \pm 0.03$ \\
XPF & $0.97 \pm 0.10$ & $1.03 \pm 0.10$ & $1.01 \pm 0.08$ & $0.99 \pm 0.06$ \\
XPG & $1.29 \pm 0.15$ & $0.83 \pm 0.15$ & $0.67 \pm 0.19$ & $0.97 \pm 0.14$ \\
\hline
\end{tabular}

Data are presented as mean \pm SEM of 4 independent experiments.

${ }^{*} P<0.05$ vs. control condition without $\mathrm{HOCl}$ treatment $(=1.00$ fold $)$.

\section{Discussion}

It is suggested that the influx of inflammatory polymorphonuclear neutrophils into the airways contributes to lung tumour development [6]. In this study, we demonstrated that activated neutrophils are potent inhibitors of the nucleotide excision repair capacity of lung target cells, most likely mediated by the formation of MPO catalysed $\mathrm{HOCl}$. Considering the widespread exposure to inhaled DNA adduct forming carcinogens, such as $\mathrm{PAH}$, as well as the simultaneous presence of neutrophils in the inflamed lung, we propose that this neutrophil induced reduction of NER may be a significant contributory factor in the development of inflammation related pulmonary mutagenesis and carcinogenesis.

MPO consumes up to $40-70 \%$ of neutrophil derived $\mathrm{H}_{2} \mathrm{O}_{2}$ to generate $\mathrm{HOCl}$ [7]. $\mathrm{HOCl}$ is a relatively stable and membrane diffusible molecule which can pass through subcellular compartments and, presumably, can reach the cell nucleus [10]. As such, it has the potential to interact with many different cellular proteins, including DNA repair proteins. We indeed demonstrated that neutrophil induced inhibition of NER is mediated by the MPO product $\mathrm{HOCl}$, by using coincubations in the presence of the MPO inhibitor 4-ABAH as well as by treating A549 cells with the MPO derived product $\mathrm{HOCl}$. This effect was persistent for up to $24 \mathrm{~h}$ and observed at physiologically relevant concentrations of $\mathrm{HOCl}$, as $\mathrm{HOCl}$ levels in the vicinity of activated neutrophils are at or above $100 \mu \mathrm{M}$ [8]. In general, these data are in line with other studies showing that NER inhibition can be caused by oxidants, such as trans-4-hydroxy-nonenal (4$\mathrm{HNE}$ ) [25] and nitric oxide [27]. Moreover, our data are in accordance with studies by Pero et al., who described an $\mathrm{HOCl}$ induced inhibition of unscheduled DNA synthesis (UDS), which can be considered as an indicator of nucleotide excision repair [15]. However, it needs to be stressed that the latter observations were in contrast with other studies that reported an induction of UDS by activated neutrophils, with no apparent role for $\mathrm{HOCl}$ [41].

The present study showed an $\mathrm{HOCl}$-induced inhibition of the NER capacity after a 15 min during treatment. In order to find an explanation for this profound and acute effect, we initially focussed on the possible role of $\mathrm{HOCl}$ in depleting ATP in lung epithelial cells [38]. In the initial steps of the NER pathway, ATP is a crucial cofactor, 
facilitating the helicase activity of XPB and XPD [24]. Nevertheless, we did not find any loss of cellular ATP in A549 cells treated with physiological NER inhibiting doses of $\mathrm{HOCl}(0-200 \mu \mathrm{M})$. This is in contrast with other studies showing a significant depletion of ATP at similar $\mathrm{HOCl}$ doses in various other cell types [42, 43] and is most likely explained by the relatively high level of antioxidant protection of the A549 cells compared with other (lung) epithelial cell lines (unpublished own observations).

Proteins are the major molecular target for $\mathrm{HOCl}$. Of primary importance among the $\mathrm{HOCl}$ mediated protein modifications are tyrosine chlorination, formation of chloramines and carbonyls [39] and in some cases crosslinking [12]. This study focused on carbonyls as a biomarker of oxidative $\mathrm{HOCl}$ attacks on proteins. In the inflamed lung, for instance, a high correlation between protein carbonyl concentration and MPO activity was observed [44]. Carbonyl groups represent an irreversible protein modification, often leading to the inactivation of these proteins [13, 14, 40]. We, therefore, hypothesised that a loss of function of NER enzymes, originating from direct $\mathrm{HOCl}$ protein interactions, is a possible mechanism explaining the observed acute $\mathrm{HOCl}$ induced inhibition of NER. However, less effective NER inhibition was observed in direct $\mathrm{HOCl}$ treated cell lysates compared to lysates obtained from $\mathrm{HOCl}$ exposed whole A549 cells. In addition, we were unable to show protein carbonyls in the A549 cells treated with NER inhibiting doses of $\mathrm{HOCl}$. Together, this would suggest that direct oxidative inactivation of repair proteins may only partly explain the acute inhibitory effects of $\mathrm{HOCl}$, and indicates that other intracellular factors, for instance the formation of protein-DNA crosslinks, may be involved in mediating $\mathrm{HOCl}$ induced inhibition of NER in the target cells [45].

We demonstrated that $\mathrm{HOCl}$ induced repression of NER capacity persisted for up to $24 \mathrm{~h}$. As a possible explanation for this long-term effect, we addressed the effect of $\mathrm{HOCl}$ on the transcription of relevant NER genes. Our repair assay is based on the capacity of cell extracts to perform the initial steps of NER, i.e. damage recognition and incision of DNA containing BPDE adducts. Thus, we only focused on the expression of genes coding for crucial enzymes involved in these specific phases of the NER process, namely ERCC-1, XPA, XPC, XPF and XPG. Our data showed a significant suppression of XPC gene expression upon incubation with $\mathrm{HOCl}$ XPC is crucially involved in damage recognition [24]. Therefore, although additional studies are needed to assess the significance of this finding, our data indicate that $\mathrm{HOCl}$ exposure may affect the ability of cells to recognise lesion containing DNA.

NER is the most important repair pathway to remove large helix distorting DNA adducts that are produced upon inhalation of chemical carcinogens, such as PAH [23, 24]. The formation of these promutagenic PAH-DNA adducts has been implicated as a causal process in lung cancer development in smokers [46]. As studies with NER deficient mice showed that effective DNA repair is crucial to prevent the carcinogenic effects of PAH induced DNA damage [47], it can be speculated that processes leading to the suppression of the relevant DNA repair pathways may have a detrimental effect on the cancer susceptibility of individuals exposed to such chemicals. Epidemiological studies have indeed shown that polymorphisms in NER genes, leading to a (hypothetically) decreased NER capacity, are associated with increased risk of lung 
carcinogenesis $[48,49]$. Our present results indicate that neutrophilic inflammation, by causing inhibition of NER, might be another important factor determining susceptibility to cancer. For instance, our findings could provide an additional explanation for the association between MPO polymorphisms and risk of pulmonary DNA adduct formation and carcinogenesis in $\mathrm{PAH}$ exposed subjects [17, 21]. Evidently, although the present paper is focused on the lung, it needs to be emphasised that our findings may also be of importance for other organs where bulky DNA adduct forming agents and neutrophils are simultaneously present.

In conclusion, in this study we demonstrated that neutrophils are potent inhibitors of NER in human pulmonary epithelial cells. Previous studies have already shown that neutrophils, by releasing MPO, are involved in the carcinogenic process by promoting the activation of precarcinogens, such as $B[a] P$ into DNA damaging metabolites. In the present study, we extended these observations by showing that MPO, via generation of $\mathrm{HOCl}$, inhibits the repair of such promutagenic DNA adducts. We propose that these two detrimental effects of activated PMN at sites of inflammation may contribute synergistically to human inflammation related carcinogenesis. Therefore, our observations may provide a further explanation for the observed association between neutrophilic inflammation, MPO and lung cancer risk.

\section{Acknowledgements}

The authors thank Yonca Güngör for linguistically reviewing the manuscript. We are grateful for financial support from the Province of Limburg, the Netherlands. Part of the studies was supported by the European Network of Excellence (NoE) "Environmental cancer, nutrition and individual susceptibility" (ECNIS), sixth Framework programme (FP6), FOOD-CT-2005-513943. A.M. Knaapen is supported by a postdoctoral fellowship from the Netherlands Organisation for Scientific Research (NWO, VENI-grant 916.46.092). 


\section{References}

1. Coussens, L.M. and Werb, Z. (2002) Inflammation and cancer. Nature, 420, 860-867.

2. Schottenfeld, D. and Beebe-Dimmer, J. (2006) Chronic inflammation: a common and important factor in the pathogenesis of neoplasia. CA Cancer J Clin, 56, 69-83.

3. Knaapen, A.M., Borm, P.J., Albrecht, C. and Schins, R.P. (2004) Inhaled particles and lung cancer. Part A: Mechanisms. Int J Cancer, 109, 799-809.

4. Noguera, A., Batle, S., Miralles, C., Iglesias, J., Busquets, X., MacNee, W. and Agusti, A.G. (2001) Enhanced neutrophil response in chronic obstructive pulmonary disease. Thorax, 56, 432437.

5. Hunninghake, G.W., Gadek, J.E., Lawley, T.J. and Crystal, R.G. (1981) Mechanisms of neutrophil accumulation in the lungs of patients with idiopathic pulmonary fibrosis. J Clin Invest, 68, 259269.

6. Knaapen, A.M., Gungor, N., Schins, R.P., Borm, P.J. and Van Schooten, F.J. (2006) Neutrophils and respiratory tract DNA damage and mutagenesis: a review. Mutagenesis, 21, 225-236.

7. Klebanoff, S.J. (1999) Myeloperoxidase. Proc Assoc Am Physicians, 111, 383-389.

8. Foote, C.S., Goyne, T.E. and Lehrer, R.I. (1983) Assessment of chlorination by human neutrophils. Nature, 301, 715-716.

9. Fliss, H. (1988) Oxidation of proteins in rat heart and lungs by polymorphonuclear leukocyte oxidants. Mol Cell Biochem, 84, 177-188.

10. Spencer, J.P., Whiteman, M., Jenner, A. and Halliwell, B. (2000) Nitrite-induced deamination and hypochlorite-induced oxidation of DNA in intact human respiratory tract epithelial cells. Free Radic Biol Med, 28, 1039-1050.

11. Cochrane, C.G. (1991) Cellular injury by oxidants. Am J Med, 91, 23S-30S.

12. Pattison, D.I. and Davies, M.J. (2001) Absolute rate constants for the reaction of hypochlorous acid with protein side chains and peptide bonds. Chem Res Toxicol, 14, 1453-1464.

13. den Hartog, G.J., Vegt, E., van der Vijgh, W.J., Haenen, G.R. and Bast, A. (2002) Hypochlorous acid is a potent inhibitor of acetylcholinesterase. Toxicol Appl Pharmacol, 181, 228-232.

14. van Haaften, R.I., den Hartog, G.J., Evelo, C.T., Haenen, G.R. and Bast, A. (2001) Hypochlorous acid is a potent inhibitor of GST P1-1. Chem Biol Interact, 138, 77-83.

15. Pero, R.W., Sheng, Y., Olsson, A., Bryngelsson, C. and Lund-Pero, M. (1996) Hypochlorous acid/N-chloramines are naturally produced DNA repair inhibitors. Carcinogenesis, 17, 13-18.

16. Van Rensburg, C.E., Van Staden, A.M. and Anderson, R. (1991) Inactivation of poly (ADP-ribose) polymerase by hypochlorous acid. Free Radic Biol Med, 11, 285-291.

17. Dally, H., Gassner, K., Jager, B., Schmezer, P., Spiegelhalder, B., Edler, L., Drings, P., Dienemann, H., Schulz, V., Kayser, K., Bartsch, H. and Risch, A. (2002) Myeloperoxidase (MPO) genotype and lung cancer histologic types: the MPO -463 A allele is associated with reduced risk for small cell lung cancer in smokers. Int J Cancer, 102, 530-535.

18. Mallet, W.G., Mosebrook, D.R. and Trush, M.A. (1991) Activation of (+-)-trans-7,8-dihydroxy-7,8dihydrobenzo[a]pyrene to diolepoxides by human polymorphonuclear leukocytes or myeloperoxidase. Carcinogenesis, 12, 521-524.

19. Petruska, J.M., Mosebrook, D.R., Jakab, G.J. and Trush, M.A. (1992) Myeloperoxidase-enhanced formation of (+-)-trans-7,8-dihydroxy-7,8-dihydrobenzo[a]pyrene-DNA adducts in lung tissue in vitro: a role of pulmonary inflammation in the bioactivation of a procarcinogen. Carcinogenesis, 13, 1075-1081.

20. Borm, P.J., Knaapen, A.M., Schins, R.P., Godschalk, R.W. and Schooten, F.J. (1997) Neutrophils amplify the formation of DNA adducts by benzo[a]pyrene in lung target cells. Environ Health Perspect, 105 Suppl 5, 1089-1093.

21. Van Schooten, F.J., Boots, A.W., Knaapen, A.M., Godschalk, R.W., Maas, L.M., Borm, P.J., Drent, M. and Jacobs, J.A. (2004) Myeloperoxidase (MPO) -463G->A reduces MPO activity and DNA adduct levels in bronchoalveolar lavages of smokers. Cancer Epidemiol Biomarkers Prev, 13, 828-833. 
22. Luch, A. (2005) Nature and nurture - lessons from chemical carcinogenesis. Nat Rev Cancer, $\mathbf{5}$, 113-125.

23. Lindahl, T. and Wood, R.D. (1999) Quality control by DNA repair. Science, 286, 1897-1905.

24. Gillet, L.C. and Scharer, O.D. (2006) Molecular mechanisms of mammalian global genome nucleotide excision repair. Chem Rev, 106, 253-276.

25. Feng, Z., Hu, W. and Tang, M.S. (2004) Trans-4-hydroxy-2-nonenal inhibits nucleotide excision repair in human cells: a possible mechanism for lipid peroxidation-induced carcinogenesis. Proc Natl Acad Sci U S A, 101, 8598-8602.

26. Feng, Z., Hu, W., Marnett, L.J. and Tang, M.S. (2006) Malondialdehyde, a major endogenous lipid peroxidation product, sensitizes human cells to UV- and BPDE-induced killing and mutagenesis through inhibition of nucleotide excision repair. Mutat Res,

27. Chien, Y.H., Bau, D.T. and Jan, K.Y. (2004) Nitric oxide inhibits DNA-adduct excision in nucleotide excision repair. Free Radic Biol Med, 36, 1011-1017.

28. Knaapen, A.M., Seiler, F., Schilderman, P.A., Nehls, P., Bruch, J., Schins, R.P. and Borm, P.J. $(1999)$ Neutrophils cause oxidative DNA damage in alveolar epithelial cells. Free Radic Biol Med, 27, 234-240.

29. Kettle, A.J., Gedye, C.A., Hampton, M.B. and Winterbourn, C.C. (1995) Inhibition of myeloperoxidase by benzoic acid hydrazides. Biochem J, 308 ( Pt 2), 559-563.

30. Klebanoff, S.J., Waltersdorph, A.M. and Rosen, H. (1984) Antimicrobial activity of myeloperoxidase. Methods Enzymol, 105, 399-403.

31. Langie, S.A., Knaapen, A.M., Brauers, K.J., van Berlo, D., van Schooten, F.J. and Godschalk, R.W. (2006) Development and validation of a modified comet assay to phenotypically assess nucleotide excision repair. Mutagenesis, 21, 153-158.

32. Collins, A.R., Dusinska, M., Horvathova, E., Munro, E., Savio, M. and Stetina, R. (2001) Interindividual differences in repair of DNA base oxidation, measured in vitro with the comet assay. Mutagenesis, 16, 297-301.

33. Redaelli, A., Magrassi, R., Bonassi, S., Abbondandolo, A. and Frosina, G. (1998) AP endonuclease activity in humans: development of a simple assay and analysis of ten normal individuals. Teratog Carcinog Mutagen, 18, 17-26.

34. Knaapen, A.M., Schins, R.P., Borm, P.J. and van Schooten, F.J. (2005) Nitrite enhances neutrophil-induced DNA strand breakage in pulmonary epithelial cells by inhibition of myeloperoxidase. Carcinogenesis, 26, 1642-1648.

35. Reddy, M.V. and Randerath, K. (1986) Nuclease P1-mediated enhancement of sensitivity of 32Ppostlabeling test for structurally diverse DNA adducts. Carcinogenesis, 7, 1543-1551.

36. Godschalk, R.W., Maas, L.M., Van Zandwijk, N., van 't Veer, L.J., Breedijk, A., Borm, P.J., Verhaert, J., Kleinjans, J.C. and van Schooten, F.J. (1998) Differences in aromatic-DNA adduct levels between alveolar macrophages and subpopulations of white blood cells from smokers. Carcinogenesis, 19, 819-825.

37. Livak, K.J. and Schmittgen, T.D. (2001) Analysis of relative gene expression data using real-time quantitative PCR and the 2(-Delta Delta C(T)) Method. Methods, 25, 402-408.

38. Dallegri, F., Goretti, R., Ballestrero, A., Ottonello, L. and Patrone, F. (1988) Neutrophil-induced depletion of adenosine triphosphate in target cells: evidence for a hypochlorous acid-mediated process. J Lab Clin Med, 112, 765-772.

39. Winterbourn, C.C. and Kettle, A.J. (2000) Biomarkers of myeloperoxidase-derived hypochlorous acid. Free Radic Biol Med, 29, 403-409.

40. Dalle-Donne, I., Aldini, G., Carini, M., Colombo, R., Rossi, R. and Milzani, A. (2006) Protein carbonylation, cellular dysfunction, and disease progression. J Cell Mol Med, 10, 389-406.

41. Janz, S. and Shacter, E. (1993) Activated murine neutrophils induce unscheduled DNA synthesis in B lymphocytes. Mutat Res, 293, 173-186.

42. Pullar, J.M., Winterbourn, C.C. and Vissers, M.C. (1999) Loss of GSH and thiol enzymes in endothelial cells exposed to sublethal concentrations of hypochlorous acid. Am J Physiol, 277, H1505-1512. 


\section{Chapter 4}

43. Whiteman, M., Hooper, D.C., Scott, G.S., Koprowski, H. and Halliwell, B. (2002) Inhibition of hypochlorous acid-induced cellular toxicity by nitrite. Proc Natl Acad Sci U S A, 99, 12061-12066.

44. Buss, I.H., Darlow, B.A. and Winterbourn, C.C. (2000) Elevated protein carbonyls and lipid peroxidation products correlating with myeloperoxidase in tracheal aspirates from premature infants. Pediatr Res, 47, 640-645.

45. Kulcharyk, P.A. and Heinecke, J.W. (2001) Hypochlorous acid produced by the myeloperoxidase system of human phagocytes induces covalent cross-links between DNA and protein. Biochemistry, 40, 3648-3656.

46. Denissenko, M.F., Pao, A., Tang, M. and Pfeifer, G.P. (1996) Preferential formation of benzo[a]pyrene adducts at lung cancer mutational hotspots in P53. Science, 274, 430-432.

47. Ide, F., lida, N., Nakatsuru, Y., Oda, H., Tanaka, K. and Ishikawa, T. (2000) Mice deficient in the nucleotide excision repair gene XPA have elevated sensitivity to benzo[a]pyrene induction of lung tumors. Carcinogenesis, 21, 1263-1265.

48. Wu, X., Zhao, H., Wei, Q., Amos, C.I., Zhang, K., Guo, Z., Qiao, Y., Hong, W.K. and Spitz, M.R. (2003) XPA polymorphism associated with reduced lung cancer risk and a modulating effect on nucleotide excision repair capacity. Carcinogenesis, 24, 505-509.

49. Zienolddiny, S., Campa, D., Lind, H., Ryberg, D., Skaug, V., Stangeland, L., Phillips, D.H., Canzian, F. and Haugen, A. (2006) Polymorphisms of DNA repair genes and risk of non-small cell lung cancer. Carcinogenesis, 27, 560-567. 




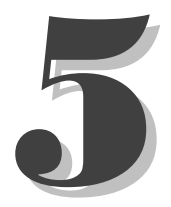

\title{
Lumg inflammation is
}

\section{associated with reduced}

\author{
pulmonary nucleotide
} excision repair in vivo

Mutagenesis, in press.

\author{
Güngör N \\ Haegens A \\ Knaapen AM \\ Godschalk RWL \\ Chiu RK \\ Wouters EF \\ van Schooten FJ
}




\begin{abstract}
Chronic pulmonary inflammation is associated with increased lung cancer risk, but the underlying process remains unknown. Recently, we showed that activated neutrophils inhibit nucleotide excision repair (NER) in pulmonary epithelial cells in vitro via the release of myeloperoxidase (MPO). To evaluate the effect of neutrophils on NER in vivo, mice were intratracheally instilled with lipopolysaccharide (LPS), causing acute lung inflammation and associated neutrophil influx into the airways. Three days post exposure, phenotypical NER capacity was assessed in lung tissue. LPS exposure inhibited pulmonary NER by approximately $50 \%$. This finding was corroborated by downregulation of the NER associated genes Xpa and Xpf. To further elicit the role of neutrophils and MPO in this process, we utilised MPO deficient mice as well as mice in which circulating neutrophils were depleted by antibody treatment. LPS induced inhibition of pulmonary NER was not affected by either $\mathrm{Mpo}^{-/-}$nor by depletion of circulating neutrophils. This contrasts with our previous in vitro observations, suggesting that inhibition of pulmonary NER following acute dosing with LPS is not fully mediated by neutrophils and/or MPO. In conclusion, these data show that LPS induced pulmonary inflammation is associated with a reduction of NER function in the mouse lung.
\end{abstract}




\section{Introduction}

Chronic inhalation of combustion derived particles (e.g. cigarette smoke) is a major determinant in the development of lung cancer, one of the most lethal types of cancer worldwide. A generally accepted explanation for this relationship is the ability of such particles to transport chemical carcinogens into the lung. However, another important characteristic is that the particles elicit an influx of polymorphonuclear neutrophils (PMN) into the lung, which is most evident in smokers who developed chronic obstructive pulmonary disease (COPD) [1]. COPD encompasses a local chronic inflammation in the airways [2, 3], dominated by invasion of neutrophils, macrophages and $\mathrm{T}$ cells [4]. Interestingly, smokers diagnosed with COPD have an increased risk of developing lung cancer (3-10 fold) even after having quit smoking [5, 6]. The prominent presence of neutrophils associated with COPD [4, 7] suggests a significant role of the ongoing neutrophilic inflammation in this carcinogenic response [8].

Neutrophils have been implicated in (pulmonary) carcinogenicity by their genotoxic capacity. This is thought to occur through the release of mutagenic reactive oxygen species (ROS) leading to oxidative DNA damage, as well as by promoting the metabolic activation of environmental chemical carcinogens via the enzyme myeloperoxidase (MPO), resulting in promutagenic DNA adducts [9]. Moreover, we have shown recently that neutrophils, via the MPO catalysed formation of hypochlorous acid $(\mathrm{HOCl})$, are potent inhibitors of the nucleotide excision repair (NER) pathway in cultured pulmonary epithelial cells, causing a delayed removal of promutagenic bulky DNA adducts [10].

To date, evidence of a role of neutrophils in pulmonary carcinogenicity has been largely derived from in vitro studies using cocultures of neutrophils and pulmonary epithelial target cells to study neutrophil induced genotoxicity [9]. Evidence from in vivo studies is, however, primarily circumstantial and additional animal studies are necessary to substantiate causality. The aim of the present study was to assess the in vivo effect of neutrophilic inflammation on NER in the mouse lung. Therefore, mice were intratracheally instilled with LPS, followed by the assessment of neutrophil infiltration, MPO activity and NER capacity in pulmonary tissues. In order to characterise the role of MPO, mice deficient in this enzyme were also subjected to LPS and similar analyses were performed. Furthermore, neutrophils were depleted by treatment with neutrophil specific antibodies to provide direct evidence for the relation between neutrophils and NER inhibition in vivo. Our results suggest that LPS induced acute lung inflammation is associated with a suppression of pulmonary NER, which is not mediated by neutrophil influx and the subsequent release of the enzyme MPO. 


\section{Materials and methods}

\section{Animals}

Male Wt C57BI6 mice ( 12 weeks old) were obtained from Charles River Breeding Laboratories (Heidelberg, Germany). $\mathrm{Mpo}^{-/}$mice were generated by Y. Aratani [11] and bred into the C57BI6 background. Mice were housed individually in standard laboratory cages and allowed food and water ad libitum throughout the experiments. The studies were carried out in accordance with an approved protocol by the Institutional Animal Care Committee of Maastricht University.

\section{LPS induced acute lung inflammation mouse model}

Mice were treated with LPS (Escherichia Coli, serotype O55:B5, Sigma, St.Louis, MO, USA) by intratracheal instillation to induce an acute pulmonary inflammation. The dose of LPS was $20 \mu \mathrm{g} /$ instillation/mouse. No signs of overall toxic effects with the employed dose of LPS were histopathologically observed in the trachea, airways and lungs, either in this study or those executed by others [12]. Intratracheal instillation was performed by a nonsurgical technique under anaesthesia as previously described [12]. Sham mice were instilled with sterile $0.9 \% \mathrm{NaCl}$.

Since a previous study [13] demonstrated that local LPS challenge in Wt mice results in a time dependent neutrophil accumulation peaking at day 3 , Wt mice $(n=6)$ were sacrificed 3 days post exposure by $115 \mathrm{mg} / \mathrm{kg}$ sodium pentobarbital (Ceva Sante Animale, Maassluis, the Netherlands). After thoracotomy, the lungs were prepared for histological evaluation (as described below) to characterise the LPS induced inflammatory cell influx. In satellite Wt mice $(n=10)$, bronchoalveolar lavage (BAL) ( $3 \mathrm{x}$ with $1 \mathrm{ml}$ sterile $0.9 \% \mathrm{NaCl}$ ) was performed 3 days post instillation to remove as much as possible inflammatory cells from the airways. After centrifugation at 1,500 rpm during $10 \mathrm{~min}$ at $4^{\circ} \mathrm{C}$, the cell-free BAL fluid (BALF) was stored at $-80^{\circ} \mathrm{C}$ for MPO activity measurement. Lavaged lungs were snapfrozen and pulverised using a mortar and pestle. The pulverised lung tissue was stored at $-80^{\circ} \mathrm{C}$ for RNA isolation and protein extraction for assessment of NER capacity.

To characterise the role of MPO, $\mathrm{Mpo}^{-/-}$mice were dosed with LPS, followed by histological evaluation of inflammatory cell influx $(n=6)$ and BAL $(n=5)$ with subsequent similar analyses on lung tissue as in Wt animals.

Furthermore, to study the direct relation between neutrophils and NER inhibition, depletion of circulating neutrophils in Wt mice $(n=5)$ was achieved by intraperitoneal injection of $0.5 \mathrm{mg}$ of the monoclonal rat anti-mouse neutrophil antibody NIMP-R14 (Hbt, Maastricht, the Netherlands), 24 hours before i.t. LPS instillation. NIMP-R14 has been shown to selectively deplete mouse neutrophils in vivo for up to 6 days $[14,15]$. IgG (eBioscience, San Diego, USA) was used as control mAb in the sham group ( $\mathrm{n}=$ 5). Again, 3 days after instillation, mice were sacrificed, and lungs were lavaged and isolated as described above. 


\section{Histopathology and quantification of cellular influx in lung tissue}

After thoracotomy, lungs were inflated through the trachea with $10 \%$ zinc buffered formalin ( $\mathrm{pH} \mathrm{5.5)}$ at a pressure of $20 \mathrm{~cm} \mathrm{H}_{2} \mathrm{O}$ and subsequently placed in $10 \%$ zinc buffered formalin during 24 hours for fixation of the tissue. After paraffin embedding, lung sections were cut at a thickness of $4 \mu \mathrm{m}$ and mounted on slides. H\&E stained sections were used to quantify infiltration of neutrophils and macrophages into the lungs. At a magnification of 200x, random fields were selected and the number of infiltrated, still intact cells was counted. At least 5 fields per section were analysed.

\section{MPO activity measurement}

MPO packaged in neutrophils will have no effect on NER in pulmonary epithelial tissue, because MPO must be released extracellularly during the oxidative burst of neutrophils. Therefore, extracellular MPO activity was measured in cell-free BALF, as described by Klebanoff et al. [16], and is indicative for the presence of activated neutrophils in the lung [17].

\section{Protein extraction}

The preparation of lung tissue protein extracts for NER capacity measurement and Western Blot analysis is based on the method developed by Redaelli et al. [18]. Pulverised frozen lung tissue was resuspended in lysis buffer (45 mM HEPES, $0.4 \mathrm{mM}$ $\mathrm{KCl}, 1 \mathrm{mM}$ EDTA, $0.1 \mathrm{mM}$ DTT, 10\% glycerol, adjusted to $\mathrm{pH} 7.8$ using $\mathrm{KOH}$ ), snapfrozen and thawed again to complete lysis by adding $1 \%$ Triton $\mathrm{X}-100$. The lysate was centrifuged at $11,000 \mathrm{rpm}$ for $5 \mathrm{~min}$ at $4^{\circ} \mathrm{C}$. Protein concentrations were determined by the DC-protein assay KT (BIORAD, Veenendaal, the Netherlands).

\section{Measurement of NER capacity}

To phenotypically assess the NER capacity in lung tissue, we applied a modified comet assay recently developed and validated in our laboratory [19]. This assay measures the ability of NER related enzymes, present in the prepared lung tissue extracts $(250 \mu \mathrm{g} / \mathrm{ml})$, to detect and incise benzo[a]pyrene-diolepoxide (BPDE)-DNA adducts in substrate DNA. The increase in DNA breaks, leading to increased tail intensities, is indicative for the NER capacity of the tissue extracts. After subtracting background levels from all data, the final repair capacity was calculated as previously reported by Langie et al. [19].

\section{NER gene expression analysis by quantitative PCR}

Total RNA was isolated and purified from snapfrozen, pulverised lung tissue (same tissue that was used for the NER capacity measurement), using the RNeasy ${ }^{\circledR}$ Mini Kit (Qiagen Westburg, Leusden, the Netherlands) in combination with a DNase treatment, according to the manufacturer's instructions. First strand cDNA was generated, using the iScript ${ }^{\mathrm{TM}}$ cDNA synthesis kit protocol (BIO-RAD) on $1 \mu \mathrm{g}$ total RNA. Aliquots were used for quantitative PCR on the BioRad MyiQ iCycler Single Colour quantitative 
detection system, using iQ SYBR Green Supermix. Reactions were initiated for 3 min at $95^{\circ} \mathrm{C}$, followed by 40 cycles of $15 \mathrm{sec}$ at $95^{\circ} \mathrm{C}$ and $45 \mathrm{sec}$ at $60^{\circ} \mathrm{C}$. After each run, a melting curve was analysed starting at $60^{\circ} \mathrm{C}$ with stepwise temperature elevations of $0.5^{\circ} \mathrm{C}$ every $10 \mathrm{sec}$ to check for non-specific products. The following NER genes were tested: Xpa, Xpc, Ercc-1, Xpf and Xpg, using primers purchased from Operon (Leiden, the Netherlands) (see Table 1 for primer sequences). Data were analysed, using the MyiQ Software system (BIO-RAD) and were expressed as relative gene expression, using the $2^{-\Delta \Delta \mathrm{Ct}}$ method and employing Hprt as housekeeping gene [20].

Table 1: Primer sequences used for Real Time RT-PCR

\begin{tabular}{lll}
\hline mRNA of interest & \multicolumn{2}{l}{ Sequences $\mathbf{5} \rightarrow \mathbf{3}^{\prime}$} \\
\hline Hprt & Sense: & AAGACTTGCTCGAGATGTCATGAA \\
& Antisense: & AAAGAACTTATAGCCCCCCTTGA \\
Ercc-1 & Sense: & TGGAGACCTACAAGGCGTATGA \\
& Antisense: & GGCCCGTGATAGGAAGTTCTG \\
Xpa & Sense: & CCAAAGGTGGCTTCATTTTAGAA \\
& Antisense: & CATGACGGGCCCTGGTT \\
Xpc & Sense: & TGAAGGCGGTGGAGATTGA \\
& Antisense: & CTCCATCTTTATCTTCTCACTTCTTTCC \\
Xpf (Ercc-4) & Sense: & TGTCACAACCCGTCACTTGAA \\
& Antisense: & GGCGGATTGTCTTGTCGAAT \\
Xpg (Ercc-5) & Sense: & TGCCTTCTCTTTGCCAAGGT \\
& Antisense: & TTCGTATCCGCCCTATTTTTGT \\
\hline
\end{tabular}

\section{Determination of XPA levels by Western Blot Analysis}

XPA protein abundance was evaluated in the lung protein extracts (which were also used for the NER capacity measurement) by Western Blotting. Samples were diluted 1:4 in Laemmli sample buffer and boiled for $5 \mathrm{~min}$ at $95^{\circ} \mathrm{C}$. Equal amounts of protein (40 $\mathrm{\mu l} /$ well) were loaded and separated on a polyacrylamide gel (12\%) (MiniPROTEAN 3 System (BIO-RAD)). Subsequently, proteins were transferred to Hybond-C-membrane (Amersham Pharmacia Biotech, Diegem, Belgium) and blocked for 1 hour with $5 \%$ skim milk powder in PBS/0.1\% Tween-20. Nitrocellulose blots were washed (PBS/0.1\% Tween-20), followed by overnight incubation with the polyclonal anti-XPA antibody (XPA [FL-273]); sc-853, Santa Cruz Biotechnology Inc., Santa Cruz, CA, USA). After washing, blots were incubated for 1 hour with a goat anti-rabbit horseradish peroxidase conjugated IgG (Dako Cytomation, Glostrup, Denmark) and visualised by means of enhanced chemiluminescence (Amersham Pharmacia Biotech) with the LAS-3000 (Fuji). Band intensity was determined by using a GS700 densitometer and MOLECULAR ANALYST software (BIO-RAD) and given as mean \pm SEM. The expected size of the band is $40 \mathrm{kDa}$, which was further identified by using protein samples from mice that do not express the XPA protein (XPA $A^{-/}$mice; a generous gift from the Laboratory for Health Protection Research, National Institute for Public Health and the Environment (RIVM), Bilthoven, the Netherlands), which was analysed together with the samples. A reference sample was included in every blot to correct blot to blot variation. 


\section{Statistical analysis}

Data are expressed as mean \pm standard error of the mean (SEM) and statistical analysis was conducted using the independent samples T-test. Values of $P \leq 0.05$ were taken to denote statistical significance.

\section{Results}

\section{LPS induced acute lung inflammation}

To characterise the LPS induced acute lung inflammation, infiltration of inflammatory cells was histologically quantified in the lung tissue of Wt mice, which revealed that LPS challenge resulted in a massive recruitment of neutrophils in the alveolar spaces $\left(650 \pm 190 / \mathrm{mm}^{2}\right)$. Furthermore, LPS instillation resulted in an increase of infiltrating macrophages $\left(40 \pm 10 / \mathrm{mm}^{2}\right)$. In the sham treated group, neither significant neutrophil nor macrophage influx was observed. To verify neutrophil activation in Wt animals, extracellular pulmonary MPO activity was determined in BALF of all mice. In agreement with the histological assessment of neutrophil infiltration, a significant MPO activity after LPS instillation in Wt animals was observed $(81.4 \pm 20.5 \mathrm{mU} / \mathrm{ml})$, whereas no MPO activity was detected in the sham group.

Also in $\mathrm{Mpo}^{-/}$mice, neutrophil $\left(60 \pm 10 / \mathrm{mm}^{2}\right)$ and macrophage $\left(10 \pm 1 / \mathrm{mm}^{2}\right)$ numbers were assessed, showing unexpected lower neutrophil, but comparable macrophage infiltration as in Wt mice. The absence of MPO activity in the BALF confirmed the $\mathrm{Mpo}^{-\%}$ status. As MPO activity is indicative for the presence of activated neutrophils in the lung [17], MPO was also assessed in BALF of neutrophil depleted mice, and no MPO activity was detected.

\section{Intratracheal LPS instillation results in pulmonary NER inhibition}

To reveal whether our previous in vitro observation, showing MPO/neutrophil dependent NER inhibition in cocultured epithelial cells [10], corresponds with the in vivo situation, we examined the role of neutrophils on NER of pulmonary tissue in mice after i.t. LPS instillation using an MPO knockout approach and a neutrophil depletion model. As shown in Figure 1, LPS treatment indeed decreased the pulmonary NER capacity in Wt mice approximately 2 -fold $(P=0.05)$. In contrast to our previous in vitro experiments, however, we found that lack of MPO or depletion of neutrophils did not result in a significant abrogation of the pulmonary NER inhibition induced by LPS instillation (Fig. 1). 


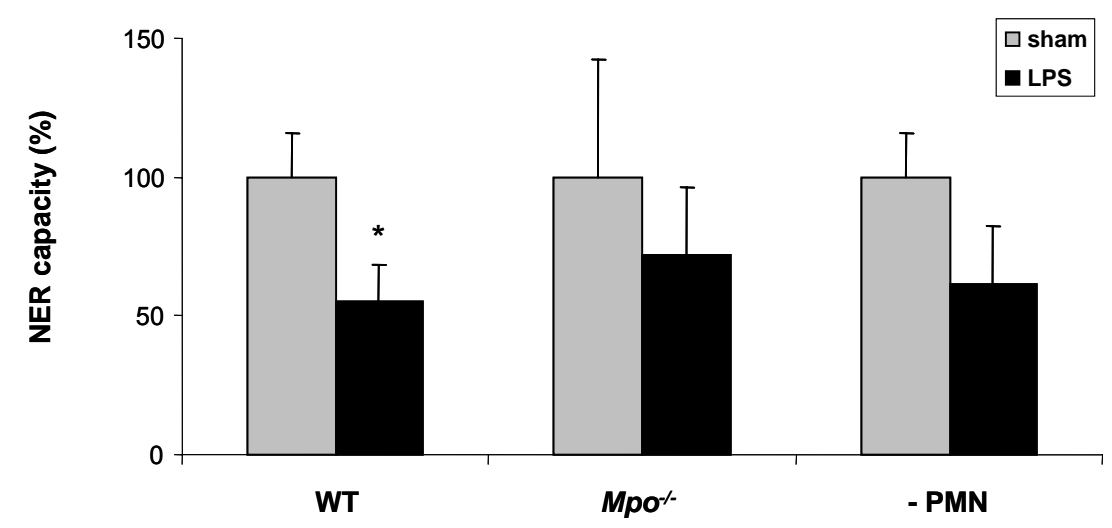

Figure 1. Effect of LPS induced neutrophil influx in the lung on phenotypical NER capacity of lung cells. Phenotypical NER capacity was determined using protein extracts from the lavaged lungs of Wt, $\mathrm{Mpo}^{-1-}$ and neutrophil depleted mice, 3 days after LPS instillation. Data are expressed as mean \pm SEM of 4-9 mice per group. ${ }^{*} P \leq 0.05$ versus sham mice.

\section{Intratracheal LPS exposure decreases expression of NER associated genes}

To address whether the observed LPS induced NER inhibition in the mouse lung was mediated by a reduction of the corresponding mRNA, we examined pulmonary mRNA expression of NER genes after local LPS exposure in vivo. We focused on those enzymes of the NER machinery that are crucially involved in the recognition and incision phase of the NER process, because the phenotypical NER assay described above reflects these processes; XPA and XPC for damage recognition, ERCC-1 and $\mathrm{XPF}$ as 5'endonucleases and XPG as 3'endonuclease [21].

As shown in Figure 2, almost all of the genes exhibited a reduction in expression upon LPS exposure to a very similar degree ( $\sim 50$ to $75 \%)$, irrespective of genetic background. However, the regulation of Xpa and Xpf seemed to be neutrophil dependent as these genes were not downregulated in the LPS exposed neutrophil depleted mice. This shift in NER gene downregulation in the LPS exposed neutrophil depleted mice did, however, not result in a different phenotypical effect. 
A

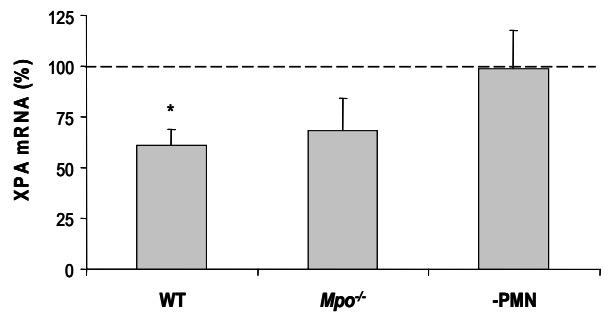

C

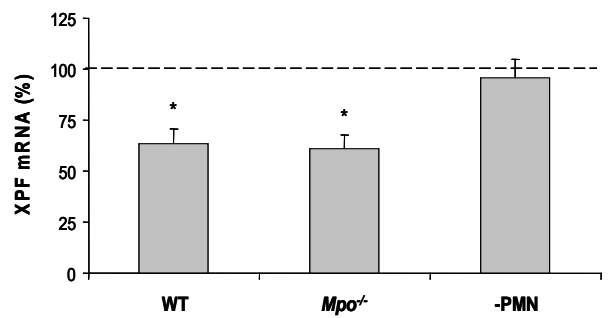

E

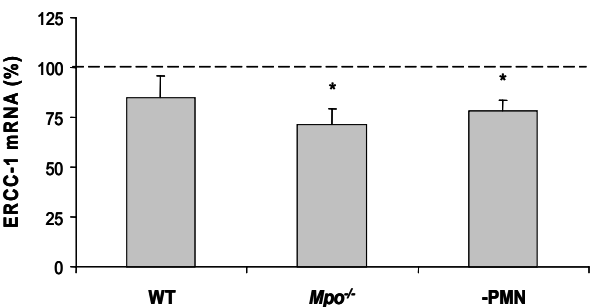

B

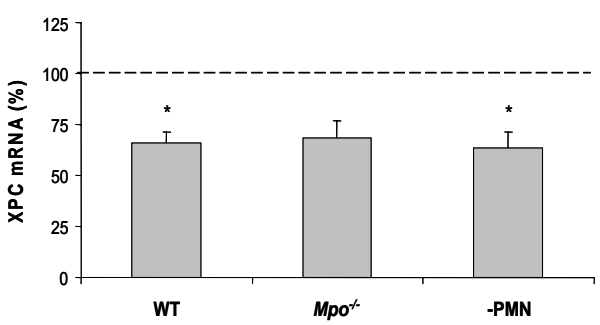

D

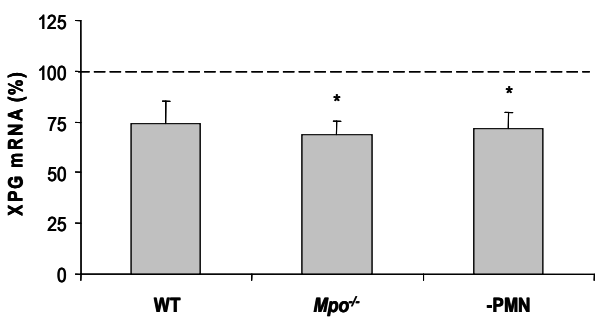

Figure 2. Relative gene expression profiles of a) $X p a$, b) $X p c$, c) $X p f$, d) $X p g$ and e) Ercc-1 in lung tissue at 3 days after i.t. LPS exposure. Data are presented as mean \pm SEM for the LPS treated Wt mice $(n=8)$ and Mpo-/- mice and neutrophil depleted mice $(n=5$ per group). Gene expression in the resp. sham groups is represented as a $100 \%$ line. ${ }^{*} P \leq 0.05$ versus sham mice.

\section{LPS induced down regulation of XPA protein}

XPA protein is the core factor for the assembly of the NER complex, and is the only factor in which disruption completely obliterates NER [21, 22]. Since Xpa gene expression was found to be neutrophil dependently downregulated after LPS exposure in Wt mice, we sought to determine whether this also occurs at the protein level. Quantification of band intensities indicated differences (about 50\% decrease, $P=$ 0.09) in XPA protein levels between LPS instilled Wt mice and sham Wt mice, but not between LPS treated $\mathrm{Mpo}^{-/}$mice compared to their respective sham group (see Fig. 3 ). These data resemble the transcriptional effect of LPS instillation on XPA expression. 
A

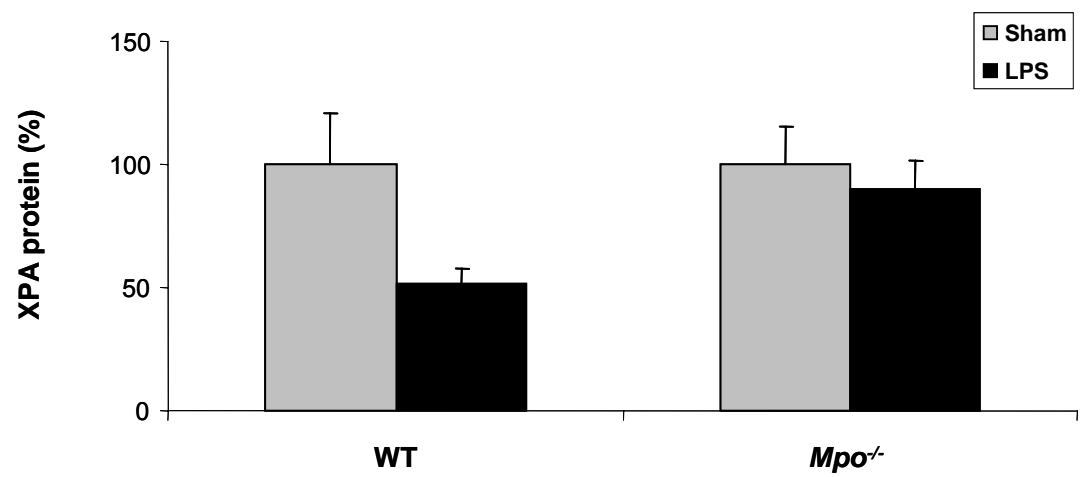

B

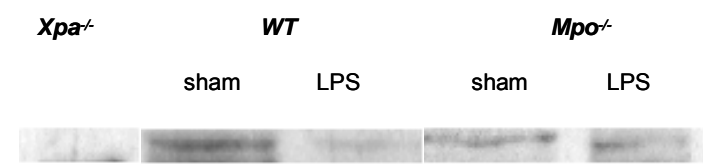

Figure 3. Western Blot analysis of XPA protein in the lung after LPS instillation. Proteins were extracted from lung tissue of sham and LPS exposed Wt and Mpo-/- mice, 3 days after exposure. XPA protein levels were analysed using Western Blots. a) Each column represent mean \pm SEM ( $n=5$ mice per group). $P=0.09$ versus sham mice. b) Blots of representative animals for each group are shown.

\section{Discussion}

Chronic inflammatory diseases of the lung are associated with lung cancer development. Over the past years, evidence has accumulated that the influx of innate immune cells, including polymorphonuclear neutrophils, into the airways contributes to inflammation associated carcinogenesis [7, 8]. Our study demonstrated an association between LPS induced pulmonary inflammation and inhibition of nucleotide excision repair in the mouse lung in vivo. Considering the exposure to inhaled carcinogens, as well as the simultaneous presence of inflammatory cells in the inflamed lung of smokers for example, we propose that this inflammation associated reduction of NER may represent a significant and previously unrecognised contributory factor in the development of inflammation related pulmonary cancer.

Neutrophilia plays a prominent role in host defence against pathogens, but is also responsible for pulmonary injury due to the release of several toxic compounds (e.g. proteases), reactive oxygen species and the enzyme MPO. MPO consumes up to 40$70 \%$ of neutrophil derived $\mathrm{H}_{2} \mathrm{O}_{2}$ to generate $\mathrm{HOCl}$ [23]. $\mathrm{HOCl}$ is a relative stable and membrane diffusible molecule that can pass through subcellular compartments and, presumably, can reach the cell nucleus [24]. Therefore, it has the potential to interact with many different cellular proteins, including DNA repair proteins. In fact, we have 
previously shown that activated neutrophils are potent inhibitors of the NER pathway in pulmonary epithelial cells via the MPO catalysed formation of $\mathrm{HOCl}$ in vitro [10].

To investigate the association between neutrophil infiltration and NER in the lung in vivo, we applied a mouse model of LPS induced acute pulmonary neutrophil influx in the airways [12], expanded with a MPO knockout approach for studying the contribution of MPO, and a systemic depletion of neutrophils to reveal the role of neutrophils. We observed that intratracheal administration of LPS in Wt mice induces lung neutrophilia and associated MPO activation that peaks 3 days after instillation. However, a lack of MPO (as in $\mathrm{Mpo}^{-/}$mice) significantly attenuated the acute inflammatory response induced by airway administration of LPS. This decreased neutrophilia can predominantly be assigned to a decreased extravasation of $\mathrm{Mpo}^{-/-}$neutrophils, as MPO plays a role in the activation of neutrophil adherence before extravasation [25], with a decreased chemokine production as a result [13].

The present in vivo results show that i.t. LPS instillation indeed induces a pulmonary suppression of NER capacity. However, in contrast to the in vitro findings, we were not able to show a distinct role of either MPO or neutrophils in the present in vivo study as LPS instillation in $\mathrm{Mpo}^{-/}$and neutrophil depleted animals caused a similar decrease in NER. Although data obtained in the $\mathrm{Mpo}^{-/}$animals cannot directly be compared with the $\mathrm{Wt}$ animals because of the unexpected lower neutrophil influx, the observed NER inhibiting effect in $\mathrm{Mpo}^{-/}$mice is nevertheless in line with the depletion model, indicating that lower MPO and a lower number of neutrophils are not affecting LPS induced NER inhibition.

As a possible explanation of the observed LPS induced NER inhibition, we addressed the effect of LPS associated lung inflammation on the transcriptional level of relevant NER genes. Our data showed a suppression of several NER genes in lung tissue after LPS induced acute lung inflammation, mainly $X p a, X p c$ and $X p f$ in Wt mice. Since XPC is the earliest distortion recognition factor [21], our data imply that LPS instillation affects the ability of lung cells to recognise damaged DNA, which corresponds with our in vitro observations [10]. However, there was no clear trend suggestive of differences in the way different types of mice respond to LPS instillation, except for the neutrophil mediated downregulation of Xpa and Xpf. XPA is the only crucial core factor in the NER complex configuration showing affinity for damaged DNA and key interactions with the other NER enzymes, which disruption completely obliterates NER [22]. From this point of view, XPA seems to be a neutrophil specific target for inflammation associated NER disruption by downregulating and possibly inhibiting its function. Although Xpa was not downregulated in $\mathrm{Mpo}^{-/-}$mice and neutrophil depleted animals, the downregulation of the other relevant NER related genes may be responsible for the decreased phenotypical NER capacity seen in these mouse models, as probably all XP factors of the NER repair complex are needed for effective DNA repair. Interestingly, the in vivo finding on Xpa downregulation was corroborated by decreased XPA protein in the inflamed lungs, further explaining the distortion of the NER process seen in the LPS exposed Wt animals. Referring to our previous in vitro observations [10], this reduced XPA protein expression implicates also a role for $\mathrm{HOCl}$ mediated oxidative inactivation of repair enzymes or other $\mathrm{HOCl}$ - 
NER protein interactions in neutrophil induced NER inhibition, although additional studies are needed to assess this.

A clarification for the differing findings on MPO dependency in vivo and in vitro can possibly be found in a study of Aratani and colleagues [26], comparing $\mathrm{Mpo}^{-/}$, Nadph oxidase ${ }^{-/}$and double $\left(\mathrm{Mpo} / \mathrm{Nadph}^{-/}\right)$knock out mice in a model of pulmonary infection. They reported that $\mathrm{H}_{2} \mathrm{O}_{2}$ used by MPO is solely produced by NADPH oxidase. It is therefore likely that $\mathrm{Mpo}^{-/-}$mice, which are incapable of inverting $\mathrm{H}_{2} \mathrm{O}_{2}$ to $\mathrm{HOCl}$, build up $\mathrm{H}_{2} \mathrm{O}_{2}$. Since $\mathrm{H}_{2} \mathrm{O}_{2}$ is a very potent oxidant, just like $\mathrm{HOCl}$, increased $\mathrm{H}_{2} \mathrm{O}_{2}$ levels in the $\mathrm{Mpo}^{-/}$mice could exert some NER suppressive effects by oxidative modulation of NER related genes (especially Ercc-1 expressional downregulation) on the lung target cells, which is in line with studies from our own laboratory [27] and $\mathrm{Hu}$ et al. [28].

Moreover, the in vivo versus in vitro discrepancy with respect of the role of neutrophils in the observed NER inhibition, may be due to the presence of resident alveolar macrophages in the in vivo situation. Alveolar macrophages are also involved in the lung inflammatory response, more specifically by neutralising pathogens and recruiting neutrophils in the initiation phase, and apoptotic/cell debris cleanup at a later stage. Additionally, (LPS) activated alveolar macrophages generate large amounts of reactive nitrogen species (by activation of iNOS), which are originally released for bacterial cell killing, but are known to be involved in DNA repair inhibition [29] and may explain the observed neutrophil independent NER inhibiting effect of lung inflammation.

In conclusion, our study is the first to show that LPS induced acute pulmonary inflammation is associated with reduced nucleotide excision repair in the mouse lung. This effect appears not to be mediated by the infiltration of neutrophils and the associated release of the enzyme myeloperoxidase. Nevertheless, these data may provide a further mechanism underlying the association between pulmonary inflammation and lung carcinogenesis.

\section{Acknowledgements}

The authors thank Dr. Aratani $Y$ for the $\mathrm{Mpo}^{-/-}$mice. We thank Yonca Güngör for linguistically reviewing the manuscript. This work was supported by the Province of Limburg, the Netherlands. Part of the studies was supported by the European Network of Excellence (NoE) "Environmental cancer, nutrition and individual susceptibility" (ECNIS), sixth Framework programme (FP6), FOOD-CT-2005-513943. 


\section{References}

1. Pesci, A., Balbi, B., Majori, M., Cacciani, G., Bertacco, S., Alciato, P. and Donner, C.F. (1998) Inflammatory cells and mediators in bronchial lavage of patients with chronic obstructive pulmonary disease. Eur Respir J, 12, 380-386.

2. Barnes, P.J. (2000) Chronic obstructive pulmonary disease. N Engl J Med, 343, 269-280.

3. Jeffery, P.K. (2000) Comparison of the structural and inflammatory features of COPD and asthma. Giles F. Filley Lecture. Chest, 117, 251S-260S.

4. Hogg, J.C., Chu, F., Utokaparch, S., Woods, R., Elliott, W.M., Buzatu, L., Cherniack, R.M., Rogers, R.M., Sciurba, F.C., Coxson, H.O. and Pare, P.D. (2004) The nature of small-airway obstruction in chronic obstructive pulmonary disease. N Engl J Med, 350, 2645-2653.

5. Tockman, M.S., Anthonisen, N.R., Wright, E.C. and Donithan, M.G. (1987) Airways obstruction and the risk for lung cancer. Ann Intern Med, 106, 512-518.

6. Mannino, D.M., Aguayo, S.M., Petty, T.L. and Redd, S.C. (2003) Low lung function and incident lung cancer in the United States: data From the First National Health and Nutrition Examination Survey follow-up. Arch Intern Med, 163, 1475-1480.

7. Drost, E.M., Skwarski, K.M., Sauleda, J., Soler, N., Roca, J., Agusti, A. and MacNee, W. (2005) Oxidative stress and airway inflammation in severe exacerbations of COPD. Thorax, 60, 293-300.

8. de Visser, K.E., Eichten, A. and Coussens, L.M. (2006) Paradoxical roles of the immune system during cancer development. Nat Rev Cancer, 6, 24-37.

9. Knaapen, A.M., Gungor, N., Schins, R.P., Borm, P.J. and Van Schooten, F.J. (2006) Neutrophils and respiratory tract DNA damage and mutagenesis: a review. Mutagenesis, 21, 225-236.

10. Gungor, N., Godschalk, R.W., Pachen, D.M., Van Schooten, F.J. and Knaapen, A.M. (2007) Activated neutrophils inhibit nucleotide excision repair in human pulmonary epithelial cells: role of myeloperoxidase. Faseb J, 21, 2359-2367.

11. Aratani, Y., Koyama, H., Nyui, S., Suzuki, K., Kura, F. and Maeda, N. (1999) Severe impairment in early host defense against Candida albicans in mice deficient in myeloperoxidase. Infect $\mathrm{Im}$ mun, 67, 1828-1836.

12. Vernooy, J.H., Dentener, M.A., van Suylen, R.J., Buurman, W.A. and Wouters, E.F. (2001) Intratracheal instillation of lipopolysaccharide in mice induces apoptosis in bronchial epithelial cells: no role for tumor necrosis factor-alpha and infiltrating neutrophils. Am J Respir Cell Mol Biol, 24, 569-576.

13. Haegens, A., Heeringa, P., van Suylen, R.J., Steele, C., Aratani, Y., O'Donoghue, R.J.J., Mutsaers, S.E., Mossman, B.T., Wouters, E.F. and Vernooy, J.H. (2009) Myeloperoxidase deficiency attenuates LPS induced acute lung inflammation and subsequent cytokine and chemokine production. Journal of Immunology,

14. Tacchini-Cottier, F., Zweifel, C., Belkaid, Y., Mukankundiye, C., Vasei, M., Launois, P., Milon, G. and Louis, J.A. (2000) An immunomodulatory function for neutrophils during the induction of a CD4+ Th2 response in BALB/c mice infected with Leishmania major. J Immunol, 165, 2628-2636.

15. Lopez, A.F., Strath, M. and Sanderson, C.J. (1984) Differentiation antigens on mouse eosinophils and neutrophils identified by monoclonal antibodies. Br J Haematol, 57, 489-494.

16. Klebanoff, S.J., Waltersdorph, A.M. and Rosen, H. (1984) Antimicrobial activity of myeloperoxidase. Methods Enzymol, 105, 399-403.

17. Knaapen, A.M., Albrecht, C., Becker, A., Hohr, D., Winzer, A., Haenen, G.R., Borm, P.J. and Schins, R.P. (2002) DNA damage in lung epithelial cells isolated from rats exposed to quartz: role of surface reactivity and neutrophilic inflammation. Carcinogenesis, 23, 1111-1120.

18. Redaelli, A., Magrassi, R., Bonassi, S., Abbondandolo, A. and Frosina, G. (1998) AP endonuclease activity in humans: development of a simple assay and analysis of ten normal individuals. Teratog Carcinog Mutagen, 18, 17-26.

19. Langie, S.A., Knaapen, A.M., Brauers, K.J., van Berlo, D., van Schooten, F.J. and Godschalk, R.W. (2006) Development and validation of a modified comet assay to phenotypically assess nucleotide excision repair. Mutagenesis, 21, 153-158. 


\section{Chapter 5}

20. Livak, K.J. and Schmittgen, T.D. (2001) Analysis of relative gene expression data using real-time quantitative PCR and the 2(-Delta Delta C(T)) Method. Methods, 25, 402-408.

21. Gillet, L.C. and Scharer, O.D. (2006) Molecular mechanisms of mammalian global genome nucleotide excision repair. Chem Rev, 106, 253-276.

22. Lindahl, T. and Wood, R.D. (1999) Quality control by DNA repair. Science, 286, 1897-1905.

23. Klebanoff, S.J. (1999) Myeloperoxidase. Proc Assoc Am Physicians, 111, 383-389.

24. Spencer, J.P., Whiteman, M., Jenner, A. and Halliwell, B. (2000) Nitrite-induced deamination and hypochlorite-induced oxidation of DNA in intact human respiratory tract epithelial cells. Free Radic Biol Med, 28, 1039-1050.

25. Lau, D., Mollnau, H., Eiserich, J.P., Freeman, B.A., Daiber, A., Gehling, U.M., Brummer, J., Rudolph, V., Munzel, T., Heitzer, T., Meinertz, T. and Baldus, S. (2005) Myeloperoxidase mediates neutrophil activation by association with CD11b/CD18 integrins. Proc Natl Acad Sci U S A, 102, 431-436.

26. Aratani, Y., Kura, F., Watanabe, H., Akagawa, H., Takano, Y., Suzuki, K., Dinauer, M.C., Maeda, $\mathrm{N}$. and Koyama, H. (2002) Relative contributions of myeloperoxidase and NADPH-oxidase to the early host defense against pulmonary infections with Candida albicans and Aspergillus fumigatus. Med Mycol, 40, 557-563.

27. Langie, S.A., Knaapen, A.M., Houben, J.M., van Kempen, F.C., de Hoon, J.P., Gottschalk, R.W., Godschalk, R.W. and van Schooten, F.J. (2007) The role of glutathione in the regulation of nucleotide excision repair during oxidative stress. Toxicol Lett, 168, 302-309.

28. Hu, J.J., Dubin, N., Kurland, D., Ma, B.L. and Roush, G.C. (1995) The effects of hydrogen peroxide on DNA repair activities. Mutat Res, 336, 193-201.

29. Chien, Y.H., Bau, D.T. and Jan, K.Y. (2004) Nitric oxide inhibits DNA-adduct excision in nucleotide excision repair. Free Radic Biol Med, 36, 1011-1017. 




\section{Transeriptional profiling of the pulmonary}

inflammatory response induced by LPS: role of neutrophils

Respir Res, submitted.

Güngör N Pennings JL Knaapen AM Chiu RK Peluso M Godschalk RWL van Schooten FJ 


\section{Abstract}

Lung cancer often develops in association with chronic pulmonary inflammatory diseases with an influx of neutrophils. More detailed information on inflammatory pathways and the role of neutrophils herein is a prerequisite for understanding the mechanism of inflammation associated cancer. In the present study, we used microarrays to gain a global view of the transcriptional responses of the lung to LPS in mice. This treatment mimics an acute lung inflammatory response. To investigate the influence of neutrophils in this process, we depleted mice from circulating neutrophils treatment with anti-PMN antibodies prior to LPS exposure. A total of 514 genes were greater than 1.5-fold differentially expressed in the LPS induced lung inflammation model. 394 of the 514 were upregulated genes mostly involved in cell cycle and immune/inflammation related processes, such as cytokine/chemokine activity and signalling. Downregulated genes represented nonimmune processes, such as development, metabolism and transport. Notably, the number of genes and pathways that were differentially expressed was reduced when animals were depleted from circulating neutrophils, confirming the central role of neutrophils in the inflammatory response. Furthermore, there was a significant correlation between the differentially expressed gene list and the promutagenic DNA lesion $M_{1} d G$, suggesting that it is the extent of the immune response which drives genetic instability in the inflamed lung. Several neutrophil specific genes could be identified and these were mostly involved in interferon signalling, the oxidative stress response and cell cycle progression. The latter refers possibly to a higher rate of cell turnover in the inflamed lung with neutrophils, suggesting that the neutrophil influx is associated with a higher risk for the accumulation and fixation of mutations. Gene expression profiling identified specific genes and pathways that are related to neutrophilic inflammation and could be associated to cancer development and indicate an active role of neutrophils in mediating the LPS induced inflammatory response in the mouse lung. 


\section{Introduction}

Inflammation is often considered as a critical component of tumourigenesis, since many cancers arise at sites of infection, chronic irritation and inflammation [1, 2]. Also subjects suffering from inflammatory pulmonary diseases, such as chronic obstructive pulmonary disease (COPD)/emphysema, have an increased risk for developing lung cancer [3]. One common characteristic of many inflammatory lung disorders is the influx of polymorphonuclear neutrophils (PMN), which are highly specialised members of the innate immune system. Neutrophils are often the first immune cells to arrive at sites of infection and their primary function is to phagocytise and destroy invading microorganisms and/or foreign material. Under normal conditions, neutrophils circulate through the bloodstream, having a half life span of about 7 hours. However, during an invasion of pathogens, neutrophils are recruited to the site of inflammation and their life span is increased up to 4 days [4]. It has been suggested that the accumulation of these neutrophils in the lumen of the lung is related to lung cancer risk [5], implying a significant role of the neutrophilic inflammation in the carcinogenic response [6].

Inflammation is thought to initiate and promote lung cancer development via the continuous formation of reactive oxygen or nitrogen species (ROS/RNS) that can bind to DNA, and thus lead to promutagenic DNA alterations [7, 8]. Furthermore, the release of ROS by neutrophils is also believed to cause a cell proliferative response, which may contribute significantly to the carcinogenic response following chronic inflammation. We have previously reported two distinct pathways of neutrophil induced genotoxicity and mutagenicity via their capacity to release the oxidant hypochlorous acid $(\mathrm{HOCl})$. Exposure of lung epithelial cells to HOCl leads to: (i) indirect DNA disturbances by attack of $\mathrm{HOCl}$ on lipids/proteins, resulting in the formation of promutagenic DNA adducts [unpublished results: 9] and (ii) impaired removal of bulky DNA lesions due to inhibition of nucleotide excision repair (NER) [10, unpublished results: 11]. Although both processes are thought to play an important role in tumourigenesis, additional processes may be involved to create a microenvironment that facilitates tumour formation and progression. Thus, a better understanding of biochemical pathways in the lung elicited by inflammatory stimuli, and the role of neutrophils herein, is required to further unravel mechanisms of inflammation related lung carcinogenesis.

In this report, we determined the transcriptional response upon neutrophilic lung inflammation in lung cells of mice treated intratracheally with lipopolysaccharide (LPS), by identifying genes that are differentially expressed. The well characterised component of gram-negative bacterial cell walls LPS was used, as it is a potent endotoxin capable of inducing a strong inflammatory response by recruiting circulating PMN to the lungs [12]. Indeed, intratracheal instillation of experimental animals with LPS induces an acute lung inflammation associated with a neutrophil influx into the alveoli [13]. We further demonstrated the specific role of neutrophils by antibody depletion of circulating neutrophils from the animals. In this report, we present the profiles of differentially expressed genes in lung tissue due to neutrophilic inflammation and investigated whether neutrophil induced genes are associated with induction of geno- 
toxicity. Moreover, we related the biological networks/pathways including these genes to the potential role of neutrophils in pulmonary inflammation related carcinogenesis.

\section{Materials and Methods}

\section{Animals}

Male C57BI6 mice ( 12 weeks old) were obtained from Charles River Breeding Laboratories (Heidelberg, Germany). Mice were housed individually in standard laboratory cages and allowed food and water ad libitum throughout the experiments. The studies were carried out in accordance with an approved protocol by the Institutional Animal Care Committee of Maastricht University.

\section{LPS induced acute lung inflammation mouse model}

Mice were exposed to LPS (Escherichia Coli, serotype O55:B5, Sigma, St. Louis, MO, USA) by intratracheal instillation to induce an acute pulmonary inflammation. The dose of LPS used was $20 \mu \mathrm{g} /$ instillation/mouse. Intratracheal instillation was performed by a nonsurgical technique under anaesthesia as previously described [14]. Sham mice $(n=5)$ were instilled with sterile $0.9 \% \mathrm{NaCl}$. Since a previous study [13] demonstrated that local LPS challenge in C57BI6 mice results in a time dependent neutrophil accumulation peaking at day 3 , mice $(n=5)$ were sacrificed 3 days postexposure by $115 \mathrm{mg} / \mathrm{kg}$ sodium pentobarbital (Ceva Sante Animale, Maassluis, the Netherlands) and bronchoalveolar lavage (BAL) (3x with $1 \mathrm{ml}$ sterile $0.9 \% \mathrm{NaCl}$ ) was performed to remove inflammatory cells from the airways. After centrifugation at 1,500 rpm during $10 \mathrm{~min}$ at $4^{\circ} \mathrm{C}$, the cell-free BAL fluid (BALF) was stored at $-80^{\circ} \mathrm{C}$ for MPO activity measurement. Lavaged lungs were snapfrozen and pulverised using a mortar and pestle. The pulverised lung tissue was stored at $-80^{\circ} \mathrm{C}$ for DNA, RNA and protein isolation.

To unravel the role of neutrophils in the inflammatory airway transcriptome, depletion of circulating neutrophils in mice $(n=5)$ was achieved by intraperitoneal injection of $0.5 \mathrm{mg}$ of the monoclonal rat anti-mouse neutrophil antibody NIMP-R14 (Hbt, Uden, the Netherlands), $24 \mathrm{~h}$ before i.t. LPS instillation. NIMP-R14 selectively depletes mouse neutrophils in vivo for up to 6 days $[15,16]$. Again, 3 days after instillation, mice were sacrificed, and lungs were lavaged and isolated as described above. In our study, a lack of MPO activity in the lung was used as a verification of the absence of neutrophils. IgG (eBioscience, San Diego, CA, USA) was used as control mAb in the sham group and LPS group without neutrophil depletion.

\section{MPO activity measurement}

MPO packaged in neutrophils will have no effect on pulmonary epithelial tissue, because MPO must be released extracellularly during the oxidative burst of neutrophils. Therefore, extracellular MPO activity was measured in cell-free BALF as described by 
Klebanoff et al. [17] and is indicative for the presence of activated neutrophils in the lung [18].

\section{MPO ELISA}

The presence of residual inflammatory neutrophils in the lavaged lung may affect the analysis of the transcriptome of lung epithelial cells. Therefore, to evaluate the degree of contamination of the lavaged lungs with resident neutrophils, proteins were extracted and MPO protein levels were determined quantitatively in lung homogenates, using a mouse MPO ELISA kit (Hbt, Uden, the Netherlands) according to the manufacturer's instructions. Protein concentrations were determined spectrophotometrically, using the DC-protein Assay Kit (BIORAD, Veenendaal, the Netherlands). The amount of MPO in the lung tissue was expressed as ng MPO/mg protein.

\section{DNA isolation}

DNA was isolated using standard phenol extraction [19]. DNA concentrations were quantified by NanoDrop (Isogen-Lifescience, De Meern, the Netherlands) and samples were frozen at $-20^{\circ} \mathrm{C}$ until further analysis.

\section{Quantification of $M_{1} d G$}

The ${ }^{32} \mathrm{P}$-postlabelling technique was used to analyse the levels of 3-(2-Deoxy- $\beta$-Derythro-pentofuranosyl)pyrimido[1,2- $\alpha$ ]purin-10(3H)-one $\left(\mathrm{M}_{1} \mathrm{dG}\right)$ adducts, as previously reported [20]. $M_{1} d G$ adduct analysis was carried out by PEl-cellulose TLC chromatography according to published conditions [21]. Detection and quantification of $M_{1} d G$ adducts and total nucleotides were obtained by phosphor imaging technology (Typhoon 9210, Amersham) and ImageQuant software (Molecular Dynamics, Sunnyvale, CA, USA). After background subtraction, the levels of DNA adducts were expressed as relative adduct labelling ( $R A L=$ adducted nucleotides/total nucleotides). Standard MDA modified [22] and unmodified DNA were routinely processed in the analysis as controls.

\section{RNA isolation and purification}

After lungs were pulverised using a liquid nitrogen cooled mortar and pestle, TRIzol ${ }^{\circledR}$ Reagent (Invitrogen, Breda, the Netherlands) was added and RNA was isolated by using an RNeasy Mini kit (Qiagen, Venlo, the Netherlands) with DNase treatment, according to the manufacturer's protocol. RNA quantity was determined by NanoDrop (Isogen-Lifescience, De Meern, the Netherlands) and RNA quality was assessed by automated gel electrophoresis on an Agilent 2100 Bioanalyser (Agilent Technologies, Amstelveen, the Netherlands). All RNA samples analysed were pure and free of RNA degradation. 


\section{RNA labelling and microarray hybridisation}

Cyanine labelled cRNA was generated by using the Two-Colour Microarray based Gene Expression Analysis kit from Agilent Technologies. All samples were labelled with Cy5 and a pool of Cy3 labelled sham group samples was used as reference. Dye incorporation rates were used to put appropriate amounts of Cy5 and Cy3 labelled samples (10 pmol each) together for hybridisation on Agilent 4x 44K Mouse Microarrays (Agilent Technologies). After hybridisation, slides were washed and dried with $\mathrm{N}_{2}$ gas before scanning.

\section{Image analysis}

Slides were scanned on a GenePix ${ }^{\circledR}$ 4000B Microarray Scanner (Molecular Devices, Sunnyvale, CA, USA). Cy5 and Cy3 were excited at wavelengths of 635 and $532 \mathrm{~nm}$ respectively. Laser power was set to $100 \%$. The photo multiplier was set to a saturation tolerance of $0.02 \%$ to minimise background and saturated spots. The images obtained (resolution 5 micron, 16 bit tiff images) were processed with Imagene 8.0.1 software (Biodiscovery, El Segundo, CA, USA) to measure median Cy3 and Cy5 signal intensities for spots and local backgrounds. Quality control was performed by means of visual inspection of the scanned images, raw data scatter plots, MA plots and normal probability plots to assess signal distribution. Positive and negative controls were used for quality control, but subsequently excluded from the further normalisation and analysis.

\section{Normalisation and data preparation}

Raw microarray signal data were normalised in R (http://www.r-project.org), using the four step approach as described by Baken et al. [23]: (1) natural log-transformation, (2) quantile normalisation of all scans, (3) correcting the sample spot signal for differences in the corresponding reference spot signal between arrays and (4) averaging data from spots annotated with an identical gene symbol. Normalised data for the resulting 25,696 genes were visualised by Principal Component Analysis (PCA) for additional quality control. Further analyses were carried out in $\mathrm{R}$ and Microsoft Excel. As PCA analysis showed heterogeneity within groups, for each gene, median expression values per group were calculated and compared between the 3 experimental groups. Genes with a more than 1.5-fold difference between experimental groups were considered differentially expressed. It has been described by Guo et al. [24] that for such strong effects, analyses of such gene lists showed good and internal consistency on the Gene Ontology and pathway level.

\section{Data analysis}

Functional Annotation and Gene Ontology (GO) term enrichment were examined with DAVID Bioinformatics Resource (http://david.abcc.ncifcrf.gov/) [25]. Additionally, MetaCore (GeneGO, San Diego, CA) was used for additional pathway enrichment analysis, as well as visualisation of differentially expressed genes in cellular pathways. To 
provide a sample specific measure for the gene expression response over the differentially expressed genes, their value was adjusted for the median of the control (sham) group, followed by calculation of the root mean square. Correlation between the gene expression response and $\mathrm{M}_{1} \mathrm{dG}$ DNA adduct lesions were compared between samples using the Spearman's rank correlation coefficient.

\section{Results}

\section{Neutrophil infiltration in lung tissue}

To determine the influx of neutrophils and to verify neutrophil activation, we assessed MPO activity in the BALF. Extracellular MPO is indicative of the presence of activated neutrophils [18]. Intratracheal instillation of mice with LPS indeed increased the mean MPO activity in BALF $(81.4 \pm 20.5 \mathrm{mU} / \mathrm{ml})$, as compared to the sham group (MPO activity $<$ detection limit, $P<0.05$ ). MPO activity was absent in animals depleted of circulating neutrophils, thereby confirming their depletion status.

Furthermore, MPO protein concentrations in lung tissue homogenates, prepared after BAL lavage, were determined to check the efficiency of the BAL and the possible contamination of the lavaged lungs with resident neutrophils and hence neutrophil RNA. MPO protein values in the lavaged lung tissues of LPS exposed mice with/without PMN (resp. $334.0 \pm 94.8$ and $188.0 \pm 51.3 \mathrm{ng} \mathrm{MPO} / \mathrm{mg}$ protein) indicated no significant neutrophilic contamination compared to background levels in sham mice (246.2 $\pm 77.3 \mathrm{ng} \mathrm{MPO} / \mathrm{mg}$ tissue). MPO protein contents of lung samples of LPS exposed mice with/without PMN that were not lavaged (obtained from another study) were resp. $875.2 \pm 284.6$ and $328.7 \pm 82.3 \mathrm{ng} \mathrm{MPO} / \mathrm{mg}$ protein compared to background levels in control mice (309.4 $\pm 43.4 \mathrm{ng} \mathrm{MPO} / \mathrm{mg}$ protein), which indicates that the lavages were successful, washing away most of the neutrophils / inflammatory cells and the microarray analysis will thus not be disturbed by remaining infiltrated neutrophils cells.

\section{Differentially expressed genes}

PCA analysis on all normalised data showed that LPS exposed groups were more heterogeneous than the sham group. This was also the case in a PCA using only the 383 commonly lung inflammation genes that were described, by Pennings et al., to be induced in multiple lung inflammatory models [26], indicating that also the inflammatory response, which is the main expected response, is subjected to relatively large inter-animal variation following LPS exposure. This observation is also reflected by the heterogeneity in MPO activity levels measured in BALF and is probably due to differences in the acute phase response of individual mice upon intratracheal LPS instillation. To make the gene expression data analysis robust against this heterogeneity and outliers within groups, we based our further analysis on the median values for each group and focussed on the genes with highest fold change ranking only. 
This data analysis approach revealed 621 genes that were differentially expressed between all experimental groups with $\mathrm{a} \geq 1.5$-fold change (Gene list can be found at http://www.grat.nl/media/file/exchange/N_Gungor_appendix_proefschrift.pdf), of which 179 were 2-fold differentially expressed. The distribution of the number of differentially regulated genes over the experimental groups is presented in a Venn diagram (Fig. 1). The expression of 514 genes was changed in the LPS group in the presence of PMN, of which 394 showed increased expression and 120 decreased expression as compared to sham control. The greatest increase was 15 -fold (serum amyloid A 3) and the greatest decrease was 2.6-fold (paraoxonase 1). In total, 360 genes were differentially expressed in the LPS group that was depleted of PMN (287 upregulated and 73 downregulated). The greatest increase in this list is 7.7-fold, again for serum amyloid A 3, and the greatest decrease was 2.7-fold (keratin complex 1, acidic gene 15). As demonstrated in Figure 1, there were overlaps between the gene lists obtained from LPS exposed animals with and without PMN depletion. Among the differentially expressed genes compared to sham mice, 265 were overlapping both groups, showing differential regulation upon LPS induced lung inflammation, irrespective of the neutrophil influx status. A correlation $(R=0.68)$ was observed between the expression of these genes in animals that were exposed to LPS with or without depletion of PMN. The slope of the regression line was 0.6 , indicating that the extent of the response was less strong in animals that were PMN depleted. Comparison of the 2 LPS exposed groups with/without PMN depletion resulted in 107 differentially expressed genes, mostly overlapping the lists of differentially expressed genes of the separate LPS groups compared to the sham group, but different in the extent of change. Only 12 genes were differentially expressed by PMN depletion and not by LPS instillation, of which only 1 gene was 2 -fold changed (i.e. resistin like gamma).

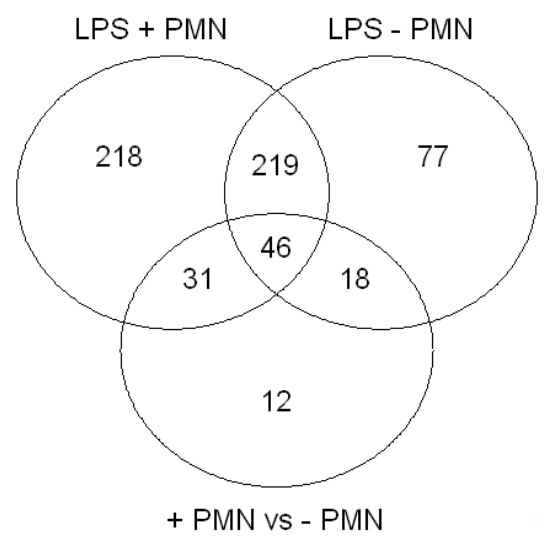

Figure 1: Venn diagram showing the distribution of the 1.5-fold differentially expressed genes over the 3 groups: LPS exposed mice compared to sham mice (LPS + PMN), LPS exposed neutrophil depleted mice compared to sham mice (LPS - PMN) and LPS exposed mice compared to LPS exposed neutrophil depleted mice (+ PMN vs. $-\mathrm{PMN})$. 


\section{Pathway regulation}

To assign functions to differentially expressed genes, we classified them according to $\mathrm{GO}$ categories. Subsequently, enrichment of GO categories in the list of 1.5-fold differentially expressed genes was assessed to identify pathophysiological processes involved in the acute phase response in the lung upon LPS induced lung inflammation and the role of neutrophils herein. As expected, this GO term enrichment analysis showed that among the 514 genes differentially expressed in the LPS exposed group in the presence of PMN, a considerable number of the 394 upregulated genes belonged to the GO categories "immune response" (74 genes) and "inflammatory response (41 genes). The functional classes of genes that were most prominently upregulated consisted of cytokines and chemokines, several genes involved in the complement cascade and a few known inflammation markers (e.g. Lcn2, Saa1, Saa3). Apart from genes involved in immune or inflammation related processes, also a substantial number of differentially regulated genes ( 46 genes) is involved in cell cycle regulation. GO-categories belonging to the 120 downregulated genes mostly represented nonimmune processes, such as development, metabolism and transport. Depleting the mice from circulating neutrophils resulted in a comparable but weaker immune/inflammatory response upon LPS exposure. Moreover, the number of genes belonging to the GO categories "immune response" and "inflammatory response" was reduced from 74 to 59 and 41 to 29 genes, respectively, due to PMN depletion. Also the number of genes belonging to the GO category cell cycle was reduced to 36 genes in PMN depleted mice.

To reveal intergene relations, we performed MetaCore analysis on the 1.5-fold regulated genes upon LPS exposure in the combined group with or without PMN depletion. The significant pathways are presented in Table 1. This analysis revealed a common significance of pathways involved in cell cycle for both LPS exposed groups, although cell cycle effects were more pronounced in the presence of neutrophils. Further, a large number of pathways involved in immune response were modulated upon LPS exposure. High ranking MetaCore pathways in both LPS groups were "Alternative complement pathway" and "Antigen presentation by MHC class II". Interestingly, several immune response pathways, including the classic and lectin induced complement cascade, interferon and IL-10 signalling, were only significantly induced in the LPS exposed group without PMN depletion. Whereas the transcriptional regulation of myeloid progenitor cell differentiation into neutrophils was only modulated in the LPS exposed group with PMN depletion, as indicated by higher Mpo expression in this group. The rest of the differentially expressed inflammation associated transcripts upon LPS exposure in depleted and undepleted mice were categorised into the following cellular processes: oxidative stress, apoptosis, $G$ protein signalling, cytoskeleton remodelling and metabolism. As shown in Table 1, the overall response is rather similar in both LPS groups compared to sham group, but generally less extensive in the group in which PMN were depleted, as indicated by fewer modulated pathways and fewer genes involved in these pathways.

Biological processes and pathways for differentially regulated genes between the PMN depleted and undepleted group (both with LPS exposure) were also identified by 
querying the MetaCore database. The significant pathways, listed in Table 2, reveal mainly a role of inflammatory neutrophil influx in immune response processes, such as interferon, IL-3 and Oncostatin M signalling.

\begin{tabular}{|c|c|c|c|c|c|c|}
\hline \multirow[t]{3}{*}{ Main cellular process } & \multirow[t]{3}{*}{ Modulated pathways } & \multicolumn{2}{|c|}{$P$ value } & \multicolumn{3}{|c|}{ Genes in pathway } \\
\hline & & \multirow[b]{2}{*}{+ PMN } & \multirow[b]{2}{*}{ - PMN } & \multicolumn{2}{|c|}{ expressed } & \multirow[t]{2}{*}{ total } \\
\hline & & & & + PMN & - PMN & \\
\hline \multirow[t]{10}{*}{ Cell cycle } & Role of APC in cell cycle regulation & $1.040 \mathrm{E}-09$ & $8.149 E-08$ & 15 & 12 & 32 \\
\hline & Chromosome condensation in prometaphase & 4.131E-06 & 8.392E-11 & 9 & 12 & 20 \\
\hline & The metaphase checkpoint & 4.423E-06 & $1.474 \mathrm{E}-04$ & 12 & 9 & 36 \\
\hline & Spindle assembly and chromosome separation & $3.170 \mathrm{E}-04$ & $1.937 \mathrm{E}-03$ & 9 & 7 & 32 \\
\hline & Start of DNA replication in early $S$ phase & $1.284 \mathrm{E}-03$ & 3.115E-02 & 8 & 5 & 31 \\
\hline & Initiation of mitosis & $1.544 \mathrm{E}-03$ & $2.483 \mathrm{E}-03$ & 7 & 6 & 25 \\
\hline & Sister chromatid cohesion & $1.530 \mathrm{E}-02$ & & 5 & & 21 \\
\hline & Transition and termination of DNA replication & & $1.523 E-02$ & & 5 & 26 \\
\hline & Role of Nek in cell cycle regulation & & $2.390 \mathrm{E}-02$ & & 5 & 29 \\
\hline & Nucleocytoplasmic transport of CDK/Cyclins & & 4.386E-02 & & 3 & 14 \\
\hline \multirow[t]{12}{*}{ Immune response } & Alternative complement pathway & 4.539E-07 & 2.737E-02 & 12 & 5 & 30 \\
\hline & Fc gamma R-mediated phagocytosis & $1.606 \mathrm{E}-03$ & $9.058 \mathrm{E}-03$ & 8 & 6 & 32 \\
\hline & Antigen presentation by MHC class II & $6.046 \mathrm{E}-03$ & $2.644 \mathrm{E}-03$ & 4 & 4 & 11 \\
\hline & Classic complement pathway & 1.517E-05 & & 12 & & 40 \\
\hline & Antiviral actions of Interferons & $2.431 \mathrm{E}-04$ & & 9 & & 31 \\
\hline & CCR3 signalling & $8.728 \mathrm{E}-04$ & & 12 & & 59 \\
\hline & Lectin Induced complement pathway & $1.251 \mathrm{E}-03$ & & 9 & & 38 \\
\hline & Lipoxin inhibitory action on Superoxide production & $1.544 \mathrm{E}-03$ & 2.483E-03 & 7 & 6 & 25 \\
\hline & IFN alpha/beta signalling pathway & $6.214 \mathrm{E}-03$ & & 6 & & 24 \\
\hline & IL-10 signalling pathway & $2.245 \mathrm{E}-02$ & & 5 & & 23 \\
\hline & Antigen presentation by MHC class I & 3.675E-02 & & 5 & & 26 \\
\hline & Transcription regulation of granulocyte development & & 3.115E-02 & & 5 & 31 \\
\hline Oxidative stress & ROS production & $8.932 \mathrm{E}-04$ & 4.113E-02 & 7 & 4 & 23 \\
\hline Apoptosis & Inhibition of ROS induced apoptosis & 3.675E-02 & & 5 & & 26 \\
\hline \multirow[t]{2}{*}{ G protein signalling } & Rac2 regulation pathway & 4.957E-03 & 4.113E-02 & 6 & 4 & 23 \\
\hline & RAC1 in cellular process & $1.361 \mathrm{E}-02$ & & 6 & & 28 \\
\hline \multirow[t]{2}{*}{ Cytoskeleton remodelling } & Regulation of actin cytoskeleton by Rho GTPases & $8.972 \mathrm{E}-03$ & & & 5 & 23 \\
\hline & Alpha- $1 \mathrm{~A}$ adrenergic receptor-dependent inhibition of PI3K & 2.887E-02 & & & 3 & 12 \\
\hline \multirow[t]{5}{*}{ Metabolic process } & Lipoprotein metabolism I. Chylomicron, VLDL and LDL metabolism & $1.630 \mathrm{E}-02$ & 9.007E-07 & 3 & 6 & 8 \\
\hline & Lipoprotein metabolism II. HDL metabolism & $1.630 \mathrm{E}-02$ & $9.007 \mathrm{E}-07$ & 3 & 6 & 8 \\
\hline & G-alpha(q) regulation of lipid metabolism & $2.245 \mathrm{E}-02$ & & 5 & & 23 \\
\hline & Urea cycle & 3.675E-02 & & 5 & & 26 \\
\hline & LDL metabolism during development of fatty streak lesion & $1.870 \mathrm{E}-02$ & & & 2 & 4 \\
\hline
\end{tabular}

Note: Significantly modulated 1.5-fold changed genes ( $P$ value $<0.05)$ versus total number of genes in pathway

Table 2: Pathways significantly modulated by neutrophil depletion as found in MetaCore

\begin{tabular}{|c|c|c|c|c|}
\hline \multirow[t]{2}{*}{ Main cellular process } & \multirow[t]{2}{*}{ Modulated pathways } & \multirow[t]{2}{*}{$P$ value } & \multicolumn{2}{|c|}{ Genes in pathway } \\
\hline & & & expressed & total \\
\hline \multirow[t]{2}{*}{ Cell cycle } & Role of APC in cell cycle regulation & $1.012 \mathrm{E}-02$ & 4 & 32 \\
\hline & Spindle assembly and chromosome separation & $1.012 \mathrm{E}-02$ & 4 & 32 \\
\hline \multirow[t]{5}{*}{ Immune response } & IFN alpha/beta signalling pathway & $2.740 \mathrm{E}-05$ & 6 & 24 \\
\hline & Alternative complement pathway & $8.024 \mathrm{E}-03$ & 4 & 30 \\
\hline & Oncostatin M signaling via MAPK & $1.683 \mathrm{E}-02$ & 4 & 35 \\
\hline & NKG2D signalling & 4.297E-02 & 3 & 29 \\
\hline & IL-3 activation and signallng pathway & 4.685E-02 & 3 & 30 \\
\hline \multirow[t]{2}{*}{ Response to extracellular stimulus } & Angiotensin signalling via STATs & 2.917E-02 & 3 & 25 \\
\hline & Ligand dependent activation of the ESR-1/AP-1 pathway & $4.756 \mathrm{E}-02$ & 2 & 13 \\
\hline Other & Mucin expression in CF via IL-6, IL-17 signalling pathways & $3.926 \mathrm{E}-02$ & 3 & 28 \\
\hline
\end{tabular}

Note: Significantly modulated 1.5-fold changed genes $(P$ value $<0.05)$ versus total number of genes in pathway

\section{Correlation of genes with phenotypic markers of effects; $M_{1} d G$ adducts}

Because the pathway analysis tool MetaCore identified only significant modulation of oxidative stress related pathways upon LPS instillation in the group without PMN 
depletion (see Table 1), we sought to link neutrophil induced gene expression changes with phenotypic genotoxic effects of neutrophil derived ROS. As a previous study indicated that neutrophils are possibly mutagenic via an indirect genotoxic hazard of neutrophil derived $\mathrm{HOCl}$, by its attack on lipids and/or proteins producing MDA and forming $M_{1} d G$ adducts [unpublished results: 9], we measured $M_{1} d G$ levels in the mouse lung as a phenotypic marker of neutrophil induced genotoxicity. LPS treatment caused a significant increase in the formation of $M_{1} d G$ adducts in the mouse lung $\left(13.6 \pm 2.8 \mathrm{M}_{1} \mathrm{dG} / 10^{8} \mathrm{nt}\right)$ compared to sham mice $\left(5.1 \pm 0.2 \mathrm{M}_{1} \mathrm{dG} / 10^{8} \mathrm{nt}\right)(\sim 4-$ fold,$P=$ 0.01 ). Reduced $M_{1} d G$ levels in LPS instilled neutrophil depleted mice (10.6 \pm 2.5 $\mathrm{M}_{1} \mathrm{dG} / 10^{8} \mathrm{nt}$ ), and a significant correlation between MPO activity in BALF and $\mathrm{M}_{1} \mathrm{dG}$ levels in lung cells (Pearson correlation $=0.67, P=0.001$ ) suggest a link between neutrophil influx, MPO mediated formation of $\mathrm{HOCl}$ and formation of $\mathrm{M}_{1} \mathrm{dG}$ adducts in vivo. Therefore, we calculated Spearman's rank correlation coefficient between gene expression response values and $\mathrm{M}_{1} \mathrm{dG}$ adduct data, indicating a significant correlation with $P=0.01$ for $R=0.64$ using the 1.5 -fold changed gene lists.

\section{Discussion}

Gene expression changes usually occur in early stages of disease development and can provide additional information on the pathogenesis of that particular disease. The present study makes use of the ability of microarray technology to define the expression of inflammation related genes in lungs, by using LPS in a mouse model combined with systemic neutrophil depletion. In this way, we were able to extend the understanding of the role of neutrophils in pulmonary inflammation and identify genes and pathways that can be related to mechanisms of inflammation related carcinogenesis.

As LPS induced pulmonary inflammation involves a massive recruitment of neutrophils into the alveoli, it raises the question whether the observed transcriptional responses in sessile lung cell can actually be attributed to the fact that the lung samples are contaminated with resident inflammatory neutrophils. However, inflammatory cells were removed from the lungs prior to expression analysis, and similar MPO protein levels in sham and LPS exposed animals indicated efficient BAL and neglectable levels of resident neutrophils. Thus, the changes in gene expression described here can predominantly be attributed to sessile pulmonary epithelial cells.

Of the 1.5-fold differentially expressed genes between all groups, the number of differentially expressed genes in the group of LPS exposure without neutrophil depletion was larger then those in the LPS group with neutrophil depletion, indicating a more pronounced response when LPS induced lung inflammation is associated with neutrophil influx in terms of changes of gene expression (Fig. 1). The reduced acute inflammatory response in the neutrophil depleted animals was also confirmed by lower expression levels of the serum amyloid genes Saa1 and Saa3, which are acute phase systemic inflammation markers known to be induced by LPS treatment [27]. Overall, there is consistency of changed gene expression profiles between LPS ex- 
posed animals with or without neutrophil depletion, which is reflected by the fact that $74 \%$ of the $>1.5$-fold changed genes in the LPS group with neutrophil depletion were overlapping the LPS group without neutrophil depletion. In comparison, a high percentage of differentially expressed genes between PMN depleted and undepleted group $(89 \%)$ were also found in the gene sets of which the expression changed in the exposed groups as compared to sham, indicating that neutrophil specific gene profile changes in the lung were almost only noticeable after LPS exposure.

The shared response of undepleted mice and neutrophil depleted mice upon LPS exposure involves predominantly increased expression of cell cycle related genes. There is apparently a rapid turnover or proliferation of cells due to increased lung epithelial renewal, which is actually often seen during acute lung inflammation [26]. As expected, besides this modulation of cell cycle, most upregulated genes are involved in immune and inflammation related processes, such as cytokine/chemokine activity and signalling, complement cascade and antigen presentation. Other modulated processes include oxidative stress response, apoptosis, cytoskeleton remodelling and lipid metabolism. Most of the genes that were downregulated by LPS exposure involved nonimmune processes, such as development, metabolism and transport. It is tempting to speculate that downregulation of these processes shifts the energy balance in favour of the immune response, which suggests that the induction of the inflammatory response goes at the expense of normally activated processes in lung tissue. Comparison of our data to several reported lung inflammatory models indicated a comparable trend for the regulation of the set of commonly lung inflammation genes, described by Pennings et al. [26].

Evidently, influx of inflammatory cells in the lung is likely to influence gene expression profiles. Pathway analysis revealed restrained cell cycle progression in the neutrophil depleted animals by modifications in cell cycle regulation, DNA replication and metaphase checkpoints, possibly referring to a higher rate of cell turnover in the undepleted LPS exposed group, suggesting that the neutrophil influx is associated with a higher risk for the accumulation and fixation of mutations. In addition, our data provide more information on the central role of PMN in the lung inflammatory response. Pathogenesis of LPS induced acute lung inflammation is characterised by a profound neutrophil influx [12], as also confirmed by pathway analysis in this study, showing the most significant induction of relevant pathways in the LPS induced inflammatory response in the group without PMN depletion. The reduced amount of genes involved in inflammatory/immune processes in the LPS group with PMN depletion can be related to the absence of neutrophils and consequently restrained lung inflammation. This suppressive effect of neutrophil depletion is most obvious in the expression of multiple genes involved in pathways related to interferon signalling, like the "IFNa/ $\beta$ signalling pathway" and the "NK62D signalling pathway". By depleting neutrophils, the interferon signalling pathways are downregulated, indicating a reduced level of lung inflammation because interferon signalling is known to play a role in the regulation of the inflammatory response in the lower respiratory tract after LPS inhalation [28]. The expression of genes involved in the "NK62D signalling pathway", resulting in GM-CSF and IFN-Y production, is, however, significantly upregulated in 
neutrophil depleted mice. GM-CSF is a proinflammatory cytokine, also synthesised by lung epithelial cells, which promotes the growth and maturation of granulocyte progenitors and the activation of mature neutrophils [29]. It primes neutrophils, making them more receptive to activation by secondary stimuli [30]. Knowing this role of GM-CSF, and the fact that several cytokines and chemokines are regulated by IFN- $\gamma$, it is conceivable that in the absence of normal PMN recruitment, homeostatic mechanism may serve to promote differentiation of myeloid progenitor cells into mature neutrophils and to enhance the production and release of cytokines after inhalation of LPS. Among the differentially regulated genes in these pathways are Stat2 and some interferon induced genes, such as Ifit2 and Isg15, but also genes involved in AP-1 signalling, for instance the 1.5-fold upregulation of Fos expression upon neutrophil depletion of LPS treated mice. c-Fos levels regulate the transcriptional activity of the transcription factor activator protein 1 (AP-1), which is a heterodimer of the proto-oncogene proteins C-FOS and C-JUN [31]. Interestingly, the promoter regions of many inflammatory cytokines contain AP-1 binding sites [32], suggesting that AP-1 activation may be necessary for the induction of acute cytokine mediated inflammation. In this way, cFos plays a role in more than one signalling process, interconnecting various signalling routes and thereby extending the inflammatory response. For instance, the interconnection of FOS, AP-1 and STAT in the "Oncostatin M signalling pathway", regulates the expression of several acute phase proteins in response to oncostatin $M$ secretion by neutrophils to reduce the local inflammation [33]. Also IL-3 activation involves AP-1; linking the previous mentioned upregulated NK62D signalling pathway to increased production of IL-3 in neutrophil depleted mice upon LPS induced lung inflammation. IL-3 stimulates the differentiation of multipotent haematopoietic stem cells into myeloid progenitor cells, as well as the proliferation of all cells in the myeloid lineage, including granulocytes, as is confirmed by the observed upregulation of the Mpo gene, which is only expressed in neutrophil precursor cells and not in mature neutrophils [34], indicating increased amounts of progenitor cells in the lungs of neutrophil depleted mice. Additionally, the chemoattractants S100a8 and S100a9, whose expression was induced in LPS exposed neutrophil depleted mice and are known to attract haematopoietic mac $1^{+}$myeloid progenitor cells in the lungs [35], may explain this observed accumulation of $\mathrm{mac}^{+} / \mathrm{gr} 1^{+}$granulocyte precursors in the lungs of neutrophil depleted mice. Altogether, these modulated pathways in the PMN depleted mice upon LPS exposure can act cooperatively to stimulate the PMN recruitment, suggesting that the organism tries to compensate for the absence of neutrophils.

Furthermore, our study provides evidence that neutrophil influx is involved in transcriptional regulation of oxidative stress during lung inflammation. A network consisting of Gp91-phox, P67-phox, P47-phox, P22-phox and Cytochrome b-558, was more expressed in LPS group with PMN. Gp91-phox and p22-phox are 2 subunits forming the core heterodimer of $\mathrm{NAD}(\mathrm{P}) \mathrm{H}$ oxidase. $\mathrm{NAD}(\mathrm{P}) \mathrm{H}$ oxidase is one of the major oxidant generating enzymes present in the lung and is induced during an inflammatory status. Imbalance of oxidants/antioxidants has long been hypothesised to play an important role in the pathogenesis of chronic lung inflammation (including COPD) [36] and is associated with cancer development [37]. Moreover, inspection of 
individual genes in the differentially expressed gene lists showed the upregulation of Noxo1 in the LPS group without PMN depletion. NOXO1 is an organiser protein that activates NADPH oxidase (NOX1) [38,39] and increased Noxo1 expression may be a marker for oxidative stress during lung inflammation. Together with the neutrophil associated "Inhibition of ROS induced apoptosis", this indicates the important role for neutrophil derived ROS in the induction of DNA damage during acute lung inflammation, which plays a significant part in the carcinogenic process. This was further confirmed by a positive correlation between gene expression changes and the DNA lesion $\mathrm{M}_{1} \mathrm{dG}$ induced by neutrophils during lung inflammation, suggesting that the extent of the inflammatory response is representative for genotoxicity. $M_{1} d G$ adducts are efficient promutagenic lesions that induce mutations in genes involved in carcinogenesis [40] and evidence has accumulated that such $M_{1} d G-D N A$ adducts play a role in several cancers, notably those with an inflammatory component in their ethiopathogenesis [41]. Thus, this correlation indicates a possible link between neutrophil induced genotoxicity, gene expression changes and inflammation related cancer.

\section{Conclusions}

We used the microarray technology to demonstrate the upregulation of inflammation associated genes in an acute lung inflammation mouse model induced by LPS. Most neutrophil dependent gene expression changes were involved in immune and inflammation related processes. A substantial amount of modulated genes and pathways provided more information on the central role of neutrophils in the inflammatory response to LPS and can impact a variety of seemingly unrelated pathological conditions. For example, sequence changes in innate immune receptors and their signalling molecules are known to alter the risk of developing not only inflammation, but also atherosclerosis and asthma [42]. Thus, the neutrophil associated profiles of the inflammatory response merit further attention, as some of these genes may increase susceptibility to inflammatory lung disease and perhaps cancer [43]. Furthermore, the positive correlation of neutrophil induced genes and the promutagenic DNA lesion $M_{1} d G$, combined with the neutrophil induced upregulation of genes in oxidative stress and cell cycle progression related pathways, suggest that the extent of the inflammatory response drives genetic instability, indicating an active role of neutrophils in tumour initiation and progression.

\section{Acknowledgements}

The authors thank Yonca Güngör for linguistically reviewing the manuscript. We are grateful for financial support from the Province of Limburg, the Netherlands. Part of the studies was supported by the European Network of Excellence ( $\mathrm{NoE}$ ) "Environmental cancer, nutrition and individual susceptibility" (ECNIS), sixth Framework programme (FP6), FOOD-CT-2005-513943. 


\section{References}

1. Coussens, L.M. and Werb, Z. (2002) Inflammation and cancer. Nature, 420, 860-867.

2. Schottenfeld, D. and Beebe-Dimmer, J. (2006) Chronic inflammation: a common and important factor in the pathogenesis of neoplasia. CA Cancer J Clin, 56, 69-83.

3. Skillrud, D.M., Offord, K.P. and Miller, R.D. (1986) Higher risk of lung cancer in chronic obstructive pulmonary disease. A prospective, matched, controlled study. Ann Intern Med, 105, 503-507.

4. Doerschuk, C.M. (2001) Mechanisms of leukocyte sequestration in inflamed lungs. Microcirculation, 8, 71-88.

5. Tockman, M.S., Anthonisen, N.R., Wright, E.C. and Donithan, M.G. (1987) Airways obstruction and the risk for lung cancer. Ann Intern Med, 106, 512-518.

6. de Visser, K.E., Eichten, A. and Coussens, L.M. (2006) Paradoxical roles of the immune system during cancer development. Nat Rev Cancer, 6, 24-37.

7. Weitzman, S.A. and Gordon, L.I. (1990) Inflammation and cancer: role of phagocyte-generated oxidants in carcinogenesis. Blood, 76, 655-663.

8. Engels, E.A. (2008) Inflammation in the development of lung cancer: epidemiological evidence. Expert Rev Anticancer Ther, 8, 605-615.

9. Gungor, N., Knaapen, A.M., Peluso, M., Haenen, G.R., Chiu, R.K., Godschalk, R.W., Schooten, F.J. (2009) Genotoxic effects of neutrophils and hypochlorous acid. Submitted to Mutagenesis (chapter 3)

10. Gungor, N., Godschalk, R.W., Pachen, D.M., Van Schooten, F.J. and Knaapen, A.M. (2007) Activated neutrophils inhibit nucleotide excision repair in human pulmonary epithelial cells: role of myeloperoxidase. Faseb J, 21, 2359-2367.

11. Gungor, N., Haegens, A., Knaapen, A.M., Godschalk, R.W., Chiu, R.K., Wouters, E.F., Schooten, F.J. (2009) Lung inflammation is associated with reduced pulmonary nucleotide excision repair in vivo. Submitted to Mutagenesis (chapter 5)

12. Martin, T.R. (2000) Recognition of bacterial endotoxin in the lungs. Am J Respir Cell Mol Biol, 23, 128-132.

13. Haegens, A., Heeringa, P., van Suylen, R.J., Steele, C., Aratani, Y., O’Donoghue, R.J., Mutsaers, S.E., Mossman, B.T., Wouters, E.F. and Vernooy, J.H. (2009) Myeloperoxidase deficiency attenuates lipopolysaccharide-induced acute lung inflammation and subsequent cytokine and chemokine production. J Immunol, 182, 7990-7996.

14. Vernooy, J.H., Dentener, M.A., van Suylen, R.J., Buurman, W.A. and Wouters, E.F. (2001) Intratracheal instillation of lipopolysaccharide in mice induces apoptosis in bronchial epithelial cells: no role for tumor necrosis factor-alpha and infiltrating neutrophils. Am J Respir Cell Mol Biol, 24, 569-576.

15. Lopez, A.F., Strath, M. and Sanderson, C.J. (1984) Differentiation antigens on mouse eosinophils and neutrophils identified by monoclonal antibodies. Br J Haematol, 57, 489-494.

16. Tacchini-Cottier, F., Zweifel, C., Belkaid, Y., Mukankundiye, C., Vasei, M., Launois, P., Milon, G. and Louis, J.A. (2000) An immunomodulatory function for neutrophils during the induction of a CD4+ Th2 response in BALB/c mice infected with Leishmania major. J Immunol, 165, 2628-2636.

17. Klebanoff, S.J., Waltersdorph, A.M. and Rosen, H. (1984) Antimicrobial activity of myeloperoxidase. Methods Enzymol, 105, 399-403.

18. Knaapen, A.M., Albrecht, C., Becker, A., Hohr, D., Winzer, A., Haenen, G.R., Borm, P.J. and Schins, R.P. (2002) DNA damage in lung epithelial cells isolated from rats exposed to quartz: role of surface reactivity and neutrophilic inflammation. Carcinogenesis, 23, 1111-1120.

19. Godschalk, R.W., Maas, L.M., Van Zandwijk, N., van 't Veer, L.J., Breedijk, A., Borm, P.J., Verhaert, J., Kleinjans, J.C. and van Schooten, F.J. (1998) Differences in aromatic-DNA adduct levels between alveolar macrophages and subpopulations of white blood cells from smokers. Carcinogenesis, 19, 819-825.

20. Munnia, A., Saletta, F., Allione, A., Piro, S., Confortini, M., Matullo, G. and Peluso, M. (2007) 32PPost-labelling method improvements for aromatic compound-related molecular epidemiology studies. Mutagenesis, 22, 381-385. 
21. Munnia, A., Bonassi, S., Verna, A., Quaglia, R., Pelucco, D., Ceppi, M., Neri, M., Buratti, M., Taioli, E., Garte, S. and Peluso, M. (2006) Bronchial malondialdehyde DNA adducts, tobacco smoking, and lung cancer. Free Radic Biol Med, 41, 1499-1505.

22. Seto, H., Seto, T., Takesue, T. and Ikemura, T. (1986) Reaction of malonaldehyde with nucleic acid. III. Studies of the fluorescent substances released by enzymatic digestion of nucleic acids modified with malonaldehyde. Chem Pharm Bull (Tokyo), 34, 5079-5085.

23. Baken, K.A., van Loveren, H., Pennings, J.L., de Vries, A., Breit, T.M. and van Steeg, H. (2006) Gene Expression Profiling of Bis(tri-n-butyltin)oxide (TBTO)-Induced Immunotoxicity in Mice and Rats. J Immunotoxicol, 3, 227-244.

24. Guo, L., Lobenhofer, E.K., Wang, C., Shippy, R., Harris, S.C., Zhang, L., Mei, N., Chen, T., Herman, D., Goodsaid, F.M., Hurban, P., Phillips, K.L., Xu, J., Deng, X., Sun, Y.A., Tong, W., Dragan, Y.P. and Shi, L. (2006) Rat toxicogenomic study reveals analytical consistency across microarray platforms. Nat Biotechnol, 24, 1162-1169.

25. Huang da, W., Sherman, B.T. and Lempicki, R.A. (2009) Systematic and integrative analysis of large gene lists using DAVID bioinformatics resources. Nat Protoc, 4, 44-57.

26. Pennings, J.L., Kimman, T.G. and Janssen, R. (2008) Identification of a common gene expression response in different lung inflammatory diseases in rodents and macaques. PLoS One, 3, e2596.

27. Larson, M.A., Weber, A., Weber, A.T. and McDonald, T.L. (2005) Differential expression and secretion of bovine serum amyloid A3 (SAA3) by mammary epithelial cells stimulated with prolactin or lipopolysaccharide. Vet Immunol Immunopathol, 107, 255-264.

28. Burch, L.H., Yang, I.V., Whitehead, G.S., Chao, F.G., Berman, K.G. and Schwartz, D.A. (2006) The transcriptional response to lipopolysaccharide reveals a role for interferon-gamma in lung neutrophil recruitment. Am J Physiol Lung Cell Mol Physiol, 291, L677-682.

29. Bittleman, D.B., Erger, R.A. and Casale, T.B. (1996) Cytokines induce selective granulocyte chemotactic responses. Inflamm Res, 45, 89-95.

30. Nagata, M., Sedgwick, J.B. and Busse, W.W. (1995) Differential effects of granulocytemacrophage colony-stimulating factor on eosinophil and neutrophil superoxide anion generation. J Immunol, 155, 4948-4954.

31. Ransone, L.J. and Verma, I.M. (1990) Nuclear proto-oncogenes fos and jun. Annu Rev Cell Biol, 6, 539-557.

32. Koj, A. (1996) Initiation of acute phase response and synthesis of cytokines. Biochim Biophys Acta, 1317, 84-94.

33. Grenier, A., Dehoux, M., Boutten, A., Arce-Vicioso, M., Durand, G., Gougerot-Pocidalo, M.A. and Chollet-Martin, S. (1999) Oncostatin M production and regulation by human polymorphonuclear neutrophils. Blood, 93, 1413-1421.

34. Friedman, A.D. (2002) Transcriptional regulation of granulocyte and monocyte development. Oncogene, 21, 3377-3390.

35. Hiratsuka, S., Watanabe, A., Aburatani, H. and Maru, Y. (2006) Tumour-mediated upregulation of chemoattractants and recruitment of myeloid cells predetermines lung metastasis. Nat Cell Biol, 8, 1369-1375.

36. MacNee, W. (2005) Pulmonary and systemic oxidant/antioxidant imbalance in chronic obstructive pulmonary disease. Proc Am Thorac Soc, 2, 50-60.

37. Ohshima, H., Tatemichi, M. and Sawa, T. (2003) Chemical basis of inflammation-induced carcinogenesis. Arch Biochem Biophys, 417, 3-11.

38. Banfi, B., Clark, R.A., Steger, K. and Krause, K.H. (2003) Two novel proteins activate superoxide generation by the NADPH oxidase NOX1. J Biol Chem, 278, 3510-3513.

39. Cheng, G., Ritsick, D. and Lambeth, J.D. (2004) Nox3 regulation by NOXO1, p47phox, and p67phox. J Biol Chem, 279, 34250-34255.

40. Zienolddiny, S., Ryberg, D. and Haugen, A. (2000) Induction of microsatellite mutations by oxidative agents in human lung cancer cell lines. Carcinogenesis, 21, 1521-1526. 
41. Nair, U., Bartsch, H. and Nair, J. (2007) Lipid peroxidation-induced DNA damage in cancer-prone inflammatory diseases: a review of published adduct types and levels in humans. Free Radic Biol Med, 43, 1109-1120.

42. Cook, D.N., Pisetsky, D.S. and Schwartz, D.A. (2004) Toll-like receptors in the pathogenesis of human disease. Nat Immunol, 5, 975-979.

43. Kline, J.N., Cowden, J.D., Hunninghake, G.W., Schutte, B.C., Watt, J.L., Wohlford-Lenane, C.L., Powers, L.S., Jones, M.P. and Schwartz, D.A. (1999) Variable airway responsiveness to inhaled lipopolysaccharide. Am J Respir Crit Care Med, 160, 297-303. 



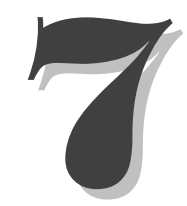

\section{Summary and}

\section{general discussion}


Inflammation has been recognised as an important factor in cancer development [1]. In some types of cancer, an oncogenic change induces and inflammatory microenvironment that promotes the development of tumours (extrinsic pathway). Regardless of its origin, 'smouldering' inflammation in the tumour microenvironment has many tumour promoting effects. It aids in the proliferation and survival of malignant cells, and promotes angiogenesis and metastasis. Conversely, in other types of cancer, inflammatory conditions are present before a malignant change occurs and augment the risk of developing cancer (intrinsic pathway). The two pathways converge in the activation of transcription factors (mainly NF-KB, STAT-3 and HIF1 $\alpha$ ), which coordinate the production of inflammatory mediators (cytokines and chemokines), which in their turn recruit and activate inflammatory cells (e.g. neutrophils), resulting in inflammation. These mediators and effectors of inflammation are important constituents of the local environment of tumours [2]. Although the connection between inflammation and cancer is now generally accepted, it remains unclear whether inflammation is sufficient for cancer development. This thesis focuses on one candidate for endogenous 'inflammatory carcinogen', namely reactive oxygen species released by inflammatory neutrophils.

For the lung, experimental studies with rats, as well as molecular epidemiological studies in humans, have provided evidence that the influx of neutrophils into the airways may be an important process linking inflammation with carcinogenesis. Nevertheless, the mechanisms involved in inflammation (neutrophil) related carcinogenesis have only partly been elucidated. Carcinogenesis is a complicated multistep process and specifically in the initiation stage, genotoxic events are thought to play a crucial role. It is suggested that the genotoxic capacity of neutrophils may be a crucial etiological factor in this carcinogenic response. Neutrophils are a major source of oxidants in the inflamed lung, and the constant release of reactive oxygen species (ROS) by these cells provides a plausible mechanism by which inflammatory cells and pulmonary carcinogenesis might be related; ROS cause genetic alterations in the lung epithelium, which may induce/promote cancer development [3]. In vitro studies, using cocultures of activated neutrophils and target cells, indeed indicated oxidative DNA disturbances induced by neutrophils, which seems mainly driven by the release of hydrogen peroxide $\left(\mathrm{H}_{2} \mathrm{O}_{2}\right)$. However, the major neutrophil derived oxidant is the myeloperoxidase (MPO) catalysed hypochlorous acid ( $\mathrm{HOCl})$ [4]. Interestingly, there is only limited data available on the potential role of this ROS in inflammation related carcinogenesis.

In addition to the direct genotoxic effects of ROS, neutrophils are also implicated in pulmonary genotoxicity via the promotion of metabolic activation of inhaled chemicals carcinogens, thereby generating highly DNA reactive and mutagenic compounds. The most relevant pathway by which neutrophils may enhance biological activation of chemical carcinogenesis is probably a MPO mediated peroxidative metabolism, activating carcinogenic polycyclic aromatic hydrocarbons (PAH), such as benzo[a]pyrene $[5,6]$. In this way, MPO has been implicated in the pathogenesis of inflammation related carcinogenesis by epidemiological studies, with reference to the $-463 \mathrm{G} \rightarrow \mathrm{A}$ polymorphism in the promoter region of the MPO gene, which is associated with a 
reduced risk of lung cancer $[7,8]$. Considering the role of MPO in the generation of $\mathrm{HOCl}$, it could also be assumed that the possible protective effect of the $-463 \mathrm{~A}$ allele is mediated through a reduced production of $\mathrm{HOCl}$.

Nevertheless, the causal role of neutrophils in ROS mediated DNA damage and mutagenesis is still primarily described by in vitro experiments. In vivo experiments, using experimental animals, have mainly provided indirect evidence implying that additional research is needed to further test the relation between neutrophils $/ \mathrm{MPO} / \mathrm{HOCl}$ and genotoxicity in the respiratory tract. The aim of the present thesis was to investigate the role of neutrophils in inflammation related carcinogenesis, focussing on three major pathways of neutrophil induced genotoxicity using both in vitro and in vivo models. In the first part of the thesis (chapter 3), we specifically focussed on mechanisms involved in primary genotoxicity induced by neutrophils and $\mathrm{HOCl}$, whereas in chapters 4 \& 5, a possible inhibitory effect of neutrophil derived $\mathrm{HOCl}$ on nucleotide excision repair is described, as an additional contribution of neutrophil derived oxidants to the genotoxic environment of lung inflammation. In the final chapter 6, a broader characterisation of the neutrophil induced effects in the mouse lung is presented by using gene expression profiling.

\section{Genotoxic effects of neutrophils and $\mathrm{HOCl}$}

At this moment, it is generally accepted that the genotoxic capacity of neutrophils is at least partly attributable to the generation of DNA damaging and mutagenic ROS. In the past, the major focus was on $\mathrm{H}_{2} \mathrm{O}_{2}$ generated by neutrophils as being the presumed primary mediator of genotoxic effects, because it serves as a latent form of hydroxyl radical, the most reactive ROS towards DNA [9]. However, under physiological conditions, up to $70 \%$ of $\mathrm{H}_{2} \mathrm{O}_{2}$ is consumed by the neutrophil derived enzyme MPO to generate the strong oxidant $\mathrm{HOCl}$ [4], of which the genotoxic capacity is still unclear.

In chapter 3, the DNA damaging and mutagenic effects of $\mathrm{HOCl}$ on lung cells have been described. This study is the first to report that $\mathrm{HOCl}$ induces mutations in the HPRT gene of lung epithelial cells, suggesting an indirect genotoxic effect of $\mathrm{HOCl}$ by its attack on lipid and/or proteins producing malondialdehyde (MDA) and subsequent formation of 3-(2-Deoxy- $\beta$-D-erythro-pentofuranosyl)pyrimido[1,2- $\alpha$ ]purin$10(3 H)$-one $\left(M_{1} d G\right)$ adducts. An LPS induced acute lung inflammation mouse model, using depletion of circulating neutrophils, confirmed the link between pulmonary neutrophil influx, $\mathrm{HOCl}$ and formation of $\mathrm{M}_{1} \mathrm{dG}$ adducts in vivo. Taken together, these data indicate that the MPO catalysed formation of $\mathrm{HOCl}$ during pulmonary inflammation should be considered as a significant source of neutrophil induced genotoxicity and possibly mutagenesis. These data support findings from recent molecular epidemiological studies, reporting a protective effect of a $463 \mathrm{G} \rightarrow$ A polymorphism in the promoter region of the MPO gene on the lung cancer risk in smokers [7, 8]. However, as the in our studies used A549 cells present an adenomacarcinoma cell line and are in fact not a progenitor cell type, these may not be the ideal cells to explore genotoxic influ- 
ence of $\mathrm{HOCl}$ relevant for tumour initiation. Therefore, further investigation of mutagenic effects of $\mathrm{HOCl}$ in primary lung epithelial cells may be more relevant for the initial genotoxic events that may occur during cancer development. While it is certainly possible that neutrophils are involved in the initiation events of pulmonary carcinogenesis, our data on $\mathrm{HOCl}$ induced genomic instability may also add to the known fact that neutrophil infiltration into tumours stimulates tumour progression [10].

\section{DNA repair inhibition by neutrophils and $\mathrm{HOCl}$}

Although $\mathrm{HOCl}$ formation has been linked to induction of DNA damage, as described above, there is growing evidence that the protective effect of the A allele for lung cancer is predominantly observed in smokers, mainly suggesting an interaction between neutrophils, MPO and cigarette smoke constituents [11, 12]. The initial explanation for this association was sought in the role of MPO in the bioactivation of inhaled carcinogens. For example, MPO has been demonstrated to enhance the transformation of the prototype PAH benzo[a]pyrene into DNA binding metabolites (e.g. benzo[a]pyrene-diol-epoxide) [6, 13]. If these helix distorting DNA lesions escape from specific DNA repair (i.e. nucleotide excision repair (NER)), they may cause replication fork blocks, ultimately leading to mutagenesis and carcinogenesis [14].

As recent data have revealed that oxidising species, such as 4-hydroxynonenal [15], MDA [16] and nitric oxide [17], are endogenous inhibitors of NER and considering the potent protein oxidising effect of $\mathrm{HOCl}$, the second hypothesis of the thesis focussed on the potential of $\mathrm{HOCl}$ to modulate DNA repair capacity in lung epithelial cells. Chapter 4 demonstrated that neutrophils are potent inhibitors of NER in human pulmonary epithelial cells in vitro, via the MPO mediated generation of $\mathrm{HOCl}$. A loss of function of NER enzymes, originating from direct $\mathrm{HOCl}$ induced oxidative attack on proteins, could only partly explain the NER inhibitory effects of $\mathrm{HOCl}$ on target cells, indicating that other mechanisms, like the formation of protein-DNA crosslinks [18], may be involved. Also the $\mathrm{HOCl}$ induced lipid peroxidation/protein oxidation product MDA, such as reported in chapter 3 , has been shown to directly interact with repair enzymes [16], providing an additional possible mechanism for the observed $\mathrm{HOCl}$ induced NER inhibition. The relevance of this in vitro finding for DNA repair in vivo has been described in chapter $\mathbf{5}$, demonstrating an association between LPS induced pulmonary inflammation and reduced NER in the mouse lung. The effect of neutrophils was revealed by the use of an MPO knockout mouse model and the systemic depletion of circulating neutrophils with specific antibodies. However, in contrast to the in vitro findings, no distinct role of either MPO (and hence $\mathrm{HOCl}$ ) or neutrophils was shown, suggesting that other factors are mediating inhibition of NER in the inflamed mouse lung. It is suggested that resident alveolar macrophages, by generating reactive nitrogen species (RNS), including nitric oxide, may be causing DNA repair inhibition [17].

Nonetheless, the results of chapter $4 \& 5$ together indicate an inflammation associated reduction of NER as a significant and previously unrecognised potential contri- 
butory factor in the development of inflammation related pulmonary cancer. This effect may be most significant in subjects that are exposed to chemical carcinogens, for instance by chronic inhalation of cigarette smoke, and showing a concomitant pulmonary inflammatory response. NER is the most important repair pathway to remove large helix distorting DNA adducts that are produced following inhalation of such chemical carcinogens (e.g. PAH) [19, 20], and the formation of these promutagenic PAH-DNA adducts have been implicated as a causal process in lung cancer development in smokers [21]. As studies with NER deficient mice showed that effective DNA repair is crucial to prevent the carcinogenic effects of PAH induced DNA damage [22], it can be speculated that processes leading to suppression of the relevant DNA repair pathways may have a detrimental effect on the cancer susceptibility of individuals exposed to such chemicals. Epidemiological studies have indeed shown that polymorphisms in NER genes, leading to (hypothetically) decreased phenotypical NER capacity, are associated with increased risk of lung carcinogenesis [23, 24]. In a wider perspective, the present finding further supports the notion that (chronic) inflammation may be an important factor determining susceptibility to cancer following exposure to environmental chemicals, and could provide an additional explanation for the association between MPO polymorphisms and risk of pulmonary DNA adducts formation and carcinogenesis in PAH exposed subjects [25, 26].

\section{Neutrophil induced inflammatory pathways and gene expression changes in the lung microenvironment}

It should be realised, however, that induction of DNA damage and mutagenesis alone does not cause cancer and that neutrophils, for instance by generating an inflammatory prooxidant environment, may have an impact on the initiation and progression of carcinogenesis. In this way, the release of ROS by neutrophils is also believed to cause a cell proliferative response, which may contribute significantly to the carcinogenic response following chronic inflammation.

As gene expression changes usually occur in early stages of disease development, the expression of inflammation associated genes and the identification of pathways related to mechanisms of inflammation related carcinogenesis, is studied in chapter 6. However, no significant effect of neutrophils was observed on genes involved in carcinogenic processes, as most gene expression changes were related to immune and inflammation related processes providing more information on the central role of neutrophils in the inflammatory response. Nonetheless, these neutrophil associated profiles of the inflammatory response merit further attention, as they may increase susceptibility to inflammatory lung disease and may also impact on seemingly unrelated pathological conditions and perhaps cancer, regarding the involvement of inflammatory mediators (chemokines and cytokines) in cancer related inflammation. Another finding is the neutrophil induced upregulation of multiple genes involved in oxidative stress related biological processes and, moreover, a positive correlation between the neutrophil induced gene expression response and the promutagenic 
DNA lesion $M_{1} d G$, as reported in chapter 3. Additionally, lung inflammation revealed neutrophil dependent upregulation of cell cycle progression related pathways, possibly referring to a higher cell turnover rate, suggesting that neutrophil influx is associated with a higher risk of accumulation and fixation of mutations. These results, in combination with the role of impaired DNA repair pathways as part of cancer ethiopathogenesis (chapter $4 \& 5$ ), provide a further confirmation for the link between inflammation and pulmonary genotoxicity and suggest that it is indeed the extent of the inflammatory response which could drive genetic instability in the genesis but also perpetuation of carcinogenesis.

\section{Closing remarks}

The emphasis of the present thesis was to investigate the role of neutrophils in inflammation related carcinogenesis. At present, there is accumulating in vivo evidence that neutrophils are an important factor in later stages of the carcinogenic process. PMN infiltration into tumours might stimulate tumour progression by contributing to genetic instability of the tumour cells through release of ROS [10]. In line with this, it has been shown that tumour growth can be inhibited by the elimination of circulating PMN [27]. However, experimental evidence on more upstream events on tumour initiation, such as DNA damage and mutagenesis, is limited. Additionally to in vitro coculture models, the use of an MPO knockout mouse model and the systemic depletion of circulating neutrophils with specific antibodies is a promising approach to further reveal the effect of neutrophils in animals acutely exposed to inflammatory agents. By using these models, this thesis described that MPO catalysed $\mathrm{HOCl}$ increases DNA damage and inhibits the repair of promutagenic bulky lesions, possibly inducing mutagenesis. However, it should be emphasised that genotoxicity only relates to DNA reactivity, which means that is essentially not the same as carcinogenicity. A major challenge would thus be to investigate if the in vitro $\mathrm{HOCl}$ induced mutagenesis, as discussed in this thesis, can be extrapolated to a neutrophil influx in the in vivo situation.

A following question that rises is whether the in vitro and in vivo mechanisms of inflammation related carcinogenesis and the role of neutrophils herein, as discussed in this thesis, can be extrapolated to humans. So far, it is still unclear whether neutrophils really cause ROS induced genotoxicity in the inflamed human respiratory tract. On the other hand, recent molecular epidemiological studies, in combination with experimental in vitro and in vivo studies, have provided consistent evidence that neutrophils and human pulmonary carcinogenesis might be causally related by the capacity of neutrophils, via the release of MPO, to promote biological activation of environmental carcinogens, like PAH, into DNA damaging metabolites [28]. Whereas data presented in this thesis extended these observations by showing that inflammatory neutrophils, via MPO catalysed $\mathrm{HOCl}$, increase DNA lesions and inhibit the repair of such promutagenic DNA adducts, possibly inducing mutagenesis in target cells relevant for tumourigenic outcomes, still a lot of work needs to be done to provide deeper 
insight in the implication of these processes in pulmonary carcinogenesis and formal proof that inflammation causes cancer is still required. Such knowledge may eventually lead to new approaches for inflammatory cancer prevention. Evidently, although the present study focussed on the lung, it needs to be emphasised that our findings may also be of importance for other organs where cancer development is associated with pre-existing neutrophilic inflammation. 


\section{References}

1. Coussens, L.M. and Werb, Z. (2002) Inflammation and cancer. Nature, 420, 860-867.

2. Mantovani, A., Allavena, P., Sica, A. and Balkwill, F. (2008) Cancer-related inflammation. Nature, 454, 436-444.

3. Weitzman, S.A. and Gordon, L.I. (1990) Inflammation and cancer: role of phagocyte-generated oxidants in carcinogenesis. Blood, 76, 655-663.

4. Hampton, M.B., Kettle, A.J. and Winterbourn, C.C. (1998) Inside the neutrophil phagosome: oxidants, myeloperoxidase, and bacterial killing. Blood, 92, 3007-3017.

5. Kensler, T.W., Egner, P.A., Moore, K.G., Taffe, B.G., Twerdok, L.E. and Trush, M.A. (1987) Role of inflammatory cells in the metabolic activation of polycyclic aromatic hydrocarbons in mouse skin. Toxicol Appl Pharmacol, 90, 337-346.

6. Mallet, W.G., Mosebrook, D.R. and Trush, M.A. (1991) Activation of (+-)-trans-7,8-dihydroxy-7,8dihydrobenzo[a]pyrene to diolepoxides by human polymorphonuclear leukocytes or myeloperoxidase. Carcinogenesis, 12, 521-524.

7. London, S.J., Lehman, T.A. and Taylor, J.A. (1997) Myeloperoxidase genetic polymorphism and lung cancer risk. Cancer Res, 57, 5001-5003.

8. Cascorbi, I., Henning, S., Brockmoller, J., Gephart, J., Meisel, C., Muller, J.M., Loddenkemper, R. and Roots, I. (2000) Substantially reduced risk of cancer of the aerodigestive tract in subjects with variant--463A of the myeloperoxidase gene. Cancer Res, 60, 644-649.

9. Henle, E.S. and Linn, S. (1997) Formation, prevention, and repair of DNA damage by iron/hydrogen peroxide. J Biol Chem, 272, 19095-19098.

10. Soo, C.C., Haqqani, A.S., Hidiroglou, N., Swanson, J.E., Parker, R.S. and Birnboim, H.C. (2004) Dose-dependent effects of dietary alpha- and gamma-tocopherols on genetic instability in mouse Mutatect tumors. J Natl Cancer Inst, 96, 796-800.

11. Schabath, M.B., Spitz, M.R., Zhang, X., Delclos, G.L. and Wu, X. (2000) Genetic variants of myeloperoxidase and lung cancer risk. Carcinogenesis, 21, 1163-1166.

12. Schabath, M.B., Spitz, M.R., Hong, W.K., Delclos, G.L., Reynolds, W.F., Gunn, G.B., Whitehead, L.W. and Wu, X. (2002) A myeloperoxidase polymorphism associated with reduced risk of lung cancer. Lung Cancer, 37, 35-40.

13. Petruska, J.M., Mosebrook, D.R., Jakab, G.J. and Trush, M.A. (1992) Myeloperoxidase-enhanced formation of (+-)-trans-7,8-dihydroxy-7,8-dihydrobenzo[a]pyrene-DNA adducts in lung tissue in vitro: a role of pulmonary inflammation in the bioactivation of a procarcinogen. Carcinogenesis, 13, 1075-1081.

14. Luch, A. (2005) Nature and nurture - lessons from chemical carcinogenesis. Nat Rev Cancer, 5, 113-125.

15. Feng, Z., Hu, W. and Tang, M.S. (2004) Trans-4-hydroxy-2-nonenal inhibits nucleotide excision repair in human cells: a possible mechanism for lipid peroxidation-induced carcinogenesis. Proc Natl Acad Sci U S A, 101, 8598-8602.

16. Feng, Z., Hu, W., Marnett, L.J. and Tang, M.S. (2006) Malondialdehyde, a major endogenous lipid peroxidation product, sensitizes human cells to UV- and BPDE-induced killing and mutagenesis through inhibition of nucleotide excision repair. Mutat Res, 601, 125-136.

17. Chien, Y.H., Bau, D.T. and Jan, K.Y. (2004) Nitric oxide inhibits DNA-adduct excision in nucleotide excision repair. Free Radic Biol Med, 36, 1011-1017.

18. Kulcharyk, P.A. and Heinecke, J.W. (2001) Hypochlorous acid produced by the myeloperoxidase system of human phagocytes induces covalent cross-links between DNA and protein. Biochemistry, 40, 3648-3656.

19. Lindahl, T. and Wood, R.D. (1999) Quality control by DNA repair. Science, 286, 1897-1905.

20. Gillet, L.C. and Scharer, O.D. (2006) Molecular mechanisms of mammalian global genome nucleotide excision repair. Chem Rev, 106, 253-276.

21. Denissenko, M.F., Pao, A., Tang, M. and Pfeifer, G.P. (1996) Preferential formation of benzo[a]pyrene adducts at lung cancer mutational hotspots in P53. Science, 274, 430-432. 
22. Ide, F., lida, N., Nakatsuru, Y., Oda, H., Tanaka, K. and Ishikawa, T. (2000) Mice deficient in the nucleotide excision repair gene XPA have elevated sensitivity to benzo[a]pyrene induction of lung tumors. Carcinogenesis, 21, 1263-1265.

23. Wu, X., Zhao, H., Wei, Q., Amos, C.I., Zhang, K., Guo, Z., Qiao, Y., Hong, W.K. and Spitz, M.R. (2003) XPA polymorphism associated with reduced lung cancer risk and a modulating effect on nucleotide excision repair capacity. Carcinogenesis, 24, 505-509.

24. Zienolddiny, S., Campa, D., Lind, H., Ryberg, D., Skaug, V., Stangeland, L., Phillips, D.H., Canzian, F. and Haugen, A. (2006) Polymorphisms of DNA repair genes and risk of non-small cell lung cancer. Carcinogenesis, 27, 560-567.

25. Dally, H., Gassner, K., Jager, B., Schmezer, P., Spiegelhalder, B., Edler, L., Drings, P., Dienemann, H., Schulz, V., Kayser, K., Bartsch, H. and Risch, A. (2002) Myeloperoxidase (MPO) genotype and lung cancer histologic types: the MPO $-463 \mathrm{~A}$ allele is associated with reduced risk for small cell lung cancer in smokers. Int $J$ Cancer, 102, 530-535.

26. Van Schooten, F.J., Boots, A.W., Knaapen, A.M., Godschalk, R.W., Maas, L.M., Borm, P.J., Drent, M. and Jacobs, J.A. (2004) Myeloperoxidase (MPO) -463G->A reduces MPO activity and DNA adduct levels in bronchoalveolar lavages of smokers. Cancer Epidemiol Biomarkers Prev, 13, 828-833.

27. Pekarek, L.A., Starr, B.A., Toledano, A.Y. and Schreiber, H. (1995) Inhibition of tumor growth by elimination of granulocytes. J Exp Med, 181, 435-440.

28. Knaapen, A.M., Gungor, N., Schins, R.P., Borm, P.J. and Van Schooten, F.J. (2006) Neutrophils and respiratory tract DNA damage and mutagenesis: a review. Mutagenesis, 21, 225-236. 



\section{Samenvatting en}

\section{algemene discussie}


Ontsteking wordt beschouwd als een belangrijke factor bij de ontwikkeling van kanker [1]. Kanker en ontstekingen zijn met elkaar verbonden door twee pathways: de extrinsieke en de intrinsieke pathway. Bij sommige kankersoorten leidt een oncogene verandering tot een ontstoken micro-omgeving die de ontwikkeling van tumoren bevordert (extrinsieke pathway). Een dergelijke 'sluimerende' ontsteking in de microomgeving van de tumor heeft, ongeacht de oorsprong ervan, verschillende tumorbevorderende effecten. Het draagt bij tot de proliferatie en de overleving van kwaadaardige cellen en bevordert de angiogenese en de metastase. Bij andere kankersoorten daarentegen, bestaat er vóór de kwaadaardige ontwikkeling reeds een ontsteking die het risico op de ontwikkeling van kanker verhoogt (intrinsieke pathway). Deze twee pathways komen samen in de activering van transcriptiefactoren (voornamelijk NF-kB, STAT-3 en HIF1 $\alpha$ ) die de productie van inflammatoire mediatoren, zoals cytokines en chemokines, coördineren. Deze stoffen produceren en activeren op hun beurt inflammatoire cellen (bijv. neutrofielen) en dit volledige proces resulteert uiteindelijk in een ontsteking. De inflammatoire mediatoren en effectoren zijn belangrijke onderdelen van de tumormicro-omgeving [2]. Hoewel het verband tussen ontstekingen en kanker tegenwoordig algemeen aanvaard is, blijft het echter onduidelijk of een ontsteking alleen volstaat om kanker te ontwikkelen. In dit proefschrift ligt de nadruk op reactieve zuurstofradicalen, vrijgegeven door inflammatoire neutrofielen, als mogelijke endogene 'inflammatoire carcinogenen'.

Wat betreft de long, bewezen zowel experimentele onderzoeken op ratten, als moleculaire epidemiologische onderzoeken bij mensen dat de infiltratie van neutrofielen in de luchtwegen mogelijk een belangrijk proces is waardoor ontstekingen worden gekoppeld aan carcinogenese. Desondanks werden de betrokken mechanismen bij ontstekingsgerelateerde (neutrofiel-) carcinogenese slechts gedeeltelijk toegelicht. Carcinogenese is een complex, meerstaps proces waarin voornamelijk de genotoxische gebeurtenissen in de beginfase een zeer belangrijke rol te spelen. Met name de genotoxische capaciteit van neutrofielen blijkt hierin een cruciale etiologische factor te zijn. Neutrofielen vormen een zeer grote bron van oxidanten in de ontstoken long en de voortdurende afscheiding van reactieve zuurstofradicalen (ROS) vormt mogelijk de basis van de relatie tussen de inflammatoire cellen en de pulmonaire carcinogenese. ROS veroorzaken genetische wijzigingen in het longepitheel die kunnen leiden tot de ontwikkeling van kanker of deze kunnen bevorderen [3]. In vitro onderzoeken met coculturen van geactiveerde neutrofielen en doelcellen indiceerden inderdaad oxidatieve DNA-schade veroorzaakt door neutrofielen, hoofdzakelijk aangedreven door de afscheiding van waterstofperoxide $\left(\mathrm{H}_{2} \mathrm{O}_{2}\right)$. De belangrijkste neutrofiel-afgeleide oxidant is echter myeloperoxidase (MPO-) gekatalyseerd waterstofhypochloriet $(\mathrm{HOCl})$ [4]. Opvallend is dat er slechts een beperkt aantal gegevens beschikbaar is over de potentiële rol van deze oxidant in ontstekingsgerelateerde carcinogenese.

Naast de rechtstreekse genotoxische effecten van ROS, zijn neutrofielen ook betrokken bij de pulmonaire genotoxiciteit via de metabolische activering van geïnhaleerde chemische carcinogenen. Als gevolg daarvan worden zeer DNA-reactieve en mutagene samenstellingen geproduceerd. De meest relevante pathway via dewelke neutrofielen de biologische activering van chemische carcinogenen bevorderen is 
waarschijnlijk een MPO-gemedieerd peroxidatief metabolisme dat carcinogene polycyclische aromatische koolwaterstoffen (PAK), zoals benzo[a]pyreen, activeert $[5,6]$. Aldus toonden epidemiologische onderzoeken aan dat MPO betrokken is bij de pathogenese van ontstekingsgerelateerde carcinogenese; het $-463 \mathrm{G} \rightarrow$ polymorfisme in de promotorregio van het MPO-gen wordt geassocieerd met een verlaagd risico op longkanker [7, 8]. Rekening houdend met de rol van MPO bij de HOCl-productie kan ook worden verondersteld dat het mogelijke beschermende effect van het $-463 \mathrm{~A}$-allel een gevolg is van een lagere productie van $\mathrm{HOCl}$.

Desondanks wordt de causale rol van neutrofielen in door ROS-veroorzaakte DNA-schade en mutagenese voornamelijk beschreven door in vitro experimenten. In vivo experimenten op proefdieren leverden vooral indirecte bewijzen, vandaar dat bijkomende onderzoeken noodzakelijk zijn voor het verder bestuderen van de relatie tussen neutrofielen/MPO/HOCl en genotoxiciteit in de luchtwegen. Dit proefschrift heeft als doelstelling de rol van neutrofielen in ontstekingsgerelateerde carcinogenese te onderzoeken door gebruik te maken van zowel in vitro als in vivo modellen, met speciale aandacht voor de drie belangrijkste pathways van door neutrofiel veroorzaakte genotoxiteit. Het eerste onderdeel van het proefschrift (hoofdstuk 3) richt zich voornamelijk op de mechanismen betrokken bij de primaire genotoxiciteit veroorzaakt door neutrofielen en $\mathrm{HOCl}$. Hoofdstukken $\mathbf{4} \& \mathbf{5}$ behandelen het mogelijke remmende effect van neutrofiel-gederiveerd $\mathrm{HOCl}$ op nucleotide excisieherstel, wat mede bijdraagt tot de genotoxische omgeving van een longontsteking. In hoofdstuk 6 wordt tot slot een bredere karakterisering van de neutrofiel-afgeleide effecten in de muizenlong geschetst door middel van genexpressieprofilering.

\section{Genotoxische effecten van neutrofielen en $\mathrm{HOCl}$}

Op dit moment is het algemeen aanvaard dat de genotoxische capaciteit van neutrofielen tenminste gedeeltelijk is toe te schrijven aan de productie van DNAbeschadigende en mutagene ROS. In het verleden lag de klemtoon voornamelijk op door neutrofielen geproduceerd $\mathrm{H}_{2} \mathrm{O}_{2}$. Deze oxidant werd beschouwd als de voornaamste mediator van de genotoxische effecten, aangezien ze fungeert als een latente vorm van het hydroxylradicaal, de meest DNA-reactieve ROS [9]. Onder fysiologische omstandigheden wordt echter tot $70 \%$ van $\mathrm{H}_{2} \mathrm{O}_{2}$ verbruikt door het neutrofielafgeleide enzym MPO om zo de sterke oxidant $\mathrm{HOCl}$ [4] te kunnen produceren waarvan de genotoxische capaciteit nog steeds niet gekend is.

Hoofdstuk 3 beschrijt de DNA-beschadigende en mutagene effecten van $\mathrm{HOCl}$ op longcellen. Dit onderzoek toonde als eerste aan dat $\mathrm{HOCl}$ mutaties veroorzaakt in het HPRT-gen van longepitheelcellen en bijgevolg een indirect genotoxisch effect zou hebben door lipiden en/of proteïnen aan te vallen, waardoor malondialdehyde (MDA) en 3-(2-Deoxy- $\beta$-D-erythro-pentofuranosyl)pyrimido[1,2- $\alpha$ ]purin-10(3H)-1 (M $\quad\left(\mathrm{M}_{1}\right)$ adducten worden gevormd. Dankzij depletie van circulerende neutrofielen slaagden we erin om in een muizenmodel met een LPS-geïnduceerde acute longontsteking het verband tussen de infiltratie van pulmonaire neutrofielen, $\mathrm{HOCl}$ en de vorming van 
$\mathrm{M}_{1} \mathrm{dG}-a d d u c t e n$ in vivo aan te tonen. Al deze resultaten indiceren dat de MPOgekatalyseerde vorming van $\mathrm{HOCl}$ tijdens een longontsteking dient te worden beschouwd als een belangrijke bron van neutrofiel-geïnduceerde genotoxiciteit en mogelijk mutagenese. De resultaten onderbouwen eveneens bevindingen uit recente moleculaire epidemiologische onderzoeken waarin het beschermende effect wordt beschreven van een $463 \mathrm{G} \rightarrow \mathrm{A}$-polymorfisme van het MPO-gen op longkanker bij rokers [7, 8]. Aangezien de in ons onderzoek gebruikte A549-cellen adenomacarcinomacellen zijn en dus niet behoren tot het progenitorceltype, zijn ze mogelijk niet ideaal geschikt voor het onderzoeken van de genotoxische invloed van $\mathrm{HOCl}$ op het ontstaan van tumoren. Daarom is verder onderzoek naar de mutagene effecten van $\mathrm{HOCl}$ in primaire longepitheelcellen waarschijnlijk veel relevanter voor de initiële genotoxische effecten die mogelijk optreden tijdens de ontwikkeling van kanker. Hoewel de mogelijkheid zeker bestaat dat neutrofielen betrokken zijn bij de initiatiefase van pulmonaire carcinogenese, vormen onze gegevens over de $\mathrm{HOCl}$-geïnduceerde genomische instabiliteit een toevoeging op het gekende feit dat de infiltratie van neutrofielen in tumoren de ontwikkeling van de tumor stimuleert [10].

\section{Inhibitie van DNA-herstel door neutrofielen en $\mathrm{HOCl}$}

Hoewel de vorming van $\mathrm{HOCl}$ werd geassocieerd met de inductie van DNA-schade, zoals hierboven beschreven, zijn er steeds meer bewijzen dat het beschermende effect van het A-allel op longkanker hoofdzakelijk wordt geobserveerd in rokers, wat een interactie tussen neutrofielen, MPO en sigarettenrookcomponenten suggereert $[11,12]$. De eerste verklaring voor dit verband werd gezocht in de rol van MPO in de bio-activering van geïnhaleerde carcinogenen. Zo werd bijvoorbeeld aangetoond dat MPO de transformatie van het prototype PAK benzo[a]pyreen in DNA-bindende metabolieten (bijv. benzo[a]pyreen-diol-epoxide) verhoogt $[6,13]$. Als deze helixverstorende DNA-lesies ontglippen aan het specifieke DNA-herstel (i.e. nucleotide excisieherstel (NER)), blokkeren zij mogelijk de replicatievork, wat uiteindelijk resulteert in mutagenese en carcinogenese [14].

Aangezien recent onderzoek heeft aangetoond dat oxiderende stoffen, zoals 4hydroxynonenal [15], MDA [16] en stikstofmonoxide [17], endogene remmers van NER zijn en gezien het mogelijke proteïne-oxiderende effect van $\mathrm{HOCl}$, handelt de tweede hypothese van dit proefschrift voornamelijk over de capaciteit van $\mathrm{HOCl}$ om DNA-herstel in de longepitheelcellen te moduleren. In hoofdstuk 4 toonden we in menselijke longepitheelcellen in vitro aan dat neutrofielen mogelijke NER-remmers zijn door de MPO-geïnduceerde productie van $\mathrm{HOCl}$. De NER-remmende effecten van $\mathrm{HOCl}$ op doelcellen konden slechts gedeeltelijk worden verklaard door de verminderde werking van de NER-enzymen, veroorzaakt door een directe $\mathrm{HOCl}$ geïnduceerde oxidatieve aanval op proteïnen. Waarschijnlijk zijn ook andere mechanismen, zoals de vorming van proteïne-DNA crosslinks, hierbij betrokken [18]. Er werd eveneens aangetoond dat het $\mathrm{HOCl}$-geïnduceerde lipideperoxidatie-/proteïneoxidatieproduct MDA, zoals beschreven in hoofdstuk 3, rechtstreeks reageert op 
herstelenzymes [16] en aldus een bijkomend mogelijk mechanisme vormt voor de geobserveerde $\mathrm{HOCl}$-geïnduceerde NER-inhibitie. De relevantie van deze in vitro bevinding voor DNA-herstel in vivo werd beschreven in hoofdstuk 5, waarin een verband tussen LPS-geïnduceerde pulmonaire ontsteking en verminderde NER in de muizenlong wordt onderbouwd. Het effect van neutrofielen werd toegelicht door het gebruik van een MPO-knockout-muizenmodel en de systemische depletie van circulerende neutrofielen met specifieke antilichamen. In tegenstelling tot de in vitro bevindingen, werd noch van MPO (en bijgevolg van $\mathrm{HOCl}$ ), noch van neutrofielen een duidelijke rol bewezen, wat wijst op het feit dat andere factoren de inhibitie van NER tot stand brengen in de ontstoken muizenlong. We veronderstellen dat de residente alveolaire macrofagen mede aan de oorzaak liggen van de inhibitie van DNA-herstel [17] door het genereren van reactieve stikstofradicalen (RNS), waaronder stikstofmonoxide.

Niettemin duiden de resultaten van hoofdstuk $4 \& 5$ de ontstekingsgerelateerde reductie van NER aan als een belangrijke en niet eerder herkende potentiële medebepalende factor in de ontwikkeling van ontstekingsgerelateerde longkanker. Dit effect is wellicht het meest doorslaggevend bij personen blootgesteld aan chemische carcinogenen (bijv. PAK), bijvoorbeeld door chronische inhalatie van sigarettenrook. NER is de belangrijkste herstelpathway voor de verwijdering van grote helixverstorende DNA-adducten die worden geproduceerd na inhalatie van dergelijke chemische carcinogenen, zoals PAK $[19,20]$. De vorming van zulke promutagene PAK-DNAadducten werd beschouwd als een causaal proces in de ontwikkeling van longkanker bij rokers [21]. Aangezien uit studies met NER-deficiënte muizen is gebleken dat een efficiënt DNA-herstel van wezenlijk belang is voor het verhinderen van de carcinogene effecten van PAK-geïnduceerde DNA-schade [22], kan worden verondersteld dat de processen, die relevante DNA-herstelpathways onderdrukken, de personen die werden blootgesteld aan dergelijke chemische stoffen mogelijk vatbaarder maken voor kanker. Epidemiologische onderzoeken toonden inderdaad aan dat de polymorfismen in NER-genen, die leiden tot een (hypothetische) verminderde fenotypische NER-capaciteit, worden geassocieerd met een verhoogd risico op longkanker [23, 24]. Bekeken vanuit een breder perspectief, onderbouwt deze bevinding de theorie die zegt dat een (chronische) ontsteking een belangrijke factor kan zijn bij de bepaling van de vatbaarheid op kanker na blootstelling aan chemische stoffen uit de omgeving. Dit biedt eventueel een bijkomende verklaring voor het verband tussen MPOpolymorfismen en het risico op de vorming van pulmonaire DNA-adducten en carcinogenese in PAK blootgestelde mensen [25, 26].

\section{Neutrofiel-geïnduceerde inflammatoire pathways en genexpressiewijzigingen in de micro-omgeving van de long}

Er moet echter ook rekening mee worden gehouden dat de inductie van DNA-schade en mutagenese alleen niet aan de oorzaak ligt van kanker en dat neutrofielen, bijvoorbeeld door het generen van een inflammatoire pro-oxidantomgeving, een impact 
kunnen hebben op de initiatie en de progressie van carcinogenese. De afscheiding van ROS door neutrofielen veroorzaakt mogelijkerwijs een celproliferatieve reactie, die een belangrijke bijdrage kan leveren aan de carcinogene respons volgend op een chronische ontsteking.

Aangezien genexpressiewijzigingen zich meestal voordoen tijdens de vroege ontwikkelingsstadia van een ziekte, werden de expressie van genen en de identificatie van pathways, betrokken bij ontstekingsgerelateerde carcinogenese, bestudeerd in hoofdstuk 6 . Er werd echter geen significant effect van neutrofielen geobserveerd in genen die betrokken zijn bij carcinogene processen, omdat het merendeel van de expressiewijzigingen verband hield met immuun- en ontstekingsgerelateerde processen die verdere informatie bieden over de centrale rol van neutrofielen in de inflammatoire reactie. Desalniettemin verdienen deze neutrofiel-geassocieerde profielen van de inflammatoire respons verdere aandacht, aangezien zij de vatbaarheid op een inflammatoire longziekte kunnen verhogen en mogelijk ook een invloed hebben op ogenschijnlijke niet verwante pathologische omstandigheden en zelfs kanker. Een andere bevinding is de neutrofiel-veroorzaakte up-regulatie van meervoudige genen betrokken bij oxidatieve stressgerelateerde biologische processen. Bovendien werd er een positieve correlatie ontdekt tussen het neutrofiel-veroorzaakte genexpressieproces en de promutagene DNA-lesie $\mathrm{M}_{1} \mathrm{dG}$, zoals beschreven in hoofdstuk 3. Daarnaast bleek longontsteking ook geassocieerd met een neutrofiel-afhankelijke up-regulatie van celcyclusgerelateerde pathways, wat mogelijk wijst op een snellere celdeling. Dit alles doet vermoeden dat de infiltratie van neutrofielen zorgt voor een vermeerdering van en tevens versnelde fixatie van mutaties. Deze resultaten bevestigen nogmaals het verband tussen ontstekingen en pulmonaire genotoxiteit en suggereren dat de omvang van het inflammatoire proces inderdaad van wezenlijk belang is voor de genetische instabiliteit in carcinogenese.

\section{Slot}

In dit proefschrift lag de klemtoon op het onderzoeken van de rol van neutrofielen in ontstekingsgerelateerde carcinogenese. Tegenwoordig zijn er steeds meer in vivo bewijzen waaruit blijkt dat neutrofielen een belangrijke rol spelen in de latere stadia van het carcinogeneseproces. PMN-infiltratie in tumoren kan de ontwikkeling ervan stimuleren door de genetische instabiliteit van de tumorcellen te beïnvloeden via de afscheiding van ROS [10]. In het verlengde van deze bevinding werd aangetoond dat de tumorgroei kan worden verhinderd door eliminatie van de circulerende PMN [27]. $\mathrm{Er}$ is slechts beperkt experimenteel bewijs voor de rol van DNA-schade en mutagenese in de vroegste stadia van carcinogenese, met name de tumorinitiatie. Ter aanvulling van de in vitro co-cultuurmodellen, is het gebruik van een MPO-knockout muizenmodel en de systemische depletie van circulerende neutrofielen met specifieke antilichamen een veelbelovende aanpak om het effect van neutrofielen op dieren, die intens werden blootgesteld aan een inflammatoire agens, te verklaren. Door gebruik van deze modellen werd in dit proefschrift beschreven dat MPO-gekatalyseerd $\mathrm{HOCl}$ 
de DNA-schade vergroot en het herstel van omvangrijke promutagene lesies verhindert en zo mogelijk de aanzet vormt tot mutagenese. Wat echter benadrukt dient te worden is dat genotoxiteit enkel refereert naar DNA-reactiviteit, wat in essentie niet hetzelfde is als carcinogeniteit. Het is bijgevolg een heel grote uitdaging om te onderzoeken of in vitro $\mathrm{HOCl}$-veroorzaakte mutagenese, zoals besproken in dit proefschrift, kan worden geëxtrapoleerd naar een neutrofielinfiltratie in vivo.

Het volgende vraagteken dat ontstaat is of de in vitro en in vivo mechanismen van ontstekingsgerelateerde carcinogenese en de rol van neutrofielen hierin, zoals beschreven in dit proefschrift, kunnen worden geëxtrapoleerd naar mensen. Tot dusver blijft het nog steeds onzeker of neutrofielen daadwerkelijk ROS-geïnduceerde genotoxiteit veroorzaken in de ontstoken menselijke luchtwegen. Anderzijds hebben recente moleculaire epidemiologische onderzoeken, in combinatie met experimentele in vitro en in vivo onderzoeken, consistente bewijzen aangevoerd waaruit blijkt dat neutrofielen en menselijke pulmonaire carcinogenese mogelijk causaal gerelateerd zijn doordat neutrofielen, via de afscheiding van MPO, de biologische activering van omgevingscarcinogenen, zoals PAK, tot DNA-beschadigende metabolieten [28] stimuleren. Dit proefschrift toont nader aan dat inflammatoire neutrofielen, via MPOgekatalyseerd $\mathrm{HOCl}$, de DNA-lesies vermeerderen en het herstel van dergelijke DNAadducten verhinderen, en aldus mogelijk leiden tot mutagenese in doelcellen met tumorverwekkende gevolgen. Toch dient er nog veel aandacht te worden besteed aan het uitdiepen van deze processen in pulmonaire carcinogenese, alsook aan het bieden van een definitief uitsluitsel dat ontstekingen inderdaad kanker veroorzaken. Dergelijke kennis kan uiteindelijk leiden tot nieuwe benaderingen voor de preventie van inflammatoire kanker. Hoewel deze studie zich beperkte tot de longen, spreekt het voor zich dat onze bevindingen ook van groot belang kunnen zijn voor andere organen waarin de ontwikkeling van kanker wordt geassocieerd met een vooraf bestaande (neutrofiel-) ontsteking. 



\section{Dankwoord}


Een promotie is een schijnbaar onmogelijke berg om te beklimmen, het proefschrift is een uitdaging om te schrijven. Hoe moeilijk het soms ook was, ik voelde me gesteund door geweldige collega's, vrienden en familie. Mede dankzij jullie kan ik tevreden terugblikken op een leerrijke ervaring en een geslaagd proefschrift. Graag zou ik een aantal personen in het bijzonder willen bedanken.

Beste (co-)promoteren, Frederik-Jan van Schooten, Ad Knaapen en Roger Godschalk, jullie zou ik graag als eerste willen bedanken voor de gegeven kansen, jullie wetenschappelijk enthousiasme, jullie flexibiliteit en natuurlijk voor de begeleiding. Het promotietraject was voor mij niet enkel een periode van wetenschappelijke groei, maar ook een ontplooiing op persoonlijk vlak. Jullie positieve blik en overtuiging waren voor mij erg motiverend en hebben me steeds een stapje verder gebracht.

Roland, thanks for your helpful comments and suggestions when reviewing my papers.

De beoordelingscommissie, bestaande uit Prof. dr. E. Wouters, Prof. dr. F. Ramaekers en Dr. R Schins, wil ik graag bedanken voor het kritisch evalueren van mijn proefschrift.

Many thanks to all co-authors of the manuscripts for the nice cooperation and their contributions. In het bijzonder: Astrid, bedankt voor je hulp bij de muizenstudie en al je antwoorden op mijn MPO-vragen. Jeroen, zonder jouw supersnelle micro-array analyses had ik hoofdstuk 6 nooit op tijd kunnen afwerken. Bedankt hiervoor!

Niets is zo fijn als werken in een omgeving met toffe collega's. Collega's van GRAT, bedankt voor jullie hulp in het lab, de fijne samenwerking en de leuke tijd, tijdens en soms ook na werktijd! 'Cool chicks' van kamer 4.106, Sabine, Karen en Nicole, het was altijd leuk om het promovendi wel-en-wee, en alles daarbuiten, met elkaar te delen. Dankjewel voor de gezellige sfeer op ons kamertje!

Ook mijn nieuwe collega's van MAASTRO wil ik graag bedanken voor hun interesse en bovenal de prettige en collegiale werksfeer.

Mijn liefste paranimfjes, Yonca en Veronique, bedankt voor jullie steun en vriendschap. Ik ben trots dat jullie op deze voor mij speciale dag aan mijn zijde staan!

Familie, schoonfamilie en vrienden erg bedankt voor jullie enorme interesse. Eindelijk zien jullie een tastbaar resultaat van waar ik de afgelopen jaren (en zeker maanden) mee bezig ben geweest. Vanaf nu heb ik meer tijd voor jullie!

Mijn zus(je), Yonca, super dat je mijn hele boekje hebt nagelezen. Ook de vertaling van de samenvatting heb ik aan jou te danken! Je hebt het zeker verdiend om mee te promoveren. Jouw vrolijkheid mag strakjes zeker niet ontbreken op de grote dag! 
Lieve mama en papa, ik ben heel dankbaar voor de rustige en stimulerende omgeving die jullie voor me zijn. Bedankt voor de steun en de kansen die jullie me al heel mijn leven geven! Sizleri çok seviyorum, büyük bir öpücük!

Wim, mijn liefje, jij weet als enige hoe moeilijk het is met een promoverende vriendin samen te leven. Toch ben je er nog altijd. Hoe kan ik je bedanken voor al je steun en hulp... Just to be with you is having the best day of my life. 



\title{
Curriculum Vitae
}

\author{
and
}

\section{Publications}




\section{About the Author}

Nejla Güngör was born on the $31^{\text {st }}$ of August 1981 in Genk, Belgium. She graduated from her secondary education at Heilig Graf Institute (Bilzen, Belgium). In the same year, she started studying Biomedical Sciences at the transnational University Limburg (tUL; cooperation between Limburgs Universitair Centrum in Diepenbeek and Maastricht University), to obtain her Magna Cum Laude 'Licenciate in the Biomedical Sciences / Master of Health Sciences'. In order to obtain this degree, she performed an internship at the BIOMED research institute in Diepenbeek on breast gland differentiation in search for early tumour markers using SAGE (Serial Analysis of Gene Expression). For this research, she was awarded the prize for the best graduation research project within the Molecular Life Sciences program. After her graduation in July 2003, she joined the BIOMED research group as a PhD student and performed research on the identification and characterisation of early and intermediary breast cancer markers by using multiple transcriptome analysis on microdissected breast cancer tissue and normal surrounding tissue. From June 2005 until August 2009, she restarted working as a PhD student at the Department of Health Risk Analysis and Toxicology (GRAT) at Maastricht University. The research conducted in these years and presented in this thesis occurred under the supervision of Prof. Dr. FJ. Van Schooten, Dr. AM. Knaapen and Dr. RWL. Godschalk. During this research project, Nejla obtained licenses for working with laboratory animals (according to art. 9 of the Dutch law on experimental animals) and with radioactive material (level of competence $5 \mathrm{~b}$, as accredited by the Dutch Government). She also participated in several national and international conferences, where she had the opportunity to present her research both orally and by poster presentations. She was awarded the best scientific presentation at the annual meeting of the Dutch Society of Toxicology (NVT) in 2007. From September 2009 onwards, Nejla has been working as a postdoctoral fellow at the Radiation Oncology department (MAASTRO) at Maastricht University. 


\section{List of Publications}

Güngör N, Pennings JL, Knaapen AM, Chiu RK, Peluso M, Godschalk RWL, van Schooten FJ. Transcriptional profiling of the pulmonary inflammatory response induced by LPS: role of neutrophils. Respir Res, submitted.

Güngör N, Knaapen AM, Peluso M, Haenen GR, Chiu RK, Godschalk RWL, van Schooten FJ. Genotoxic effects of neutrophils and hypochlorous acid. Mutagenesis, in press.

Güngör N, Haegens A, Knaapen AM, Godschalk RWL, Chiu RK, Wouters EF, van Schooten FJ. Lung inflammation is associated with reduced pulmonary nucleotide excision repair in vivo. Mutagenesis, in press.

Güngör N, Godschalk RWL, Pachen DM, van Schooten FJ, Knaapen AM. Activated neutrophils inhibit pulmonary nucleotide excision repair in human pulmonary epithelial cells: role of myeloperoxidase. FASEB J 2007; 21(10):2359-67.

Knaapen AM, Güngör N, Schins RP, Borm PJ, van Schooten FJ. Neutrophils and respiratory tract DNA damage: a review. Mutagenesis 2006; 21:225-236.

Verlinden I, Güngör N, Wouters K, Janssens J, Raus J, Michiels L. Gene expression profiling of pregnancy induced mammary gland differentiation. Eur $J$ Cancer Prev 2005; 14(2):129-137.

Janssens J, Verlinden I, Güngör N, Raus J, Michiels L. Protein biomarkers for cancer prevention. Eur J Cancer Prev 2004; 13(4):307-317. 